VANESSA NEVES GOMES

\title{
AVALIAÇÃO DO HÁBITO ALIMENTAR DE PACIENTES SENESCENTES TOTALMENTE DESDENTADOS ANTES E APÓS A REABILITAÇÃO PROTÉTICA, ESTIMANDO A INSERÇÃO DE ALGUNS ALIMENTOS NA DIETA
}




\section{Vanessa Neves Gomes}

\section{Avaliação do hábito alimentar de pacientes senescentes totalmente desdentados antes e após a reabilitação protética, estimando a inserção de alguns alimentos na dieta}

\footnotetext{
Tese apresentada à Faculdade de Odontologia da Universidade de São Paulo, para obter o título de Mestre pelo Programa de Pós-Graduação em Odontologia.

Área de Concentração: Prótese Dentária

Orientadora: Profa. Dra. Maria Luiza Moreira Arantes Frigerio
}

São Paulo 


\section{FOLHA DE APROVAÇÃO}

Gomes VN. Avaliação do hábito alimentar de pacientes senescentes totalmente desdentados antes e após a reabilitação protética, estimando a inserção de alguns alimentos na dieta [Dissertação de Mestrado]. São Paulo: Faculdade de Odontologia da USP; 2005.

São Paulo, 1

\section{Banca Examinadora}

1) $\operatorname{Prof}(a) . \operatorname{Dr}(a)$.

Titulação:

Julgamento:

Assinatura:

2) $\operatorname{Prof}(a) . \operatorname{Dr}(a)$.

Titulação:

Julgamento:

Assinatura:

3) $\operatorname{Prof}(a)$. Dr(a).

Titulação:

Julgamento:

Assinatura: 


\section{DEDICATÓRIA}

A Deus,

por me dar força em todos os

momentos difíceis e por não me

deixar desistir dos meus objetivos.

Aos meus pais,

Manoel Gomes e Miriam Cristina Neves Gomes,

por me apoiarem incondicionalmente durante este período da minha vida, entendendo minha ausência em alguns momentos familiares.

Ao meu irmão Mauricio, um excelente profissional, que por reconhecer a importância desta minha conquista, me apoiou e principalmente, assumiu as nossas responsabilidades sem muito questionar. 
Ao meu namorado, Cleber, por

seu amor e por compreender a minha ausência durante muitos momentos e principalmente nos finais de semana.

\begin{abstract}
À minha avó, Norma, por escutar as minhas lamentações com muito amor e carinho e por me aconselhar sempre que precisei.
\end{abstract}

Aos meus amigos do Projeto

Envelhecer Sorrindo Fernanda, Gislene, Laura, Mário Sérgio, Renata Franco, Renata Marques, Sérgio, Vanessa Papa e Alberto Zimbres que me ajudaram durante todo esse meu caminhar, Muitas vezes acrescentando mais tarefas em suas terças-feiras. 


\section{AGRADECIMENTOS}

Ao Prof. Dr. Ney Soares de Araújo, diretor da Faculdade de Odontologia da Universidade de São Paulo, pelo trabalho dinâmico frente à administração.

Ao Prof. Dr.João Humberto Antoniazzi, presidente da Comissão de Pós-Graduação da FOUSP e demais membros, responsáveis pela relevância, qualidade e seriedade do curso oferecido.

À Profa. Dra. Maria Cecília Miluzzi Yamada, coordenadora do Curso de Pós-Graduação em Odontologia da FOUSP, área de concentração em Prótese Dentária, pelo trabalho desempenhado, pelas oportunidades dadas e por sua preocupação com relação ao desenvolvimento da minha dissertação durante o curso de Pós-Graduação em Odontologia. Todas as suas atitudes são merecedoras de nossa admiração.

À Profa. Dra. Maria Luiza Moreira Arantes Frigerio, orientadora desta pesquisa, pela sua brilhante orientação, carinho, compreensão, paciência e excepcional dedicação a este nosso trabalho e principalmente à minha formação. Agradeço muito por sua amizade e por sua incansável ajuda durante todas as fases desta pesquisa. 
Aos professores da Disciplina de Prótese Total e demais professores da FOUSP, grandes mestres colaboradores nesta carreira, pela oportunidade do convívio profissional edificante dado a nós.

À nutricionista Márcia Fidelex, por suas orientações e pela atenção carinhosa prestada durante todo o desenvolvimento da pesquisa, nos apoiando com seus conhecimentos nutricionais.

À Profa. Miriam Turbino, do Departamento de Dentística da FOUSP por sua atenção e carinho durante toda a elaboração da análise estatística.

Aos Pacientes, pela ternura, paciência, carinho e compreensão. 0 consentimento da sua participação foi imprescindível na realização desta pesquisa.

Aos colegas de Pós-Graduação, pelo afetuoso convívio, pela relação profissional nacional e internacional enriquecedora do ser, do profissionalismo e da teia da vida.

Aos funcionários do Departamento de Prótese Dentária da FOUSP, sempre solícitos, pela colaboração dispensada.

À Rosalina e a Raque, pelas revisões gramaticais e ortográficas dos textos. O trabalho talentoso de ambas pôde enriquecer e facilitar a leitura do texto. 
A Águida Feliziani e à Vânia M. B. O. Funaro, pelo o auxílio na revisão deste trabalho.

Aos nossos amigos e a todos que participaram direta ou indiretamente na elaboração dessa pesquisa, os incentivos e apoios nortearam as perspectivas de uma relação compassiva. 
Gomes VN. Avaliação do hábito alimentar de pacientes senescentes totalmente desdentados antes e após a reabilitação protética, estimando a inserção de alguns alimentos na dieta [Dissertação de Mestrado]. São Paulo: Faculdade de Odontologia da USP; 2005.

\section{RESUMO}

Nesta pesquisa, foi avaliado o hábito alimentar de pacientes senescentes totalmente desdentados, antes e após a reabilitação por próteses totais bimaxilares convencionais. A avaliação foi realizada por meio de exame clínico, entrevista e a aplicação de questionários pela própria pesquisadora. O trabalho foi conduzido em três fases distintas: a primeira, desenvolvida antes do início de qualquer procedimento relacionado com a confecção das próteses e consistiu no preenchimento de ficha clínica, avaliação protética e da realização de uma anamnese alimentar, sendo essa última elaborada com a orientação de uma nutricionista. Já a segunda e a terceira fases foram executadas em períodos compreendidos entre aproximadamente dois a três meses e cinco a seis meses após

a reabilitação protética respectivamente, quando novos exames clínicos eram realizados. Os dados coletados nesses três períodos distintos foram processados por um computador utilizando-se do software BioEstat 3.0,sendo o nível de significância estabelecido para $\mathrm{p}<0,05$, em uma prova bilateral. Os resultados demonstraram que após a instalação de uma nova prótese total convencional confeccionada no rigor da técnica tivemos, não só melhora funcional do aparelho protético, como alteração positiva na habilidade mastigatória dos indivíduos, além de alteração da consistência da dieta acompanhada da introdução de novos alimentos. Os resultados demonstraram ainda, que quando o aparelho protético apresentava 
retenção e estabilidade consideradas satisfatórias, aquele acabava influenciando positivamente o hábito intestinal do paciente.Contudo, através desse estudo, não foi possível identificar se houve uma real modificação da dieta dos pacientes com inserção de nutrientes, uma vez que para obtermos esses dados seriam necessários exames complementares.

Palavras-Chave: Prótese total; Hábito alimentar; Reabilitação protética; Paciente senescentes; Avaliação 
Gomes VN. Evaluation of the alimentary attitude in senescent edentulous patients, before and after prosthetic rehabilitation, considering the addition of different foods in the diet [Dissertação de Mestrado]. São Paulo: Faculdade de Odontologia da USP; 2005.

\section{ABSTRACT}

In this research, the alimentary attitude of senescent edentulous patients was evaluated, before and after the rehabilitation by new complete dentures. A clinical exam, an interview and a survey were performed. The work was accomplished in three different phases: the first was developed before the beginning of any procedure related to the construction of the new dentures and consisted of a clinical record, a prosthetic evaluation and an alimentary anamnesis. The second and the third phases took place after the prosthetic rehabilitation and were done in periods between two to three months and five to six months respectively, together with new clinical exams. The data collected during those three different periods were processed using software BioEstat 3.0 ; the level of significant was $p<0,05$, in a bilateral proof. The results demonstrated that after the installation of new complete dentures made according to the technique there was a functional improvement of the dentures noticed as a better performance in the individuals' masticatory ability. It was reported also changes in the consistence of the diet associated to the increasing of different nutrients to the diet. It was also possible to verify that when the prostheses presented satisfactory retention and stability, intestinal habit was influenced positively. However, through this study only, it was not possible to identify if there was a real modification in patients' alimentary habit or if different nutrients were inserted to it. To make sure 
those modifications had happened complementary exams should have been performed as well.

Key-Words: Complete dentures; Alimentary habit; Prosthetic rehabilitation; Senescent patient; Evaluation 


\section{LISTA DE TABELAS}

Tabela 5.1 - Distribuição de freqüências de pacientes relacionando o sexo à idade e à raça da amostra estudada

Tabela 5.2 - Distribuição de freqüências de pacientes relacionando sexo com o tipo de prótese usada antes da pesquisa, estado de conservação das PTCs, período de uso da última prótese e o tempo em que os pacientes se encontram desdentados

Tabela 5.3a - Distribuição de freqüências de pacientes quanto aos resultados obtidos após a análise do perfil alimentar antes e após a instalação da PTC nova.

Tabela 5.3b - Distribuição de freqüências de pacientes quanto aos resultados obtidos após a análise do perfil protético antes e após a instalação da PTC nova

Tabela 5.3c - Distribuição de freqüências de pacientes quanto aos resultados obtidos após a análise do hábito intestinal antes e após a instalação da PTC nova

Tabela 5.4 - Distribuição de freqüências de pacientes de acordo com o sexo, quanto aos resultados referentes à inserção de novos alimentos obtidos no segundo controle após a instalação da PTC nova

Tabela 5.5 - Distribuição de freqüências de pacientes quanto aos resultados após o relacionamento dos dados iniciais obtidos através do IMC com: o tipo de prótese usada antes da reabilitação protética, habilidade mastigatória e consistência da dieta com a PTC antiga

Tabela 5.6 - Distribuição de freqüências de pacientes relacionando os resultados obtidos do IMC após a reabilitação protética com: habilidade mastigatória e consistência da dieta e a inserção de novos alimentos na dieta 
Tabela 5.7 - Distribuição de freqüências de pacientes em relação à consistência da dieta: considerando o tipo de prótese usada antes da reabilitação protética e a habilidade mastigatória com a PTC antiga

Tabela 5.8 - Distribuição de freqüências de pacientes quanto aos resultados obtidos após relacionar consistência da dieta com habilidade mastigatória e inserção de novos alimentos, com a PTC nova

Tabela 5.9 - Distribuição de freqüências de pacientes quanto aos resultados obtidos após o relacionamento dos dados referentes à habilidade mastigatória com: o tipo de prótese usada antes da reabilitação protética, dimensão vertical, oclusão, retenção e estabilidade, com PTC antiga

Tabela 5.10 - Distribuição de freqüências de pacientes quanto aos resultados obtidos após o relacionamento dos dados referentes à habilidade mastigatória com a inserção de novos alimentos na dieta, dimensão vertical, oclusão, retenção e estabilidade, com PTC nova

Tabela 5.11 - Distribuição de freqüências de pacientes quanto aos resultados obtidos após o relacionamento dos dados referentes ao hábito intestinal com o tipo de prótese usada antes da reabilitação protética, habilidade mastigatória, consistência da dieta, ingestão de líquidos, dimensão vertical, oclusão, retenção e estabilidade, com a PTC antiga

Tabela 5.12 - Distribuição de freqüências de pacientes quanto aos resultados obtidos após o relacionamento dos dados referentes ao hábito intestinal com a habilidade mastigatória, consistência da dieta, inserção de novos alimentos, ingestão de líquidos, dimensão vertical, oclusão, retenção e estabilidade, com a PTC nova.................................................. 75

Tabela 5.13 - Distribuição de freqüências de pacientes quanto aos resultados obtidos após o relacionamento dos dados referentes à consistência das fezes com o tipo de prótese 
usada antes da reabilitação protética, habilidade mastigatória, consistência da dieta, ingestão de líquidos, dimensão vertical, oclusão, retenção e estabilidade, com a

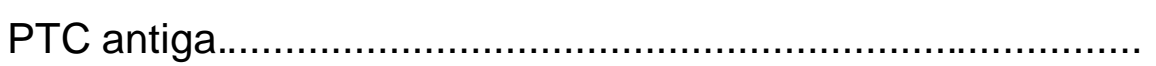

Tabela 5.14 - Distribuição de freqüências de pacientes quanto aos resultados obtidos após o relacionamento dos dados referentes à consistência das fezes com a habilidade mastigatória, consistência da dieta, inserção de novos alimentos, ingestão de líquidos, dimensão vertical, oclusão, retenção e estabilidade, com a PTC nova.

Tabela 5.15 - Distribuição de freqüências de pacientes quanto às respostas referentes à comparação da ingestão de alguns alimentos como: pão francês e pão macio, bolacha seca e bolacha no leite, fruta dura e macia, saladas cruas e cozidas, legumes crus e cozidos, leguminosas, oleaginosas, carne frita e macia, ovos, doces e sopas antes e após a reabilitação protética 


\section{LISTA DE ABREVIATURAS E SIGLAS}
C
Coluna
DV
Dimensão Vertical
DVO
Dimensão Vertical de Oclusão
DVR
Dimensão Vertical de Repouso
EFP
Espaço Funcional de Pronúncia
FOUSP
Faculdade de Odontologia da Universidade de São Paulo
IMC
Índice de Massa Corporal
$\mathrm{Kg}$
Quilogramas
L
Linha
m
Metro
MNA
Mini Avaliação Nutricional
OMS
Organização Mundial da Saúde
ONU
Organização das Nações Unidas
PTC
Prótese Total Convencional
USP
Universidade de São Paulo 


\section{INTRODUÇÃO}

O perfil da população mundial vem sendo alterado com o passar dos anos. O predomínio de crianças e jovens era uma realidade até o início do século XIX nos países desenvolvidos. Devido à atuação de duas forças demográficas fundamentais que são a redução da fertilidade e o aumento da longevidade, as pessoas com 65 anos ou mais, passaram a representar um papel novo no planeta. A primeira força atuaria reduzindo o número de jovens, enquanto a segunda elevaria a quantidade de idosos na população global (GÓIS, 2004; NOS NÚMEROS [...], 2004).

A Organização das Nações Unidas (ONU) (apud CERVATO,1999) define a idade de 65 anos como o momento a partir do qual os indivíduos pertencentes aos países desenvolvidos são considerados idosos. No caso dos países em desenvolvimento como o Brasil, onde a expectativa de vida é menor, essa idade limítrofe passa a ser 60 anos (ESTATUTO DO IDOSO[...], 2003). Essa mesma idade observada no Brasil foi definida também como um marco na Assembléia Mundial sobre Envelhecimento, ocorrida em 1982, em Viena.

Há 150 anos, a proporção de pessoas com 65 anos ou mais não passava de $2 \%$ ou $3 \%$ da população mundial. Hoje representa quase $15 \%$ e no ano de 2030 , essa proporção se aproximará dos $25 \%$, podendo chegar a $30 \%$ em alguns países da Europa continental que envelheceram rapidamente (PINHEIRO, 2003). Em 2050, um quinto da população mundial, que será de 9 bilhões de habitantes,terá mais de 60 anos; hoje a população dessa faixa etária corresponde a 600 milhões de habitantes (COELHO, 2005). 
O envelhecimento populacional não é uma característica restrita aos países desenvolvidos, onde esse processo transcorreu de forma gradual, possibilitando avanços consideráveis no que diz respeito às condições de vida e bem estar geral da população idosa (FERRARI, 1999). Essa mudança demográfica também está sendo vivida pelos países em desenvolvimento, como é o caso do Brasil.

De 1980 a 2000, estimou-se que o crescimento da população idosa brasileira seria da ordem de $4,9 \%$ ao ano, enquanto que o grupo correspondente aos indivíduos com idade entre 0 a 14 anos cresceria apenas 0,6\% ao ano (CAMARGO; YAZAKI, 1990). Atualmente, os idosos correspondem a 8\% (PINHEIRO, 2003), ou seja, em torno de 13 milhões de habitantes. Em 2030, a previsão é de que essa fração da população represente $20 \%$ da população do país (PINHEIRO, 2003), lembrando que existe uma grande heterogeneidade, proveniente das importantes diferenças regionais que prevalecem no Brasil, conseqüência de um modelo de desenvolvimento desigual.

Apesar do envelhecimento ser uma conseqüência natural do desenvolvimento e modernização, pode se transformar em um grave problema, quando essa população crescente começar a clamar por demandas específicas, que por sua vez acabarão por exercer pressão sobre o conjunto da sociedade, que não consegue responder a essas expectativas.

Nesse contexto é de fundamental importância o desenvolvimento de estudos visando a aprofundar o conhecimento dos mecanismos responsáveis pelo processo de envelhecimento. Esses estudos teriam como objetivo amenizar os efeitos adversos das transformações sócio-econômicas, culturais e do bem-estar físico e psíquico dessa faixa da população, proporcionando uma melhor qualidade de vida. 
Existem muitas alterações que são consideradas normais como: diminuição da força e do vigor físico, perda de elasticidade da pele, dores, esquecimento (FERRARI, 1999). Além desses, pode haver a redução dos §ntidos, como da audição, visão ou mudanças no paladar que também são consideradas conseqüências comuns nessa fase da vida (PEDERSEN; LÖE, 1996). Além disso, existe a instalação de doenças crônicas no lugar das infecto-contagiosas, que geram incapacidades e dependências, levando os profissionais da saúde a mudar o seu enfoque de tratamento. Esses passam a orientar o idoso como conviver com a doença, uma vez que o desaparecimento completo dela ainda não faz parte da realidade terapêutica.

Apesar do avanço das técnicas odontológicas de prevenção (JONES et al., 2003), a perda dos elementos dentais é outra importante alte ração percebida com o passar dos anos, uma vez que traz no seu bojo a alteração da capacidade mastigatória. Acredita-se que a capacidade, ou a habilidade mastigatória seja de fundamental importância para a seleção dos alimentos a serem ingeridos estando relacionada ainda com a qualidade de vida e a saúde geral (ÖSTERBERG et al., 2002). Como conseqüência um ciclo vicioso faria com que a má nutrição propiciasse o surgimento de problemas sistêmicos e bucais, que criariam condições para que o processo de envelhecimento fosse acelerado (ROISINBLIT, 1995). 


\section{REVISÃO DA LITERATURA}

No intuito de conferir maior clareza à leitura desta revisão da literatura, procurourse inicialmente buscar um breve entendimento sobre a população idosa e o significado psicológico da perda dos dentes para essa faixa etária, para que só então, o tema proposto pudesse ser desenvolvido através dos itens:

- relação de fatores que possam influenciar na nutrição dos idosos;

- necessidades protéticas;

- ferramentas de avaliação nutricional;

- necessidades nutricionais.

Dentro de cada item, as resenhas sobre os autores organizam-se de acordo com o assunto abordado.

\subsection{A população idosa}

O Estatuto do Idoso[...] (2003), por meio da Lei n. 10.741 , de $1^{\circ}$ de outubro de 2003, e a Organização Mundial da Saúde (OMS) (apud FRANK; SOARES, 2004), segundo a Lei n. 8842/94, em seu artigo 2ํㅜ, parágrafo único, 
consideram idosas as pessoas maiores de 60 anos, de ambos os sexos, sem distinção de cor, raça ou etnia e ideologia.

Essa população idosa, compreendida em maior número por mulheres (CAMARGO; YAZAKI, 1990; MARUCCI, 1992), exceto quando atinge idade superior a 85 anos (PERLS, 2004), no início do século XX correspondia a 3,2 $\%$ dos brasileiros, passando para 5,1\% em 1970; 7,05 \% em 1990 (SAÚDE BUCAL[...], 1993), até chegar atualmente a uma porcentagem correspondente a $9 \%$ (COLLUCCI, 2004), equivalendo a aproximadamente, 15 milhões de habitantes.

Um outro dado interessante, é que além de envelhecer, a população crescerá cada vez menos. O crescimento de indivíduos na faixa etária superior a 70 anos será de $440 \%$, bem acima do avanço de $53 \%$ da população total, que atingirá 259,8 milhões ao fim do mesmo período. O grupo dos 60 a 69 anos também aumentará significativamente (263\%). Assim, segundo o Jornal da Tarde em 2004 (NOS NÚMEROS[...], 2004), os sexagenários, somados aos idosos maiores de 70 anos, somarão $25 \%$ da população em 2050. O envelhecimento populacional acontecerá tanto no Brasil como em todo o mundo (GÓIS, 2004; NOS NÚMEROS[...], 2004).

Com essa notável mudança na configuração etária, o envelhecimento passa a ser um assunto muito discutido pelos setores político, social e da saúde, este último englobando a Odontologia (SAÚDE BUCAL[...], 1993).

Portanto, cabe à odontologia participar do processo de envelhecimento bem sucedido, mantendo o sistema estomatognático em condições satisfatórias. O bom funcionamento favorece a efetivação de uma alimentação equilibrada, por meio da seleção adequada dos alimentos. Os grandes beneficiados 
seriam os indivíduos que atinjam o bem estar físico e mental com conseqüente melhora da qualidade de vida. (ÖSTERBERG et al., 2002).

\subsection{0 significado psicológico da perda dos dentes}

Apesar das inevitáveis alterações sistêmicas e bucais que acompanham o ser humano durante todo o processo de envelhecimento (FERRARI, 1999; PEDERSEN; LÖE, 1996) a região bucal tem ainda um papel expressivo graças ao significado emocional e simbólico que representa.

Embora ocorra um decréscimo progressivo da taxa de edentulismo em várias partes do mundo, ainda existe um amplo segmento populacional que permanece desdentado (JONES et al., 2003; HÁ 30 MI[...], 2004; PAPAS et al., 1998; SANDSTRÖM; LINDQUIST, 1987). No Brasil, esses números chegam a 30 milhões e, destes, 4,9 milhões encontram-se com idade variando entre 65 e 74 anos, o que representaria $75 \%$ da população mundial de desdentados nessa faixa etária (HÁ 30 MI[...], 2004). Este é um fator preocupante, uma vez que as perdas dentárias exercem implicações na sustentação das estruturas orofaciais (KAPUR; SOMAN, 1964; YURKSTAS; EMERSON, 1964; WAYLER; CHAUNCEY, 1983) e podem, segundo Fiske et al. (1998), tornar a cavidade bucal vulnerável. Tal processo poderia desencadear diversos tipos de emoções, além de influenciar negativamente no tratamento protético reabilitador.

Dentre as emoções poderiam ser citadas a privação do contato social, o comprometimento da autoconfiança, a deterioração da aparência e 
auto-imagem, a sensação da perda dos dentes como uma mutilação, a preocupação em manter sigilo do fato, a necessidade de reclusão durante o tratamento protético, as alterações de comportamento além do envelhecimento precoce.

Segundo McMillan e Wong (2004) e Oliveira (2001), as emoções desencadeadas pela perda total ou parcial dos dentes que comprometem a integridade bucal, também podem gerar desequilíbrios das condições de saúde física e emocional, restringindo e alterando as atividades do cotidiano.

A ansiedade é um outro reflexo psicológico que acompanha os indivíduos, principalmente, quando da ausência total dos dentes. Esse quadro pode ser consideravelmente agravado nas semanas que antecedem à instalação dos aparelhos protéticos e se não for corretamente diagnosticado e trabalhado pelo profissional da saúde, poderá ocasionar problemas durante o período de adaptação. Justifica-se assim, segundo Bergendal (1989), Fiske et al. (1998), Nagle e Sears (1965), Turano (2000), dentre outros, a necessidade de se conhecer o perfil psicológico do paciente para que o profissional possa intervir adequadamente prevenindo traumas futuros. Tamaki (1988) mostrou estar ciente de que o êxito final do trabalho depende da cooperação do paciente, fazendo referência à classificação de Fox (apud TAMAKI, 1988), que dividia os pacientes em: receptivos, cépticos, histéricos e indiferentes.

McMillan e Wong (2004) citam a possibilidade de existirem benefícios psicológicos para os pacientes com ausências dentárias, se houver uma melhor comunicação entre este e o cirurgião-dentista.

No entanto, os problemas emocionais não são as únicas causas do insucesso do tratamento reabilitador. Algumas pessoas apresentam problemas como reflexos de enjôo e atividades parafuncionais que dificultam a adaptação às 
próteses, comprometendo a utilização das mesmas. Portanto, o uso das próteses totais de forma satisfatória é um exercício que demanda habilidade, não apenas do cirurgião - dentista, mas também do paciente, que deverá procurar se adequar funcionalmente à nova condição.

Lowental e Tau (1980) relataram que o tratamento protético muitas vezes pode ser comprometido pela senilidade, apatia ou processo depressivo. Devido a tais fatos os fatores étnico-cultural e sócio-econômico devem ser considerados para que possa ser atingido um índice mais elevado de sucesso. Por conta disso, pacientes geriátricos desdentados constituem um desafio terapêutico e requerem um tratamento protético-psicológico combinado.

\subsection{Relação de fatores que podem influenciar na nutrição dos idosos}

A perda de elementos dentais, com uma possível diminuição da dimensão vertical, é um dos principais fatores que podem influenciar na nutrição dos idosos. É sabido que a falta desses elementos diminui a capacidade mastigatória, podendo apresentar como conseqüência alterações diretas ou indiretas na ingestão de alimentos (McMILLAN; WONG, 2004), que segundo Soini et al. (2003) podem levar a um quadro de má nutrição.

Para Berg (1992), Budtz-Jorgensen (1999), Garret, Kapur e Perez (1996), Obrez e Grussing (1999), as condições dos aparelhos protéticos, usados na tentativa de amenizar os problemas ocasionados pelas perdas dentárias, podem influir negativamente na seleção dos alimentos. Os autores mencionam ainda a 
existência de outros fatores que estariam atuando sobre a nutrição, como a relação do envelhecimento com problemas médicos e doenças, a idade, sexo, atitude em relação às próteses, personalidade e experiências anteriores com aparelho protético.

Rugg-Gunn e Nunn (1999) consideraram freqüentes, nessa faixa etária, alterações nas funções cardíaca, pulmonar e renal, além de modificações relacionadas com o metabolismo e com o sistema excretor (ROISINBLIT, 1995). No que diz respeito ao aparelho digestivo, é possível observar diminuição do peristaltismo intestinal, redução do paladar e do olfato, alteração deletéria dos músculos mastigatórios, dificuldade de deglutição, decréscimo da secreção salivar, dentre outras ETTINGER, 1998; FRANK; SOARES, 2004; LAURIN; BRODEUR; LEDUC, 1992; ROISINBLIT, 1995; SAÚDE BUCAL[...], 1993). Tais subtrações poderiam influenciar de maneira negativa a seleção dos alimentos e conseqüentemente o hábito alimentar.

Para driblar o problema da diminuição da secreção salivar xerostomia, muitos idosos passam a ingerir mais líquidos, sopas, alimentos macios e molhados ou pastosos, muitas vezes com um baixo valor nutricional o que pode acabar comprometendo sua saúde geral e bucal (LAURIN; BRODEUR; LEDUC, 1992; OLIVEIRA, 2001; RUGG-GUNN; NUNN, 1999; SOINI et al., 2003). Tais alimentos costumam ser selecionados na tentativa de minimizar o longo tempo gasto pelos idosos na mastigação e preparação do bolo alimentar, devido à diminuição da saliva.

Masseler (1979) menciona a água como fator que pode interferir indiretamente, também, na função mastigatória. Para o autor, a falta de água no organismo dos idosos, leva à desidratação, tornando-os apáticos e cansados, além de tornar pele, olhos e mucosa oral secos e facilmente irritáveis. Nessa situação, o 
apetite, a função mastigatória e o conforto oral ficam comprometidos, dificultando a reabilitação protética (BUDTZ-JORGENSEN, 1999).

Horwath (1991), também mencionou que evitar certos alimentos, formando, portanto, um padrão alimentar característico, tem sido uma atitude adotada e desenvolvida em decorrência da percepção subjetiva de fatores associados ao paladar, odor, cor, temperatura, textura, forma, tamanho e a disponibilidade dos alimentos (ETTINGER, 1998). Seria conveniente considerar ainda o perfil sócio-econômico do paciente (BERG, 1992; BUDTZ-JORGENSEN, 1999; GARRET; KAPUR; PEREZ, 1996; OBREZ; GRUSSING, 1999).

Não existem, no entanto, comprovações de que algum desses fatores, isoladamente ou em grupo, teria capacidade de predizer o sucesso durante a adaptação de pacientes desdentados a suas próteses, ou mesmo explicar a variabilidade das mudanças de resposta mastigatória da população.

Assim, a renda é um fator de grande importância no que diz respeito à condição nutricional dos idosos, pois pode induzir, tanto em situações de pobreza como de riqueza, à busca por alternativas alimentares que, muitas vezes, deixam a desejar quanto à eficiência nutricional. No primeiro caso, pode restringir os idosos a uma pequena variedade de alimentos, enquanto que no segundo pode levar à busca por alimentos pré-processados (FRANK; SOARES, 2004).

Rugg-Gunn e Nunn (1999) também mencionaram o fato de que freqüentemente os vegetais e frutas frescas são evitados por serem considerados caros e de difícil transporte. Outros fatores que justificariam essa evasão seria a necessidade de preparo e cozimento, além de serem mais perecíveis do que os demais alimentos. 
Existem ainda fatores indiretos que podem contribuir negativamente com as deficiências nutricionais, como a diminuição da ingestão de água, a menor motivação para comer e preparar uma refeição adequada pela presença de artrite e limitações motoras (RUGG-GUNN; NUNN, 1999), o hábito de comer sozinho (ETTINGER, 1998), a dificuldade para obtenção de alimentos, devido à dependência de terceiros (instituições, cuidadores) (ROISINBLIT, 1995), além de alterações orgânicas como gastrites e úlceras.

Contribuindo ainda para uma dieta inadequada em nutrientes está a presença de transtornos psicológicos como a depressão e psicose muitas vezes desencadeadas pela presença de fatores psicossociais como a perda de amigos, de parentes próximos e a aposentadoria (ETTINGER, 1998; FRANK; SOARES, 2004; RUGG-GUNN; NUNN, 1999).

Frank e Soares (2004), Roisinblit (1995) e Rugg-Gunn e Nunn (1999) citam a interação medicamentosa como mais um fator que pode interferir na ingestão de alimentos devido à redução do fluxo salivar. Essa interferência poderia agir também na absorção e no metabolismo de nutrientes. Os autores associam o abuso de fármacos (antidepressivos, tranqüilizantes, anticolinérgicos), o uso exagerado de álcool e tabaco à ingestão deficiente de alimentos.

\subsection{Necessidades protéticas}

O aparelho mastigatório é composto pelos dentes, tecido periodontal, mucosa oral, glândulas salivares, sistema neuromuscular, ossos da maxila e da 
mandíbula e articulações temporomandibulares. Sua função é triturar e umidificar os alimentos, preparando-os para a deglutição (GUNNE, 1985).

No caso dos indivíduos com falta de elementos dentais, a capacidade do aparelho mastigatório fica diminuída, pois, com a perda da integridade bucal, ocorre não só uma redução da habilidade e da eficiência mastigatória como um decréscimo do apetite, o que faz com que muitos pacientes, para minimizar esses problemas, busquem os tratamentos protéticos reabilitadores (JEMT, 1981; MANLY; VINTON, 1951; PAPAS; PALMER; ROUNDS, 1989; WAYLER; CHAUNCEY, 1983). Apesar dessa constatação, a Folha de São Paulo em 2004 relatou a existência de $36 \%$ dos idosos desdentados brasileiros como não sendo usuários de próteses.

Carlsson (1984) definiu a eficiência mastigatória como sendo a capacidade de reduzir o tamanho dos alimentos durante o ato da mastigação, enquanto a habilidade mastigatória avaliaria a função mastigatória como um todo.

É bom ressaltar que pessoas reabilitadas por aparelhos protéticos não voltarão a mastigar com a mesma eficiência de quando possuíam dentes naturais. Campos, Monteiro e Ornelas (2000) relataram que indivíduos com perda total dos dentes, quando reabilitados por próteses totais convencionais, mastigam com uma eficiência 75 a $85 \%$ menor do que aqueles com dentes naturais, o que faz com que diminua o consumo de carnes, frutas e vegetais frescos. O grupo de pacientes de maior risco seria o de idosos classificados como frágeis (ETTINGER; BECK, 1984) ou aqueles idosos que moram sozinhos (ETTINGER, 1998).

Segundo Budtz-Jorgensen (1999) e Soini et al. (2003), idosos frágeis são aqueles que perderam parte da sua independência, mas que continuam vivendo na comunidade com a ajuda de algum serviço de suporte. 
Entretanto, Sandström e Lindquist (1987) observaram que sempre deve ser feito algum tipo de reabilitação protética quando se verifica a perda de elementos dentais. Segundo os autores, independente da reabilitação protética realizada, sempre ocorrerá uma melhora na função mastigatória, muito embora não tenha observado uma mudança significativa nos hábitos alimentares.

Desta forma, cientes das limitações impostas pelos aparelhos protéticos reabilitadores, para que a função mastigatória seja desempenhada a contento, é mister que esses sejam confeccionados da maneira mais adequada possível (SHI; OUYANG; GUI, 1990; SHINKAl et al., 2002), uma vez que indivíduos com menor quantidade de dentes podem apresentar uma maior deterioração da saúde geral (SHIMAZAKlet al., 2001).

Buscando minimizar os problemas resultantes da reabilitação com próteses totais bimaxilares e para que estas sejam realizadas da melhor forma possível, Budtz-Jorgensen (1999) e Tamaki (1988), enfatizaram a importância de um exame clínico criterioso para a elaboração de um plano de tratamento, que satisfaça as necessidades do paciente. Nesse exame devem ser diagnosticados os fatores de risco que possam interferir no sucesso da prótese total bimaxilar. Tais fatores seriam: reabsorção do rebordo residual, atrofia muscular, sintomatologia dolorosa localizada, ardência bucal, redução da força máxima de mordida, alterações sistêmicas, alergias a componentes das próteses, qualidade precária dos aparelhos protéticos e, por fim, problemas decorrentes da redução do fluxo salivar (ADAMS, 1961; BERRY, 1972; HARTSOOK, 1974; HEATH, 1982; JOSHIPURA; WILLE; DOUGLAS, 1996; OBREZ; GRUSSING, 1999; PAPAS; PALMER; ROUNDS, 1989). 
Além desses, fatores como alterações da dimensão vertical, instabilidade oclusal, aumento do plano oclusal posterior, bordas sobrestendidas, patologias de mucosa devido ao contato exagerado com a prótese, redução do espaço disponível para a língua, e por fim, satisfações dos pacientes com suas próteses totais antigas também são vistas por Budtz-Jorgensen (1999) como fatores que devem ser bem identificados antes do tratamento protéticos reabilitadores.

Essa satisfação dos pacientes com os seus aparelhos protéticos deve ser analisada cautelosamente pelo cirurgião-dentista, uma vez que os critérios utilizados pelos odontólogos para a substituição das próteses muitas vezes não equivalem aos adotados pelos pacientes. Esse dado pode ser observado no estudo de Nevalainen et al. (1997), que encontrou uma variação de 10 a $84 \%$ no julgamento da necessidade de troca das próteses, reforçando o ponto de vista de que o tratamento não pode ser baseado somente no exame clínico, devendo-se considerar também a opinião do paciente e a satisfação com os seus aparelhos.

Portanto, cabe ao profissional informar bem os seus pacientes sobre quais alterações funcionais podem vir a ocorrer, caso essas próteses não sejam trocadas e alertar que um aparelho protético diagnosticado como insatisfatório em um exame clínico, pode vir a interferir na ingestão de alimentos e ocasionar problemas de saúde. Na tentativa de conviver com a ausência de elementos dentais ou com a presença de próteses mal adaptadas, os indivíduos passariam a ingerir pedaços maiores de alimentos, aumentando o tamanho do bolo alimentar (OBREZ; GRUSSING, 1999). Segundo Marucci (1992), Roisinblit (1995) e Tosello et al. (2001), um bolo alimentar de maior tamanho poderia propiciar a instalação de gastrite, obstrução intestinal e outras patologias gastrointestinais e nutricionais. Um recurso usado para contornar os problemas digestivos costuma ser a ingestão de 
antiácidos, que dependendo do agente ativo, podem interferir na absorção do ferro, aumentando o risco para pacientes com insuficiência cardíaca (MARUCCI, 1992).

Geering, Kundert e Kelsey (1993) e Oliveira (2001) discutem a associação indesejável de uma dieta mal balanceada com próteses insatisfatórias, como sendo deletéria para a manutenção dos tecidos de sustentação das próteses. Oliveira ainda ressalta que essa associação indesejável torna a fibromucosa vulnerável a traumas durante o ato da mastigação.

A preocupação de Hoad-Reddick (1989) em trocar os aparelhos protéticos depois de 5 anos de uso e de Lang (1994) em efetuar a substituição num período compreendido entre 6 e 9 anos se deve ao desgaste da superfície oclusal dos dentes artificiais. Tal processo aceleraria a reabsorção do rebordo residual, alterando o espaço intermaxilar com conseqüente diminuição da dimensão vertical de oclusão (DVO).

Com relação à análise da parte funcional, autores como Perez, Kapur e Garrett (1985) observaram que uma melhora na retenção, estabilidade e oclusão das próteses não implicava necessariamente na alteração da habilidade mastigatória, uma vez que essa estaria na dependência da dinâmica do sistema neuromuscular envolvido. Tamaki (1988) e Fiore (1999), no entanto, discordam dessa afirmação por acreditarem que o requisito mastigatório esteja relacionado diretamente com a retenção e estabilidade do aparelho protético.

Autores como Galanos et al. (1994) e Marshall et al. (2002) se preocuparam em observar a relação da retenção e estabilidade com a função mastigatória e a ingestão inadequada de nutrientes. Esses nutrientes seriam proteínas, tiamina, riboflavina, vitamina $D$, cálcio, ferro, magnésio e fósforo, entre outros. 
Obrez e Grussing (1999) conduziram uma pesquisa com o objetivo específico de determinar os fatores responsáveis pela adaptação da mastigação a próteses completas. Nesta, foram analisadas as dificuldades de mastigação, levando-se em consideração o alimento, a textura, sensação de temperatura, experiência com o paladar, tamanho do bolo alimentar, alimentos que eram evitados, estabilidade e retenção das próteses, constrangimento social, satisfação geral com as próteses, experiência de uso dos aparelhos protéticos, sensação de dor durante a mastigação, cuidados com a higienização das próteses depois da alimentação e o tempo envolvido com a mastigação. O autor e colaboradores observaram que a percepção da textura afeta significantemente a escolha dos alimentos por pacientes portadores de próteses.

\subsection{Ferramentas de avaliação nutricional}

Trivalle (2002) sugeriu estratégias para o diagnóstico e avaliação precoce das alterações nutricionais. Tais estratégias constariam de ferramentas nutricionais como o questionário de Payette, a Mini Avaliação Nutricional (MNA), a Escala de Blandford, entre outras. Elas permitiriam avaliar a necessidade de uma orientação na dieta, investigar problemas de comportamento alimentar, pesquisar o estado nutricional, além de avaliar a desnutrição proteino-energética ou o risco de desnutrição proteino-energética junto às pessoas idosas.

Frank e Soares (2004) mencionaram o método de bioimpedância como mais uma opção para avaliar a composição corporal. A mesma autora cita 
ainda os questionários de freqüência de consumo de alimentos, os registros alimentares e o recordatório de 24 horas como recursos que permitiriam apontar o perfil qualitativo de um grupo de estudos. No entanto, todos os métodos de análise retrospectiva que fornecem informação dietética com o apoio da memória dos indivíduos entrevistados podem conter dados pouco precisos. Mesmo com limitações, esses métodos têm sido amplamente utilizados devido ao baixo custo, uma vez que avaliações bioquímicas envolvem custos laboratoriais.

Atualmente, a técnica mais usada na avaliação dos inquéritos dietéticos é a de sistemas ou programas computadorizados, para conversão dos dados obtidos através da alimentação, em energia e nutrientes (FRANK; SOARES, 2004).

Segundo Isosaki e Cardoso (2004) e Frank e Soares (2004), a escolha do parâmetro utilizado para a avaliação do estado nutricional vai depender da avaliação das vantagens e desvantagens do método, do objetivo pretendido, das condições presentes e dos recursos disponíveis.

O questionário de Payette é um questionário curto, sensível e específico, sendo facilmente utilizado por todos os profissionais da área de saúde. Essa ferramenta permite avaliar as pessoas idosas que têm necessidade de uma ajuda na sua alimentação e que devido a suas carências nutricionais poderiam perder peso.

A avaliação da MNA é facilmente utilizável, muito bem aceita pelas pessoas idosas e de baixo custo, uma vez que não faz uso de dosagens biológicas. Permite avaliar o estado nutricional além de diagnosticar a desnutrição proteinoenergética de pessoas idosas. 
Já a Escala de Blandford pode ser utilizada para evidenciar distúrbios de comportamento alimentar em pessoas idosas que sofrem de alguma síndrome demencial.

Estudos como o de Fiore (1999), Marucci (1992) e Oliveira (2001) utilizaram algumas variáveis antropométricas como peso, altura, circunferência do braço e prega cutânea triciptal como auxílio para a avaliação nutricional. A antropometria tem sido usada para avaliar o tamanho e as proporções dos segmentos corporais, por meio de equações que estimam a composição corporal (ISOSAKI; CARDOSO, 2004).

A mensuração das pregas cutâneas é um método que deve ser realizado com muito cuidado, pois não é fácil e nem claro para o avaliador separar o tecido adiposo subcutâneo do muscular, em função da baixa elasticidade que os tecidos apresentam com o avanço da idade (FRANK; SOARES, 2004).

Em contrapartida o Índice de Massa Corporal (MC) é um indicador muito usado na avaliação parcial da composição corporal e consiste em relacionar peso corporal $(\mathrm{Kg})$ com altura $\left(\mathrm{m}^{2}\right)$ (FRANK; SOARES, 2004).

\subsection{Necessidades nutricionais}

Thomas (1998) e Fiore (1999) definem uma dieta adequada como sendo aquela que supre as necessidades nutricionais de um indivíduo para a manutenção, reparação e o crescimento ou desenvolvimento, incluindo todos os nutrientes em quantidades adequadas e respeitando as proporções entre eles. 
Portanto, quando ocorre qualquer desequilíbrio no trato alimentar, que se estende da boca ao ânus, sendo composto pelo canal alimentar e seus órgãos anexos como o fígado, árvore biliar e pâncreas, o resultado pode ser a diminuição da qualidade e quantidade de alimentos absorvidos (McMILLAN; WONG, 2004; SOINI et al., 2003). A conseqüência seria o decréscimo de energia e de nutrientes ingeridos promovendo a má nutrição.

Esse processo deletério poria em risco a saúde do indivíduo, graças ao comprometimento da cognição, aumentando a susceptibilidade a infecções, hospitalizações e mortalidade (MIDDLETON et al., 2001; đLLIANI; ROMAGNONI; VOLPATO, 2001). Ficariam favorecidas dentro desse contexto uma maior incidência de quedas (TRIVALLE, 2002).

Calcula-se que cerca de 33 a 50 por cento dos problemas sistêmicos estejam relacionados com deficiências nutricionais (ROISINBLIT, 1995). Anderson (1971) e Marucci (1992) acreditam que os problemas nutricionais possam ser gerados, não só por desequilíbrios no trato alimentar, como por outras alterações sistêmicas. Portanto, a nutrição desempenharia um papel fundamental na prevenção de doenças, no tratamento de problemas crônicos de saúde, assim como na maneira de lidar com as enfermidades e as lesões agudas (LUECKENOTTE, 2002).

É importante mencionar que além dos fatores citados no item 2.3 , a nutrição dos idosos pode ser comprometida pela diminuição da eficiência metabólica (ROISINBLIT, 1995), ou seja, um idoso e um jovem do mesmo sexo, peso e altura necessitariam das mesmas quantidades de nutrientes; no entanto, para compensar a diminuição da eficiência metabólica, o idoso deve reduzir de 8 a 10 por cento a ingestão energética global. A variedade de alimentos em uma dieta completa é 
fundamental para prevenir enfermidades crônicas e degenerativas (THOMAS, 1998; FIORE, 1999).

Ciente das variações no metabolismo, do risco de desnutrição e suas conseqüências para essa faixa etária, Trivalle (2002) relata que, além das diferenças presentes entre indivíduos jovens e idosos, existe uma enorme heterogeneidade dentro deste último grupo, principalmente no plano nutricional. Para facilitar a compreensão o autor classifica os idosos em três grupos: pessoas idosas em bom estado de saúde, inclusive o nutricional; pessoas idosas doentes, que vivem em asilos ou que necessitam de cuidados em domicílio e que na maioria dos casos são dependentes e desnutridas, e pessoas idosas fragilizadas, muitas vezes com déficits cognitivos, que propiciam a perda de autonomia e o risco de desnutrição.

Frank e Soares (2004) afirmaram que as deficiências nutricionais, resultantes da ingestão insuficiente de nutrientes, estão relacionadas a diabetes melitus e alterações cardiovasculares. Laurin, Brodeur e Leduc (1992) relataram que tais carências poderiam ocasionar também queda da resposta imunológica e da resistência a infecções, além de retardar a cicatrização de feridas (FRANK; SOARES, 2004; PAPAS; PALMER; ROUNDS, 1989).

A redução da resposta imunológica pode ser atribuída ao œnsumo em níveis abaixo do recomendado de zinco, que é encontrado principalmente em carnes vermelhas, alguns mariscos, cereais integrais e leite, de vitamina C (REAVLEY; HOLT, 1999) e vitamina B6, encontradas em frutas e verduras, bem como de vitamina $\mathrm{E}$, presentes em óleos vegetais como o de girassol, espinafre, noz, abacate e cereais integrais (FRANK; SOARES, 2004; KRALL; HAYES; GARCIA, 1998). 
Outros problemas causados pela ausência de vitamina B6 e ferro (nutriente este que se encontra presente principalmente em carnes, leites e derivados, hortaliças, leguminosas e cereais) são as glossites, lábios inflamados (FRANK; SOARES, 2004; RUGG-GUNN; NUNN, 1999) e a falha na síntese de niacina (vitamina B3) cujo déficit produz debilidades emocionais, fadiga, depressão e alterações cognitivas. Segundo Roisinblit (1995), modificações no estado cognitivo podem ser relacionadas com a falta de ácido fólico.

A falta de ferro, de vitamina B12 e de vitamina B2 (riboflavina) pode estar associada à presença de queilite angular (FRANK; SOARES, 2004; RUGGGUNN; NUNN, 1999; ROIS INBLIT, 1995). Para Hartssok (1974), a deficiência de ferro na dieta dos idosos é muito comum.

A diminuição da ingestão de vitaminas A, C, betacaroteno, fibras, ácido fólico, ferro, e de outras fontes de energia foram associadas a indivíduos com ausência de elementos dentais ou portadores de próteses mal adaptadas. Frank e Soares (2004) mencionaram as alterações de pele e mucosa como conseqüência da hipovitaminose A no organismo. Segundo autores, tais deficiências poderiam interferir no processo de mastigação, influenciando negativamente a escolha dos alimentos (ETTINGER, 1998; FRANK; SOARES, 2004; GREKSA; PARRAGA; CLARK, 1995; KRALL; HAYES; GARCIA, 1998; MARSHALL et al., 2002; PAPAS et al., 1998).

De acordo com Geisseler e Bates (1984), Joshipura, Wille e Douglas (1996), Roisinblit (1995), Sheiham et al. (1999), Sheiham et al. (2001), Willett (1994), os indivíduos com ausências parciais ou totais de elementos dentais, ou portadores de próteses mal adaptadas passavam a consumir mais freqüentemente alimentos macios e fáceis de serem mastigados, muitas vezes processados e pastosos, os 
quais, por possuírem poucas fibras e serem pobres em nutrientes comprometem o estado nutricional. Observaram ainda diminuição no consumo de cereais inteiros e talos de vegetais (ROISINBLIT, 1995), vegetais crus e saladas, alimentos que são fonte primária de vitaminas e minerais essenciais (DAVIS; WATSON, 2000; YURKSTAS; EMERSON, 1964). A mesma observação pode ser feita com relação a frutas frescas e carnes (FRANK; SOARES, 2004; JOSHIPURA; WILLE; DOUGLAS, 1996; HUTTON; FEINE; MORAIS, 2002; REAVLEY; HOLT, 1999). Em contrapartida foi verificado um aumento da obesidade devido a maior ingestão de gorduras saturadas, colesterol e calorias elevando o risco de doenças cardiovasculares, infartos do miocárdio e hipertensão.

Já Greksa, Parraga e Clark (1995) não puderam observar, no estudo que desenvolveram, essa tendência dos indivíduos desdentados, que são mais propensos a apresentarem problemas mastigatórios e de selecionarem alimentos mais fáceis de serem mastigados.

Com relação à obesidade, Frank e Soares (2004) relataram que esta influenciaria o metabolismo da glicose e lipídeos sanguíneos, podendo levar ao aparecimento de desordens crônicas e diminuição da eficiência funcional em muitos idosos.

Já o aumento do risco de catarata (JOSHIPURA; WILLE; DOUGLAS, 1996; FRANK; SOARES, 2004; OLIVEIRA, 2001; WILLETT, 1994) e de cânceres de estômago (MARUCCI, 1992), de boca e de faringe (RUGG-GUNN; NUNN, 1999) são outras conseqüências da falta de zinco e de vitaminas C e E. Essas vitaminas, por serem antioxidantes, agem no processo de eliminação dos radicais livres mutagênicos das células danificadas, prevenindo o desenvolvimento da doença. 
Com relação à vitamina $\mathrm{E}$ especificamente, esta desempenharia um papel crucial nas funções neurológicas normais (FRANK; SOARES, 2004).

Um estudo realizado por Nowjack-Raymer e Sheiham (2003) comparando a alimentação de indivíduos dentados com portadores de próteses totais convencionais observou menor ingestão de alimentos ricos em fibras e em nutrientes anticarcinogênicos entre os usuários de próteses totais.

Reavley e Holt (1999) observaram que a baixa ingestão de vitamina B1 (tiamina), presente em hortaliças, leguminosas (feijão, lentilha, ervilha, grão-debico), cereais integrais,leite e pescados pode favorecer o surgimento de problemas como náusea, constipação, perda de peso e apetite, além de aumentar o risco de doenças cardíacas.

A constipação intestinal é um problema apresentado por muitos idosos que pode estar associado à falta de exercícios físicos, ingestão hídrica insuficiente, tônus muscular reduzido (FRANK; SOARES, 2004) e principalmente à pouca ingestão de fibras, que complicaria o trânsito intestinal (FRANK; SOARES, 2004; KRAUSE; MAHAN, 1991). Na tentativa de minimizar tal problema, fazem uso de laxantes, que interferem na absorção de colesterol, de caroteno e das vitaminas lipossolúveis (MARUCCI, 1992).

Convém mencionar o enfraquecimento da massa óssea e o desenvolvimento da osteoporose como conseqüência da ingestão deficiente de cálcio (FRANK; SOARES, 2004). O cálcio pode ser encontrado no leite e derivados, nozes e oleaginosas, pescados, verduras, entre outros alimentos.

$\mathrm{Na}$ tentativa de associar as deficiências nutricionais com a falta de adaptação aos aparelhos protéticos, Baxter (1984) procurou relacionar a deficiência de zinco à perda do paladar e à diminuição do fluxo salivar. Já Budtz-Jorgensen 
(1999) relacionou a diminuição da concentração plasmática de vitaminas do complexo $\mathrm{B}$, riboflavina ou ácido fólico na população idosa à intolerância às próteses removíveis. O mesmo autor, em 1994, observou que a deficiência de niacina pode propiciar o surgimento de lesões na mucosa oral e língua, além de colaborar para que o paciente apresente reflexos sistêmicos como confusões, lassidão, perda de peso e debilidade, que em muitos casos podem ser acompanhados por uma sensação de queimação na língua. Na fase aguda essa deficiência pode causar excesso de salivação, aumento da sensibilidade, dores e ulcerações, que se propagam rapidamente, dificultando o uso dos aparelhos protéticos.

Portanto, a falta de nutrientes estaria diretamente relacionada com o insucesso protético, uma vez que estes são essenciais à saúde e ao conforto dos tecidos de suporte das próteses (BAXTER, 1984; BUDTZ-JORGENSEN, 1999; FANTASIA, 1997; GEERING; KUNDERT; KELSEY, 1993).

Somente após um adequado exame clínico e protético do paciente, uma análise dos fatores que podem influenciar na sua alimentação, bem como um estudo detalhado dos fatores sistêmicos que podem interferir na sua correta alimentação e conseqüentemente na sua nutrição é que o cirurgião-dentista, juntamente com uma nutricionista terá condições de buscar uma dieta mais adequada à realidade vivida pelo idoso. Papas et al. (1998), já chamavam a atenção para a necessidade dos pacientes de faixa etária mais avançada, manterem alguns dos dentes naturais. Os autores alertavam o odontólogo para a importância de orientação nutricional aos pacientes portadores de próteses.

Autores como Ettinger (1998), MacEntee e Walton (1998), Sandström e Lindquist (1987) e Sebring et al. (1995), também reforçaram a importância de uma 
orientação profissional direta e individual na tentativa de provocar mudança de atitude com relação à seleção de alimentos.

Cientes da importância que a nutrição exerce sobre o estado bucal e geral do paciente, muitas linhas de pesquisas estão sendo desenvolvidas com o objetivo de provar, ou não, a existência de relação entre a condição bucal e seus reflexos na nutrição. Dentre as pesquisas que demonstraram a relação direta entre uma dentição em estado funcionalmente precário e o efeito negativo gerado sobre a quantidade e qualidade dos alimentos ingeridos encontram-se aquelas desenvolvidas por Apopollonio et al. (1997), Greksa, Parraga e Clark (1995), Krall, Hayes e Garcia (1998), Marshall et al. (2002), Nordstrom (1990), Papas, Palmer e Rounds (1989) e Papas et al. (1998), Soini et al. (2003).

Seguindo o mesmo raciocínio Kapur e Soman (1964) e Wayler e Chauncey (1983) avaliaram as conseqüências que o estado nutricional poderia gerar sobre a saúde física e emocional desses indivíduos.

Greksa, Parraga, Clark (1995), Krall, Hayes e Garcia (1998), Marshall et al. (2002), Papas, Palmer e Rounds (1989) e Papas et al. (1998) procuraram relacionar as condições bucais dos pacientes e a qualidade dos nutrientes ingeridos. Na pesquisa desenvolvida por Papas, Palmer e Rounds (1989), os autores puderam observar, após a análise do total de calorias e de 19 nutrientes (proteínas, cálcio, potássio, niacina, tiamina entre outros), uma queda estatisticamente significante na qualidade nutricional da dieta entre os pacientes com próteses totais unimaxilares ou bimaxilares, quando comparados com os pacientes que possuíam dentes e não usavam próteses, ou ainda, com aqueles que eram portadores de próteses parciais removíveis. 
Greksa, Parraga, Clark (1995) mostraram que a dieta dos pacientes dentados tendia a ser superior à dos desdentados, o que foi identificado pelo baixo consumo de gorduras e colesterol, além do consumo elevado de proteína, vitaminas e minerais.

Já Krall, Hayes e Garcia (1998) observaram que o consumo de calorias, proteínas e fibras tendia a declinar com a piora do estado dental, enquanto que o consumo de gordura tendia a aumentar. Para os autores, a diminuição da ingestão de frutas, vegetais, nozes (vitamina B6) e carne (zinco e magnésio) também estava diretamente relacionada com a função mastigatória.

Marshall et al. (2002) concluíram que a associação entre dentes naturais e próteses bem adaptadas favorecia uma maior e mais variada ingestão de nutrientes, com magnífica qualidade dietética.

Österberg et al. (2002) procuraram analisar a relação entre a habilidade mastigatória e a ingestão de calorias, nutrientes e outros itens alimentares em uma amostra da população idosa. Puderam observar uma fraca, ou na maioria dos casos, a inexistência de uma correlação estatisticamente significante tanto quando se associou o estado dental dos pacientes com a força de mordida obtida ou quando se relacionou ao estado dental com a ingestão dietética. Concluíram que existia uma grande variação do estado dental, força de mordida e habilidade mastigatória, mas que esses fatores apresentavam uma pequena influência tanto na ingestão como na seleção dos alimentos.

Já pesquisadores como Budtz-Jorgensen (1994), Davis e Watson (2000), Gunne (1985), Norlen, Johansson, Birkhed (1996), acreditam que o valor nutricional de uma dieta não esteja associado à situação dos dentes, muito embora estes possam ser um obstáculo para a melhoria da dieta. 
Gunne (1985) observou que apesar de um aumento significante na habilidade mastigatória após a confecção de próteses totais convencionais adequadas, os indivíduos estudados não tiveram o seu padrão alimentar alterado.

Budtz-Jorgensen (1994) não considerou esclarecida a maneira como a eficiência mastigatória influencia o modelo padrão de alimentação ou a qualidade nutricional da dieta. Para o autor, o estado nutricional dependeria de outros fatores como da saúde geral e bucal, de uma ingestão adequada de alimentos e do estado sócio-econômico do paciente.

O mesmo pode ser observado por Ettinger (1998), MacEntee e Walton (1998), Sandström e Lindquist (1987) e Sebring (1995), Para esses autores, a substituição das próteses ou até mesmo a colocação de próteses sobre implantes osteointegrados, na tentativa de proporcionar uma melhora na eficiência mastigatória, não necessariamente resultaria em uma mudança na seleção dos alimentos.

Entretanto, Sandström e Lindquist (1987) verificaram nesse estudo um consumo ligeiramente maior de frutas frescas e pão torrado por parte dos pacientes usuários de próteses implanto-muco-suportadas, mesmo não sendo estatisticamente significante para esta pesquisa.

Sebring (1995) relataram que a ingestão de calorias e de 27 nutrientes analisados era semelhante tanto no período em que os pacientes eram reabilitados por próteses totais convencionais, quanto após a reabilitação por próteses totais sobre implantes. O que se observou foi uma ingestão inadequada de fibras, cálcio e de vitaminas A, E,D, B6 e/ou magnésio em ambos os grupos.

Ettinger (1998) procurou relacionar a eficiência mastigatória com a presença de dentes. Segundo o autor, após uma reabilitação protética, o indivíduo 
teria uma melhor capacidade mastigatória, apesar disso não implicar numa alteração significante na ingestão de alimentos, favorecendo a crença de que fatores sócioculturais sejam mais significantes do que os dentes em si.

Já comparando indivíduos com dentição natural e portadores de próteses totais convencionais, Lucas et al. (1986) não relataram diferenças qualitativas com relação à eficiência mastigatória desses pacientes.

Österberg e Steen (1982) e Österberg et al. (2002) não encontram alterações significativas no padrão da dieta alimentar após a perda de dentes, a colocação, ou não, de próteses, e a reabilitação protética.

Horn, Hodge e Treuer (1994) reportaram os resultados de um estudo clínico retrospectivo que avaliava as condições dentais na manutenção do peso. 0 estudo foi conduzido em uma instituição para idosos e a população em questão apresentava algum grau de demência. O grupo avaliado era constituído por pacientes dentados e desdentados, portadores, ou não, de próteses totais. Não foi encontrada diferença significante que relacionasse perda de peso com condições dentais.

Fiore (1999) verificou o consumo alimentar de 114 adultos e idosos portadores de próteses totais e parciais removíveis. Por meio desse estudo observou que não foram encontradas diferenças estatisticamente significantes entre os grupos estudados, segundo o uso, ou não, de próteses e o consumo de proteínas, de gorduras, de carboidratos, de vitamina $\mathrm{C}$, de ferro e de cálcio além do valor energético da dieta. Mais da metade da amostra estudada fazia algum tipo de restrição alimentar. As maiores restrições envolviam frutas, seguidas de alimentos do grupo dos pães e dos cereais, das hortaliças, das oleaginosas, dos açúcares e das carnes. 
Oliveira (2001) discutiu a relação do edentulismo com o aspecto nutricional em pacientes geriátricos, considerando-a controversa. Para a autora, o efeito da eficiência mastigatória sobre o estado nutricional precisa ser melhor esclarecido.

Shinkai et al. (2002) concluíram que prótese tecnicamente perfeita não é essencial quando se considera a qualidade da dieta. A autora chama a atenção para a necessidade de um trabalho personalizado, realizado por uma equipe multidisciplinar como sendo fundamental para melhorar a qualidade da dieta dos pacientes desdentados, portadores de próteses.

Por tudo que foi levantado na literatura, até o presente momento, não seria absurdo admitir que pessoas idosas podem apresentar limitações relacionadas com a função mastigatória. É consenso, ainda, o fato de que a digestão dos alimentos se inicia na boca e que existe uma relação direta entre alimentação adequada e qualidade de vida. Baseados nessa linha de raciocínio, é que se pensou em fazer um estudo procurando relacionar hábito alimentar com reabilitação protética. 


\section{PROPOSIÇÃO}

Este estudo propõe-se a avaliar, por meio de dados comparativos, a relação entre o hábito alimentar e a reabilitação protética em pacientes senescentes, desdentados totais bimaxilares, reabilitados por Prótese Total Convencional (PTC).

Levando-se em consideração o período anterior e posterior à reabilitação protética, serão avaliados:

3.1 Com relação ao exame clínico protético:

- a qualidade funcional das próteses;

- a habilidade mastigatória dos pacientes.

3.2 Com relação aos hábitos alimentares:

- o IMC e sua classificação;

- a consistência da dieta;

- a ingestão hídrica;

- o hábito intestinal;

- a inserção de alguns alimentos na dieta após a reabilitação protética. 


\section{CASUÍSTICA - MATERIAL E METÓdO}

\subsection{Casuística}

O presente estudo foi realizado dentro do Projeto Envelhecer Sorrindo, que pertence ao Departamento de Prótese Dentária da Faculdade de Odontologia da Universidade de São Paulo e constituiurse de 32 pacientes desdentados completos bimaxilares, funcionalmente independentes e autônomos, com mais de 60 anos de idade, de ambos os sexos, das raças branca e não-branca e que não apresentavam problemas de deglutição relacionados a doenças, como por exemplo, problemas neurológicos. Os 32 participantes da pesquisa foram reabilitados por próteses totais convencionais maxilar e mandibular.

Antes de iniciar o tratamento protético, obedecendo aos critérios definidos anteriormente para a inclusão dos pacientes na pesquisa, estes receberam instruções referentes à garantia da privacidade e à certeza do atendimento. Após os esclarecimentos, os pacientes assinaram o termo de consentimento de acordo com o modelo da tese de doutorado de Oliveira 2001) (Anexo A), viabilizando a sua participação. O protocolo 247/02 da pesquisa foi aprovado pelo Comitê de Ética em Pesquisa da Faculdade de Odontologia da Universidade de São Paulo (FOUSP) com o parecer número 231/02, no dia 20 (vinte) de novembro de 2002 (Anexo B). Tais procedimentos atendem a Resolução $n^{\circ}$ 196, de 10 de outubro de 1996, do Conselho Nacional de Saúde. O exame clínico, a entrevista e a aplicação do questionário da análise da alimentação foram realizados pela própria pesquisadora. 


\subsection{Material (Instrumental)}

4.2.1 Para a avaliação nutricional

- Ficha clínica (Anexo C)- para análise antes da instalação da prótese;

- Anamnese alimentar (Anexo D);

- Ficha clínica (Anexo E) - para análise depois da instalação da prótese;

- Balança antropométrica mecânica, com capacidade para 150 kg (Welmy Indústria e Comércio, Santa Bárbara D'Oeste - S.P.).

4.2.2 Para a avaliação clínica

- Ficha clínica (Anexo C)- para análise antes da instalação da prótese;

- Ficha clínica (Anexo E )- para análise depois da instalação da prótese;

- Consultório odontológico;

- Equipamentos de proteção para biossegurança no consultório odontológico tais como:

gorro;

máscara;

$>$ luvas;

$>$ óculos de proteção; 
$>$ avental;

$>$ embalagens para esterilização;

> coberturas descartáveis para os equipamentos odontológicos;

$>$ sugadores;

$>$ guardanapos de papel;

$>$ gaze.

- Espátulas de madeira;

- Instrumental clínico (pinça, espelho, explorador);

- Papel para articulação - Detecto (Dentsply Indústria e Comércio Ltda. Rua Alice Hervê,86-Petrópolis-RJ, CNPJ=31116239/0001-55);

- Compasso de Willis.

\subsection{Método}

O método utilizado para compor a amostra foi o não-probabilístico, pela amostragem intencional. Desta forma, foram atendidos os pacientes que ingressaram na clínica do Projeto Envelhecer Sorrindo da FOUSP para receberem o tratamento reabilitador por PTC, continuando-se a dinâmica do atendimento enquanto ainda houvesse pacientes com o perfil selecionado.

Esta pesquisa foi realizada em três fases distintas. A primeira fase foi desenvolvida antes de iniciarmos qualquer procedimento relacionado com a confecção das próteses totais bimaxilares. Nesta fase era preenchida uma ficha clínica e feita uma avaliação protética (Anexo C), além da realização de uma 
entrevista com a aplicação de uma anamnese alimentar (Anexo D). A segunda e a terceira fases constaram do preenchimento de uma ficha clínica e da realização de uma avaliação protética (Anexo E). Enquanto a segunda fase era realizada dois a três meses após a reabilitação protética, a terceira era concluída depois de cinco a seis meses decorrida a instalação. Na segunda e na terceira fases da pesquisa eram realizados novos exames clínicos (Anexo $E$ ) acrescidos de mais dois questionamentos referentes à ingestão de alimentos na dieta após a reabilitação protética.

A avaliação protética foi baseada naquela elaborada por Oliveira (2001) sendo que esta sofreu algumas modificações para adaptar-se aos propósitos do presente estudo. O questionário para a análise inicial da alimentação, bem como a forma de comparação dos dados e a estimativa da inserção de alguns alimentos na dieta, antes e depois da reabilitação protética, foram elaborados pela nutricionista.

4.3.1 Avaliação do estado nutricional

Constou das seguintes avaliações:

- antropométrica;

- do hábito alimentar;

- relacionada com ingestão de alimentos;

- do hábito intestinal;

- da ingestão hídrica. 


\subsubsection{1 avaliação antropométrica}

Medida antropométrica é a medida da estatura, peso corporal, composição e proporções, sendo a base para a avaliação nutricional dos idosos. Quando as medidas são tomadas e registradas a intervalos regulares, podem fornecer uma idéia do quadro nutricional com o passar do tempo, permitindo, assim, a rápida identificação de problemas nutricionais, antes que ocorram conseqüências sérias para a saúde (LUECKENOTTE, 2002).

Os critérios utilizados para a tomada de peso e da medida do paciente foram aqueles utilizados por Oliveira (2001). Esses dados foram obtidos antes e após a reabilitação protética, conforme descrito anteriormente e seguindo a padronização descrita a seguir:

\section{A) TOMADA DE PESO}

- Ajustava-se a balança antropométrica, deixando-a no zero;

- Solicitava-se que o paciente retirasse os sapatos e meias, agasalho de inverno e objetos pesados (Ex: chaves, moedas, celulares);

- Solicitava-se que o paciente subisse na plataforma da balança, juntasse os pés e endireitasse o corpo, colocando os calcanhares contra o estatiômetro da balança; 
- Os pesos eram movidos na haste graduada em quilogramas $(\mathrm{kg})$ e em gramas (g) até que houvesse um equilíbrio da haste, quando então era realizada a tomada de peso;

- O peso em $\mathrm{kg}$ era verificado e anotado.

B) MEDIDA DA ALTURA

- Solicitava-se ao paciente para que retirasse os sapatos, meias e adorno para cabelos;

- Solicitava-se que o paciente subisse na plataforma da balança e ficasse com as costas voltadas para o medidor de altura, juntasse os pés, endireitasse o corpo e olhasse para a frente;

- O estatiômetro era posicionado sobre o topo da cabeça do paciente;

- A altura era verificada e anotada em metros (m).

O IMC (Índice de Massa Corporal) era determinado pelo peso do paciente $(\mathrm{Kg})$ dividido pelo quadrado da sua altura $\left(\mathrm{m}^{2}\right)$. A classificação seguiu a tabela abaixo, respeitando-se a classificação do Estado Nutricional de acordo com o IMC para idosos (ISOSAKI; CARDOSO, 2004). 


\begin{tabular}{|c|c|}
\hline \multicolumn{2}{|c|}{ Classificação do IMC (idosos) } \\
\hline IMC $\left(\mathbf{K g} / \mathbf{m}^{2}\right)$ & $\begin{array}{c}\text { Estado } \\
\text { Nutricional }\end{array}$ \\
\hline$<22,00$ & $\begin{array}{c}\text { Desnutrição/ } \\
\text { baixo peso }\end{array}$ \\
\hline $22,00-27,00$ & Eutrofia \\
\hline$>27,00$ & $\begin{array}{c}\text { Sobrepeso/ } \\
\text { obesidade }\end{array}$ \\
\hline
\end{tabular}

\subsubsection{2 avaliação do hábito alimentar}

A avaliação do hábito alimentar constituia-se de uma planilha (Anexo D) elaborada com a colaboração da nutricionista. Por meio dessa planilha tomava-se conhecimento do que era ingerido habitualmente pelo paciente, em todas as refeições.

\subsubsection{3 avaliação relacionada com a ingestão de alimentos}

Eram feitos questionamentos quanto à dificuldade do paciente em engolir alimentos, bem como quanto à consistência da dieta ingerida, antes e após a reabilitação protética. Esses eram feitos nos itens 6 e 7 das fichas clínicas tanto do Anexo C como a do Anexo E. 
4.3.1.4 avaliação do hábito intestinal

Esse aspecto foi analisado no item de número 5 das fichas clínicas tanto do Anexo C como do Anexo E. Com esse questionamento tomava-se conhecimento da freqüência com o que o paciente fazia suas evacuações, bem como a consistência de suas fezes.

4.3.1.5 avaliação da ingestão hídrica

A avaliação da ingestão hídrica era analisada de forma quantitativa, através da questão de número 8, dos anexos $\mathrm{C}$ e $\mathrm{E}$.

\subsection{Exame clínico protético constava das seguintes avaliações}

- Do período em que o paciente e ncontrava-se desdentado total;

- Do tempo de uso da última prótese total;

- Do estado de conservação das próteses;

- Da qualidade funcional das próteses;

- Da satisfação do paciente com as próteses e

- Da habilidade mastigatória. 
4.4.1 Avaliação do período em que o paciente encontrava-se desdentado total

Essa averiguação informava o período em que o paciente se tornou desdentado e era avaliado na questão 1 do Anexo C.

4.4.2 Avaliação do tempo de uso da última prótese total

Através da questão 2, do Anexo C, pode-se determinar de forma geral, o tempo de uso da última Prótese Total Convencional ( PTC), maxilar e mandibular.

4.4.3 Avaliação do estado de conservação das próteses

O estado de conservação das próteses totais convencionais era avaliado no item 3 do Anexo $C$ e no item 1 do Anexo $E$, sendo considerado satisfatório quando não existissem fraturas, reembasamentos, porosidades e trincas na base da prótese que pudessem ser detectadas clinicamente e, também, quando não fosse observada perda ou fratura de dentes. 
4.4.4 Avaliação da qualidade funcional das próteses

A dimensão vertical (DV) e oclusão das próteses totais bimaxilares eram avaliadas como sendo satisfatórias ou insatisfatórias nas questões de número 4 e 5 no Anexo $\mathrm{C}$ e de número 2 e 3 no Anexo $\mathrm{E}$, antes e após a reabilitação protética, tendo como suporte a metodologia do estudo de Oliveira (2001).

Aplicou-se o método métrico com o objetivo de calcular a DV a partir da Dimensão Vertical de Oclusão (DVO), da Dimensão Vertical de Repouso (DVR) e do Espaço Funcional de Pronúncia (EFP). Para a obtenção dos valores necessários, utilizou-se o compasso de Willis. Além disso, foi analisada a harmonia da face do paciente e foram realizados testes fonéticos, a fim de se poder classificar a DV como sendo satisfatória, ou não.

Na busca da DVO, antes e após a reabilitação protética, foi aplicado o método de Lytle, modificado por Tamaki (1988), adotado pela disciplina de Prótese Total da FOUSP. Obtinha-se a DVO, quando o paciente buscava a máxima intercuspidação com suas próteses completas. Nesse momento, apoiavase a haste vertical do compasso de Willis entre a base do nariz e o bordo inferior do mento, medindo-se assim a distância correspondente a DVO.

Para calcularmos a DVR, o paciente era solicitado a ficar em repouso, com os músculos relaxados; assim, media-se a distância entre a base do nariz e o mento. Subtraindo-se a DVO da DVR era obtido o Espaço Funcional de Pronúncia (TAMAKI, 1988). 
Em relação ao teste fonético, preconizava-se a pronúncia de fonemas sibilantes como Mississipi, sessenta e seis, estando os músculos em atividade, com o objetivo de observar o Espaço Funcional de Pronúncia. Essa referência era adotada por ser considerada mais estável. A DV era considerada normal quando, na pronúncia, não havia contato dos dentes posteriores nem anteriores (OLIVEIRA, 1994; OLIVEIRA, 2001).

Ao considerar a DV, avaliava-se a reconstituição da fisionomia do paciente, diante da conformação do sulco nasolabial, da harmonia do terço inferior da face com as demais partes do rosto e da plenitude facial em relação à idade do paciente (TAMAKI, 1988). Na ausência de um desses fatores, a DV era considerada insatisfatória.

Para os pacientes que não usavam prótese total, a DV era considerada como sendo inexistente, mesmo sabendo que esta poderia ser calculada a partir da DVR e do Espaço Funcional de Pronúncia (OLIVEIRA, 2001; SILVERMAN, 1956).

Para análise da oclusão do paciente, tanto no Anexo $\mathrm{C}$ como no Anexo E, eram avaliados os movimentos mandibulares de abertura, fechamento, protrusão e de lateralidade. Nos movimentos de abertura e de fechamento, com a prótese em posição, o paciente era solicitado a fechar a boca lentamente até que os dentes se contatassem. Nessa posição, buscava-se uma correta intercuspidação com um máximo de contatos simultâneos posteriores, de mesma intensidade, e ausência de prematuridade no fechamento habitual repetitivo.

Nos movimentos de lateralidades, ambas as próteses, além de não apresentarem travamento, deveriam ter três pontos de contato no mínimo: um na região anterior e dois posteriores, sendo um de cada lado do arco. A oclusão era 
considerada balanceada quando as próteses totais bimaxilares apresentavam contatos entre os arcos antagonistas, durante os movimentos de lateralidade e protrusão (OLIVEIRA, 2001; TAMAKI, 1988).

Ao não se verificar uma ou mais das condições mencionadas, a oclusão era considerada insatisfatória.

4.4.5 Avaliação da satisfação do paciente com as próteses

A satisfação do paciente com a sua prótese era avaliada através da questão 6 do Anexo $\mathrm{C}$ e da questão 4 do Anexo E e essa satisfação parecia estar relacionada com a retenção, principalmente da prótese total mandibular.

Eram consideradas satisfatórias, quando não havia queixa de deslocamento da prótese e, insatisfatórias, quando era feita referência a algum deslocamento.

4.4.6 Avaliação da habilidade mastigatória

A habilidade mastigatória dos pacientes envolvidos nesse estudo era avaliada por meio das questões de número 7 do Anexo $\mathrm{C}$ e de número 5 do Anexo E. Nesse item também era possível tomarmos conhecimento se o paciente 
conseguia mastigar tudo o que gostaria de comer. Tal pergunta era válida tanto em relação às próteses antigas quanto às novas.

\subsection{Método estatístico}

Na análise dos resultados foram aplicadas as provas estatísticas nãoparamétrica do Qui-Quadrado partições $L$ x C, adequadas à comparação das variáveis em estudo. Quando as condições exigidas pela prova do Qui-Quadrado não foram satisfeitas, no caso da subdivisão referente à comparação dos alimentos ingeridos antes e após a reabilitação protética, foi aplicado o teste Kappa. Para ambos os testes foram utilizados o software BioEstat 3.0 AYRES et al. (2003), sendo o nível de significância estabelecido para $p<0,05$, em uma prova bilateral.

Com o objetivo de verificar se houve diferenças significantes entre as freqüências de respostas obtidas pela avaliação dos pacientes antes e após a instalação das próteses totais bimaxilares, foi aplicada a prova do Qui-Quadrado (AYRES et al., 2003). As variáveis em estudo foram: Índice de Massa Corporal, tempo de uso e tipo de prótese usada antes da confecção da nova PTC, inserção de novos alimentos na dieta, consistência dos alimentos, ingestão de líquidos, hábito intestinal e consistência das fezes, dificuldade para deglutir, habilidade mastigatória, além de análise da dimensão vertical, oclusão e retenção, e estabilidade da prótese. 


\section{RESULTADOS}

\subsection{Amostra}

Essa pesquisa foi realizada avaliando-se 32 pacientes portadores de prótese total convencional bimaxilar. Dentre os indivíduos avaliados, 8 (oito) eram do sexo masculino e 24 (vinte e quatro) do sexo feminino, sendo a média de idade do total da amostra 72 anos e 8 meses (desvio-padrão de 5,08 anos) ocorrendo uma variação entre 61 e 83 anos.

Ainda detendo-se ao perfil da amostra estudada, na Tabela 5.1 estão demonstradas as freqüências de pacientes de acordo com o sexo, relacionando a idade e a raça respectivamente.

Já na Tabela 5.2, estão apresentados os perfis dos pacientes como usuários de próteses, considerando o sexo da amostra. Procurourse demonstrar o tempo em que esses pacientes se encontravam desdentados, o tipo de prótese usada antes da realização deste trabalho, o estado de conservação das PTCs e o período de uso da última prótese. 
Tabela 5.1- Distribuição de freqüências de pacientes relacionando o sexo à idade e à raça da amostra estudada

\begin{tabular}{|c|c|c|c|c|c|c|c|}
\hline \multicolumn{2}{|c|}{ Avaliação } & \multicolumn{2}{|c|}{ Masculino } & \multicolumn{2}{|c|}{ Feminino } & \multicolumn{2}{|c|}{ Total geral } \\
\hline \multirow{6}{*}{$\begin{array}{l}\text { Faixa } \\
\text { etária }\end{array}$} & 60 a 65 & 2 & 6,25 & 2 & 6,25 & 4 & 12,5 \\
\hline & 65 a 70 & 1 & 3,12 & 4 & 12,5 & 5 & 15,625 \\
\hline & 70 a 75 & 2 & 6,25 & 8 & 25 & 10 & 31,25 \\
\hline & 75 a 80 & 3 & 9,38 & 5 & 15,62 & 8 & 25 \\
\hline & 80 a 85 & 0 & 0 & 5 & 15,62 & 5 & 15,625 \\
\hline & Total parcial & 8 & 25 & 24 & 75 & 32 & 100 \\
\hline \multirow{3}{*}{ Raças } & Branca & 5 & 15,62 & 17 & 53,12 & 22 & 68,75 \\
\hline & Não-branca & 3 & 9,38 & 7 & 21,88 & 10 & 31,25 \\
\hline & Total parcial & 8 & 25 & 24 & 75 & 32 & 100 \\
\hline
\end{tabular}

$N=$ número de indivíduos

Tabela 5.2- Distribuição de freqüências de pacientes relacionando sexo com o tipo de prótese usada antes da pesquisa, estado de conservação das PTCs, período de uso da última prótese e o tempo em que os pacientes se encontram desdentados

\begin{tabular}{c|c|c|c|c|c}
\hline \multicolumn{2}{c}{ Avaliação } & \multirow{2}{*}{ Masculino } & \multirow{2}{*}{ Feminino } & \multicolumn{2}{c}{ Total geral } \\
\cline { 3 - 6 } & & & & N & $\%$ \\
\hline \multirow{3}{*}{ Tempo desdentado } & 1 a 9 anos & 1 & 3 & 4 & 12,5 \\
& 10 anos ou mais & 7 & 21 & 28 & 87,5 \\
& Total parcial & $\mathbf{8}$ & $\mathbf{2 4}$ & $\mathbf{3 2}$ & $\mathbf{1 0 0}$ \\
\hline \multirow{2}{*}{$\begin{array}{c}\text { Tipo de prótese usada antes } \\
\text { da confecção da prótese } \\
\text { total }\end{array}$} & PTC bimaxilar & 4 & 17 & 21 & 65,62 \\
& PTC unimaxilar & 2 & 6 & 8 & 25 \\
& Não usavam prótese & 2 & 1 & 3 & 9,38 \\
\hline \multirow{2}{*}{$\begin{array}{c}\text { Estado de conservação das } \\
\text { próteses maxilares }\end{array}$} & Total parcial & $\mathbf{8}$ & $\mathbf{2 4}$ & $\mathbf{3 2}$ & $\mathbf{1 0 0}$ \\
\hline \multirow{2}{*}{$\begin{array}{c}\text { Estado de conservação das } \\
\text { próteses mandibulares }\end{array}$} & Satisfatória & 0 & 11 & 11 & 37,93 \\
& Insatisfatória & 6 & 12 & 18 & 62,07 \\
& Total parcial & $\mathbf{6}$ & $\mathbf{2 3}$ & $\mathbf{2 9}$ & $\mathbf{1 0 0}$ \\
\hline \multirow{3}{*}{$\begin{array}{c}\text { Período de uso da última } \\
\text { prótese }\end{array}$} & Satisfatória & 2 & 10 & 12 & 52,18 \\
& Insatisfatória & 2 & 9 & 11 & 47,82 \\
& Total parcial & $\mathbf{4}$ & $\mathbf{1 9}$ & $\mathbf{2 3}$ & $\mathbf{1 0 0}$ \\
\hline & 1 a 6 anos & 1 & 6 & 7 & 21,87 \\
& 7 anos ou mais & 5 & 17 & 22 & 68,75 \\
& Nunca usou prótese & 2 & 1 & 3 & 9,38 \\
& Total parcial & $\mathbf{8}$ & $\mathbf{2 4}$ & $\mathbf{3 2}$ & $\mathbf{1 0 0}$ \\
\hline
\end{tabular}




\subsection{Resultados e análise estatística dos resultados}

Os dados coletados durante a pesquisa estão expostos nesse item através de três subdivisões. Na primeira subdivisão estão os resultados relacionados com o perfil alimentar dos pacientes (Tabela, 5.3a), com o perfil protético (Tabela 5.3b) e com o hábito intestinal (Tabela 5.3c) obtidos antes e após a instalação das PTCs novas; já na segunda subdivisão ocorre um relacionamento dos dados obtidos na primeira subdivisão, e na terceira subdivisão estão as comparações dos alimentos ingeridos antes e após a reabilitação protética.

Os resultados das freqüências encontradas em cada item da avaliação foram analisados por meio do teste do Qui-quadrado partições $L \times C$, exceto na subdivisão referente à comparação dos alimentos ingeridos antes e após a reabilitação protética, quando foi aplicado o teste Kappa.Para ambos os testes foram utilizados o software Bioestat 3.0, que serão descritos no decorrer do trabalho.

O valor do Qui-quadrado crítico foi $x^{2}=3,84$, como grau de liberdade, de acordo com a Tabela dos Valores Críticos do Qui-Quadrado (AYRES et al., 2003). Quando o valor do Qui-Quadrado encontrado era maior do que o QuiQuadrado crítico, concluía-se que haveria diferença significante entre as comparações realizadas. 
a) Perfil nutricional dos pacientes

Tabela 5.3a - Distribuição de freqüências de pacientes quanto aos resultados obtidos após a análise do perfil alimentar antes e após a instalação da PTC nova

\begin{tabular}{|c|c|c|c|c|c|c|c|c|c|}
\hline \multicolumn{2}{|c|}{ Avaliação } & \multicolumn{2}{|c|}{$\begin{array}{c}\text { Antes da } \\
\text { instalação da } \\
\text { PTC nova }\end{array}$} & \multicolumn{2}{|c|}{$1^{\circ}$ controle } & \multicolumn{2}{|c|}{$2^{\circ}$ controle } & \multirow[t]{2}{*}{$\begin{array}{c}\text { Qui- } \\
\text { quadrado }\end{array}$} & \multirow[t]{2}{*}{$\mathbf{P}$} \\
\hline & & $\mathbf{N}$ & $\%$ & $\mathbf{N}$ & $\%$ & $\mathbf{N}$ & $\%$ & & \\
\hline \multirow{4}{*}{$\begin{array}{c}\text { Classificação } \\
\text { do IMC }\end{array}$} & Baixo peso & 6 & 18,75 & 7 & 21,88 & 7 & 21,88 & \multirow{4}{*}{0,1465} & \multirow{4}{*}{$\begin{array}{l}0,9974 \\
\text { (N.S.) }\end{array}$} \\
\hline & Eutrofia & 15 & 46,88 & 14 & 43,75 & 14 & 43,75 & & \\
\hline & Obesidade & 11 & 34,38 & 11 & 34,37 & 11 & 34,37 & & \\
\hline & Total geral & 32 & 100 & 32 & 100 & 32 & 100 & & \\
\hline \multirow{3}{*}{$\begin{array}{l}\text { Dificuldade } \\
\text { para engolir } \\
\text { os alimentos }\end{array}$} & $\begin{array}{c}\text { Engole } \\
\text { normalmente }\end{array}$ & 27 & 84,38 & 29 & 90,62 & 28 & 87,5 & \multirow{3}{*}{0,5714} & \multirow{3}{*}{$\begin{array}{l}0,7515 \\
\text { (N.S.) }\end{array}$} \\
\hline & $\begin{array}{l}\text { Apresenta } \\
\text { dificuldade }\end{array}$ & 5 & 15,62 & 3 & 9,38 & 4 & 12,5 & & \\
\hline & Total geral & 32 & 100 & 32 & 100 & 32 & 100 & & \\
\hline \multirow{4}{*}{$\begin{array}{l}\text { Consistência } \\
\text { da dieta }\end{array}$} & Geral & 14 & 43,75 & 21 & 65,63 & 26 & 81,25 & \multirow{4}{*}{9,9309} & \multirow{4}{*}{$\underset{*}{0,0416}$} \\
\hline & Branda & 14 & 43,75 & 9 & 28,12 & 5 & 15,63 & & \\
\hline & Pastosa/líquida & 4 & 12,5 & 2 & 6,25 & 1 & 3,12 & & \\
\hline & Total geral & 32 & 100 & 32 & 100 & 32 & 100 & & \\
\hline \multirow{3}{*}{$\begin{array}{l}\text { Habilidade } \\
\text { mastigatória }\end{array}$} & $\begin{array}{c}\text { Consegue mastigar } \\
\text { tudo }\end{array}$ & 14 & 43,75 & 18 & 56,25 & 26 & 81,25 & \multirow{3}{*}{9,7568} & \multirow{3}{*}{$\underset{*}{0,0076}$} \\
\hline & Não mastiga tudo & 18 & 56,25 & 14 & 43,75 & 6 & 18,75 & & \\
\hline & Total geral & 32 & 100 & 32 & 100 & 32 & 100 & & \\
\hline \multirow{4}{*}{$\begin{array}{l}\text { Ingestão de } \\
\text { líquidos }\end{array}$} & 3 copos ou menos & 7 & 21,88 & 14 & 43,75 & 10 & 31,25 & \multirow{4}{*}{4.6871} & \multirow{4}{*}{$\begin{array}{l}0,3209 \\
\text { (N.S.) }\end{array}$} \\
\hline & 4 a 6 copos & 17 & 53,12 & 11 & 34,38 & 17 & 53,12 & & \\
\hline & 7 copos ou mais & 8 & 25 & 7 & 21,87 & 5 & 15,63 & & \\
\hline & Total geral & 32 & 100 & 32 & 100 & 32 & 100 & & \\
\hline
\end{tabular}


Tabela 5.3b - Distribuição de freqüências de pacientes quanto aos resultados obtidos após a análise do perfil protético antes e após a instalação da PTC nova

\begin{tabular}{|c|c|c|c|c|c|c|c|c|c|}
\hline \multicolumn{2}{|c|}{ Avaliação } & \multicolumn{2}{|c|}{$\begin{array}{c}\text { Antes da } \\
\text { instalação da } \\
\text { PTC nova }\end{array}$} & \multicolumn{2}{|c|}{$1^{\circ}$ controle } & \multicolumn{2}{|c|}{$2^{\circ}$ controle } & \multirow[t]{2}{*}{$\begin{array}{c}\text { Qui- } \\
\text { quadrado }\end{array}$} & \multirow[t]{2}{*}{$\mathbf{p}$} \\
\hline & & $\mathbf{N}$ & $\%$ & $\mathbf{N}$ & $\%$ & $\mathbf{N}$ & $\%$ & & \\
\hline \multirow{4}{*}{$\begin{array}{c}\text { Dimensão } \\
\text { Vertical }\end{array}$} & Satisfatória & 4 & 12,5 & 31 & 96,88 & 31 & 96,88 & \multirow{4}{*}{70,9091} & \multirow{4}{*}{$\underset{*}{0,0000}$} \\
\hline & Insatisfatória & 20 & 62,5 & 1 & 3,12 & 1 & 3,12 & & \\
\hline & Inexistente & 8 & 25 & 0 & 0 & 0 & 0 & & \\
\hline & Total geral & 32 & 100 & 32 & 100 & 32 & 100 & & \\
\hline \multirow{4}{*}{ Oclusão } & Satisfatória & 12 & 37,5 & 28 & 87,5 & 29 & 90,62 & \multirow{4}{*}{31,5973} & \multirow{4}{*}{$\underset{*}{0,0000}$} \\
\hline & Insatisfatória & 12 & 37,5 & 4 & 12,5 & 3 & 9,38 & & \\
\hline & Inexistente & 8 & 25 & 0 & 0 & 0 & 0 & & \\
\hline & Total geral & 32 & 100 & 32 & 100 & 32 & 100 & & \\
\hline \multirow{4}{*}{$\begin{array}{l}\text { Retenção e } \\
\text { estabilidade }\end{array}$} & Satisfatória & 5 & 15,62 & 25 & 78,12 & 31 & 96,88 & \multirow{4}{*}{52,8962} & \multirow{4}{*}{$\underset{*}{0,0000}$} \\
\hline & Insatisfatória & 19 & 59,38 & 7 & 21,88 & 1 & 3,12 & & \\
\hline & Inexistente & 8 & 25 & 0 & 0 & 0 & 0 & & \\
\hline & Total geral & 32 & 100 & 32 & 100 & 32 & 100 & & \\
\hline
\end{tabular}

$\left(^{*}\right)$ significante quando $p<0,05 \quad$ Não significante quando $p>0,05 \quad N=$ número de indivíduos

Tabela 5.3c - Distribuição de freqüências de pacientes quanto aos resultados obtidos após a análise do hábito intestinal antes e após a instalação da PTC nova

\begin{tabular}{|c|c|c|c|c|c|c|c|c|c|}
\hline \multicolumn{2}{|c|}{ Avaliação } & \multicolumn{2}{|c|}{$\begin{array}{c}\text { Antes da } \\
\text { instalação da } \\
\text { PTC nova }\end{array}$} & \multicolumn{2}{|c|}{$1^{\circ}$ controle } & \multicolumn{2}{|c|}{$2^{\circ}$ controle } & \multirow[t]{2}{*}{$\begin{array}{l}\text { Qui- } \\
\text { quadrado }\end{array}$} & \multirow[t]{2}{*}{$\mathbf{p}$} \\
\hline & & $\mathbf{N}$ & $\%$ & $\mathbf{N}$ & $\%$ & $\mathbf{N}$ & $\%$ & & \\
\hline \multirow{4}{*}{$\begin{array}{c}\text { Freqüência } \\
\text { de } \\
\text { evacuações }\end{array}$} & Diário & 27 & 84,38 & 26 & 81,25 & 26 & 81,25 & \multirow{4}{*}{1,1110} & \multirow{4}{*}{$\begin{array}{l}0,8925 \\
\text { (N.S.) }\end{array}$} \\
\hline & A cada 2 dias & 3 & 9,37 & 2 & 6,25 & 2 & 6,25 & & \\
\hline & 3 dias ou mais & 2 & 6,25 & 4 & 12,5 & 4 & 12,5 & & \\
\hline & Total geral & 32 & 100 & 32 & 100 & 32 & 100 & & \\
\hline \multirow{4}{*}{$\begin{array}{l}\text { Consistência } \\
\text { das fezes }\end{array}$} & Normal & 19 & 59,37 & 19 & 59,28 & 20 & 62,5 & \multirow{4}{*}{0,4378} & \multirow{4}{*}{$\begin{array}{l}0,9793 \\
\text { (N.S.) }\end{array}$} \\
\hline & Ressecada & 7 & 21,88 & 8 & 25 & 6 & 18,75 & & \\
\hline & Pastosa & 6 & 18,75 & 5 & 15,62 & 6 & 18,75 & & \\
\hline & Total geral & 32 & 100 & 32 & 100 & 32 & 100 & & \\
\hline
\end{tabular}


De acordo com os valores demonstrados nas Tabelas 5.3a, somente foram encontradas diferenças significantes com relação à consistência da dieta e a habilidade mastigatória. Portanto, quando comparados os dados coletados inicialmente com os dados obtidos após o segundo controle, pode-se observar que aumentou significativamente o número de pacientes que conseguiam mastigar aquilo que pretendiam comer. Aumentou também a quantidade de pacientes que passaram a se alimentar com uma dieta de consistência geral.

Nos valores demonstrados na Tabela 5.3b, que avaliou o perfil protético, foram encontradas diferenças significantes referentes aos 3 (três) aspectos avaliados. Foi observado um aumento significativo no número de pacientes portadores de próteses em condições funcionais satisfatórias.

Já com relação aos valores encontrados na Tabela 5.3c, que foram analisados os dados referentes ao hábito intestinal antes e após a instalação da PTC nova, não foram encontradas diferenças significantes nem com relação à freqüência de evacuações e nem quanto à consistência das fezes, em nenhuma das avaliações realizadas, ou seja, após a instalação da PTC nova esses dois itens não sofreram modificações.

b) Relacionamento dos dados obtidos na primeira subdivisão, com o uso da PTC antiga e da PTC nova 
$\mathrm{Na}$ Tabela 5.4 está demonstrada a freqüência de pacientes, de acordo com o sexo, quanto aos resultados referentes à inserção de novos alimentos obtidos no segundo controle, portanto, 6 meses após a instalação da PTC nova.

Tabela 5.4 - Distribuição de freqüências de pacientes de acordo com o sexo, quanto aos resultados referentes à inserção de novos alimentos obtidos no segundo controle após a instalação da PTC nova

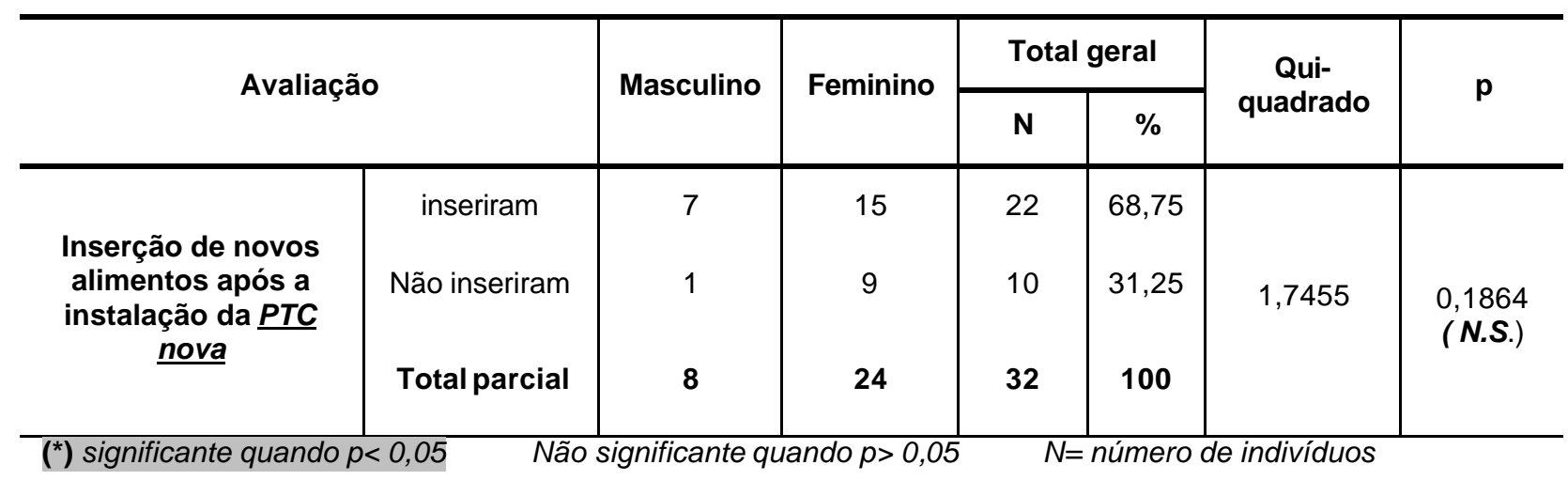

De acordo com os valores apresentados na Tabela 5.4, não foi encontrada uma correlação positiva significante entre a inserção de novos alimentos e o sexo da amostra considerada.

Nas Tabelas 5.5 e 5.6 estão demonstradas as freqüências de pacientes, quanto aos resultados obtidos após o relacionamento dos dados iniciais obtidos através do IMC com: o tipo de prótese usada antes da reabilitação protética, habilidade mastigatória e consistência da dieta com a PTC antiga e PTC nova respectivamente. 
Tabela 5.5 - Distribuição de freqüências de pacientes quanto aos resultados após o relacionamento dos dados iniciais obtidos através do IMC com: o tipo de prótese usada antes da reabilitação protética, habilidade mastigatória e consistência da dieta com a PTC antiga

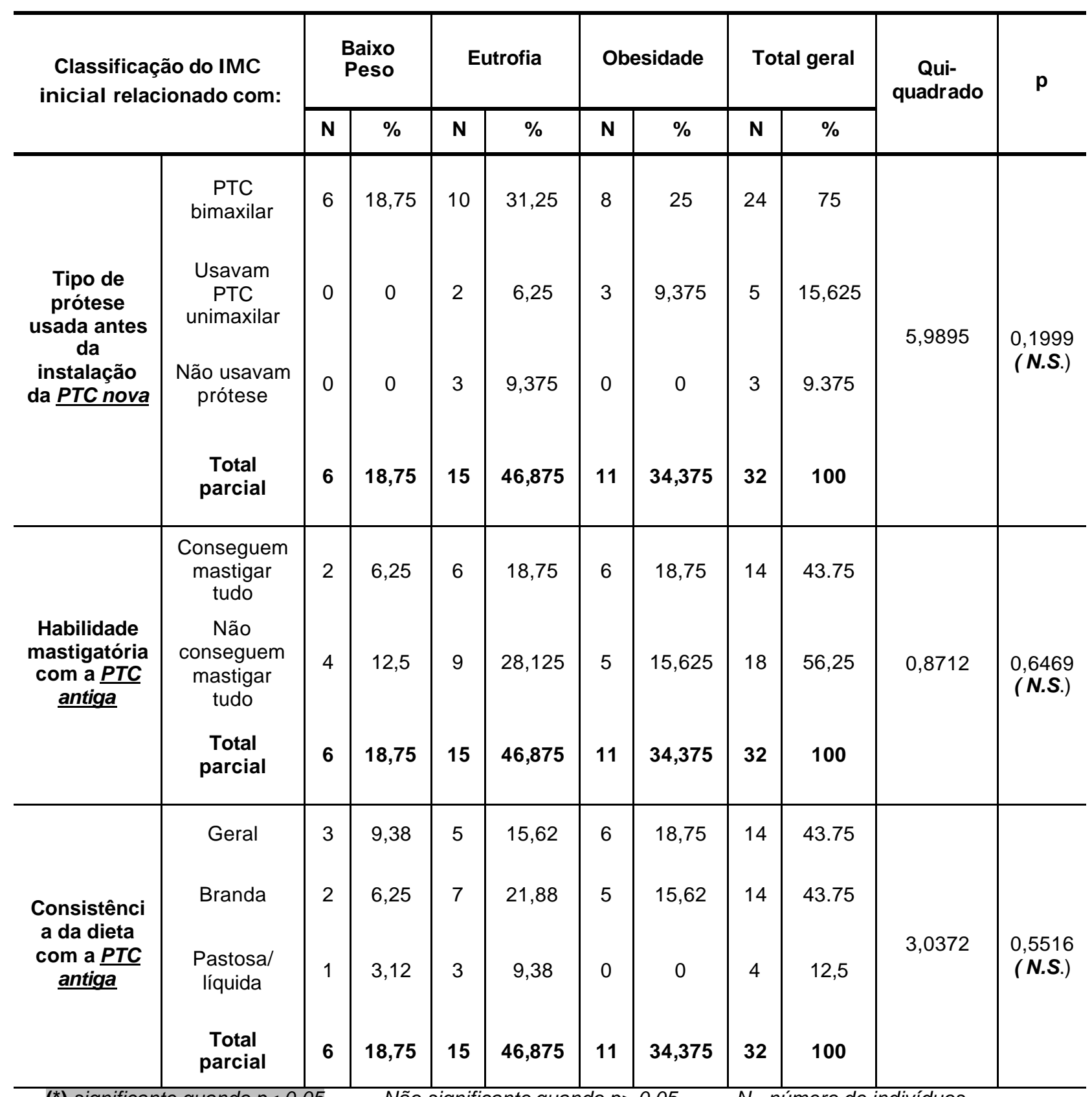

$\left(^{*}\right)$ significante quando $p<0,05 \quad$ Não significante quando $p>0,05 \quad N=$ número de indivíduos


Tabela 5.6 - Distribuição de freqüências de pacientes relacionando os resultados obtidos do IMC após a reabilitação protética com: habilidade mastigatória e consistência da dieta e a inserção de novos alimentos na dieta

\begin{tabular}{|c|c|c|c|c|c|c|c|c|c|c|c|}
\hline \multirow{2}{*}{\multicolumn{2}{|c|}{$\begin{array}{l}\text { Classificação do IMC do } 2^{a} \\
\text { controle relacionado com: }\end{array}$}} & \multicolumn{2}{|c|}{$\begin{array}{l}\text { Baixo } \\
\text { Peso }\end{array}$} & \multirow{2}{*}{\multicolumn{2}{|c|}{ Eutrofia }} & \multirow{2}{*}{\multicolumn{2}{|c|}{ Obesidade }} & \multirow{2}{*}{\multicolumn{2}{|c|}{ Total geral }} & $\begin{array}{c}\text { Qui- } \\
\text { quadrado }\end{array}$ & $p$ \\
\hline & & & & & & & & & & & \\
\hline \multirow{3}{*}{$\begin{array}{c}\text { Habilidade } \\
\text { mastigatória } \\
\text { com a PTC } \\
\underline{\text { nova }}\end{array}$} & $\begin{array}{l}\text { Conseguem } \\
\text { mastigar tudo }\end{array}$ & 5 & 15,62 & 11 & 34,38 & 10 & 31,25 & 26 & 81,25 & & \\
\hline & $\begin{array}{l}\text { Não } \\
\text { conseguem } \\
\text { mastigar tudo }\end{array}$ & 2 & 6,25 & 3 & 9,38 & 1 & 3,12 & 6 & 18,75 & 1,1828 & $\begin{array}{l}0,5535 \\
\text { (N.S.) }\end{array}$ \\
\hline & Total parcial & 7 & 21,87 & 14 & 43,76 & 11 & 34,37 & 32 & 100 & & \\
\hline \multirow{4}{*}{$\begin{array}{l}\text { Consistência } \\
\text { da dieta com } \\
\text { a PTC nova }\end{array}$} & Geral & 6 & 18,75 & 9 & 28,125 & 11 & 34,38 & 26 & 81,25 & \multirow{4}{*}{5,5033} & \multirow{4}{*}{$\begin{array}{c}0,2394 \\
\text { (N.S.) }\end{array}$} \\
\hline & Branda & 1 & 3,12 & 4 & 12,5 & 0 & 0 & 5 & 15,625 & & \\
\hline & $\begin{array}{l}\text { Pastosa/ } \\
\text { líquida }\end{array}$ & 0 & 0 & 1 & 3,125 & 0 & 0 & 1 & 3,125 & & \\
\hline & Total parcial & 7 & 21,87 & 14 & 43,75 & 11 & 34,38 & 32 & 100 & & \\
\hline \multirow{3}{*}{$\begin{array}{l}\text { Inserção de } \\
\text { novos } \\
\text { alimentos na } \\
\text { dieta }\end{array}$} & Inseriram & 5 & 15,62 & 10 & 31,25 & 7 & 21,88 & 22 & 68,75 & \multirow{3}{*}{0,2040} & \multirow{3}{*}{$\begin{array}{r}0,9030 \\
\text { (N.S.) }\end{array}$} \\
\hline & $\begin{array}{c}\text { Não } \\
\text { inseriram }\end{array}$ & 2 & 6,25 & 4 & 12,5 & 4 & 12,5 & 10 & 31,25 & & \\
\hline & Total parcial & 7 & 21,87 & 14 & 43,75 & 11 & 34,38 & 32 & 100 & & \\
\hline
\end{tabular}

Tanto na Tabela 5.5, onde foram apresentados os dados referentes ao IMC inicial comparando com o tipo de prótese usada, habilidade mastigatória e consistência da dieta com a PTC antiga, quanto na Tabela 5.6, que relacionava o IMC obtido no segundo controle com a inserção de novos alimentos, habilidade mastigatória e consistência da dieta com a PTC nova não foram encontradas diferenças significantes. Este fato sugere que mesmo ocorrendo uma melhora significativa na habilidade mastigatória e uma alteração positiva na consistência da dieta (Tabela 5.3a) a instalação da PTC nova não influenciou de maneira significante que propiciasse uma mudança do IMC da amostra estudada. 
Nas Tabelas 5.7 e 5.8 estão demonstradas respectivamente as freqüências de pacientes, quanto aos resultados obtidos após o relacionamento dos dados referentes a consistência da dieta, tipo de prótese usada antes da reabilitação protética, habilidade mastigatória em relação às PTCs (antiga e nova) e inserção de novos alimentos na dieta.

Tabela 5.7 - Distribuição de freqüências de pacientes em relação à consistência da dieta: considerando o tipo de prótese usada antes da reabilitação protética e a habilidade mastigatória com a PTC antiga

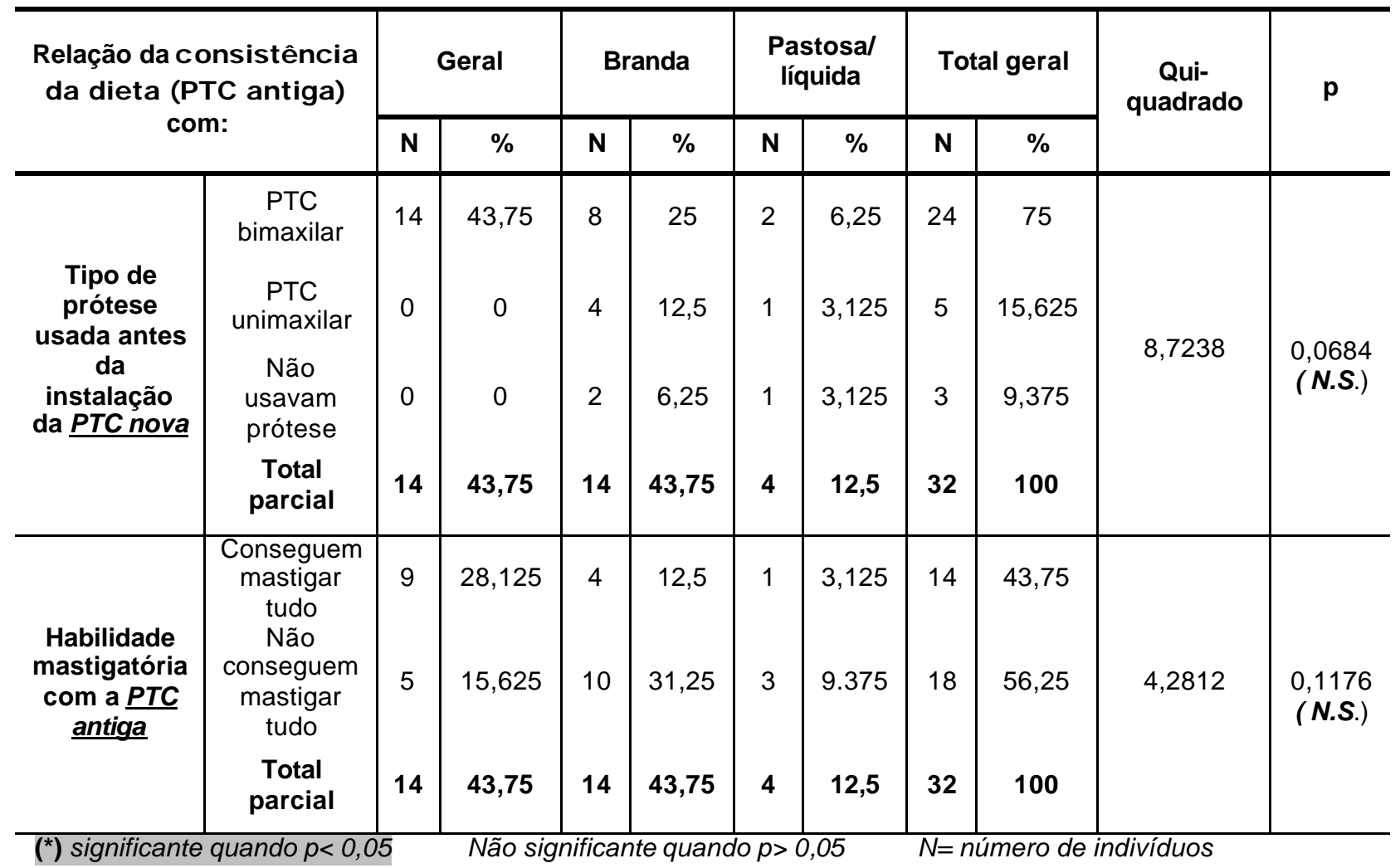


Tabela 5.8 - Distribuição de freqüências de pacientes quanto aos resultados obtidos após relacionar consistência da dieta com habilidade mastigatória e inserção de novos alimentos, com a PTC nova

\begin{tabular}{|c|c|c|c|c|c|c|c|c|c|c|c|}
\hline \multirow{2}{*}{\multicolumn{2}{|c|}{$\begin{array}{l}\text { Relação da c onsistência } \\
\text { da dieta (PTC nova) com: }\end{array}$}} & \multicolumn{2}{|c|}{ Geral } & \multicolumn{2}{|c|}{ Branda } & \multicolumn{2}{|c|}{$\begin{array}{l}\text { Pastosa/ } \\
\text { líquida }\end{array}$} & \multicolumn{2}{|c|}{ Total geral } & \multirow{2}{*}{$\begin{array}{c}\text { Qui- } \\
\text { quadrado }\end{array}$} & \multirow{2}{*}{$\mathbf{p}$} \\
\hline & & $\mathbf{N}$ & $\%$ & $\mathbf{N}$ & $\%$ & $\mathbf{N}$ & $\%$ & $\mathbf{N}$ & $\%$ & & \\
\hline $\begin{array}{c}\text { Habilidade } \\
\text { mastigatória } \\
\text { com a } P T C \\
\underline{\text { nova }}\end{array}$ & $\begin{array}{c}\text { Conseguem } \\
\text { mastigar tudo } \\
\text { Não } \\
\text { conseguem } \\
\text { mastigar tudo } \\
\text { Total parcial }\end{array}$ & $\begin{array}{l}21 \\
5 \\
26\end{array}$ & $\begin{array}{l}65,625 \\
15,625 \\
81,25\end{array}$ & 5 & $\begin{array}{r}3,125 \\
15,625\end{array}$ & 1 & $\begin{array}{c}3,125 \\
0 \\
3,125\end{array}$ & 26 & $\begin{array}{r}81,25 \\
18,75 \\
100\end{array}$ & 0,2398 & $\begin{array}{l}0,8870 \\
\text { (N.S.) }\end{array}$ \\
\hline $\begin{array}{c}\text { Inserção de } \\
\text { novos } \\
\text { alimentos na } \\
\text { dieta com a } \\
\text { PTC nova }\end{array}$ & $\begin{array}{c}\text { Inseriram } \\
\text { Não } \\
\text { inseriram } \\
\text { Total parcial }\end{array}$ & 26 & $\begin{array}{l}28,125 \\
81,25\end{array}$ & 4 & $\begin{array}{r}3,125 \\
15,625\end{array}$ & 1 & $\begin{array}{c}3,125 \\
0 \\
3,125\end{array}$ & 10 & $\begin{array}{r}31,25 \\
100\end{array}$ & 0,8862 & $\begin{array}{l}0,6421 \\
\text { (N.S.) }\end{array}$ \\
\hline
\end{tabular}

De acordo com os valores apresentados na Tabela 5.7 e 5.8, não foram encontradas correlações positivas significantes entre a consistência da dieta e o tipo de prótese usada antes da reabilitação protética, a habilidade mastigatória com as PTCs (antiga e nova) e a inserção de novos alimentos.

Nas Tabelas 5.9 e 5.10 estão demonstradas respectivamente as freqüências de pacientes, quanto aos resultados obtidos após o relacionamento dos dados referentes à habilidade mastigatória e: tipo de prótese usada antes da reabilitação protética, inserção de novos alimentos, no caso da PTC nova, além da dimensão vertical, oclusão, retenção e estabilidade em ambas as PTCs . 
Tabela 5.9 - Distribuição de freqüências de pacientes quanto aos resultados obtidos após o relacionamento dos dados referentes a habilidade mastigatória com: o tipo de prótese usada antes da reabilitação protética, dimensão vertical,oclusão, retenção e estabilidade, com PTC antiga

\begin{tabular}{|c|c|c|c|c|c|c|c|c|c|}
\hline \multirow{2}{*}{\multicolumn{2}{|c|}{$\begin{array}{c}\text { Relação da habilidade } \\
\text { mastigatória ( PTC antiga) } \\
\text { com: }\end{array}$}} & \multicolumn{2}{|c|}{$\begin{array}{l}\text { Conseguem } \\
\text { mastigar tudo }\end{array}$} & \multicolumn{2}{|c|}{$\begin{array}{l}\text { Não conseguem } \\
\text { mastigar tudo }\end{array}$} & \multicolumn{2}{|c|}{ Total geral } & \multirow[t]{2}{*}{$\begin{array}{c}\text { Qui- } \\
\text { quadrado }\end{array}$} & \multirow[t]{2}{*}{ p } \\
\hline & & $\mathbf{N}$ & $\%$ & $\mathbf{N}$ & $\%$ & $\overline{\mathbf{N}}$ & $\%$ & & \\
\hline \multirow{4}{*}{$\begin{array}{l}\text { Tipo de prótese } \\
\text { usada antes da } \\
\text { instalação da } \\
\text { PTC nova }\end{array}$} & PTC bimaxilar & 11 & 34,38 & 13 & 40,62 & 24 & 75 & \multirow{4}{*}{0,2032} & \multirow{4}{*}{$\begin{array}{r}0,9034 \\
\text { (N.S.) }\end{array}$} \\
\hline & PTC unimaxilar & 2 & 6,25 & 3 & 9,38 & 5 & 15,63 & & \\
\hline & $\begin{array}{l}\text { Não usavam } \\
\text { prótese }\end{array}$ & 1 & 3,12 & 2 & 6,25 & 3 & 9,37 & & \\
\hline & Total parcial & 14 & 43,75 & 18 & 56,25 & 32 & 100 & & \\
\hline \multirow{4}{*}{$\begin{array}{c}\text { Dimensão } \\
\text { Vertical da } \underline{P T C} \\
\underline{\text { antiga }}\end{array}$} & Satisfatória & 3 & 9,375 & 1 & 3,125 & 4 & 12,5 & \multirow{4}{*}{1,8286} & \multirow{4}{*}{$\begin{array}{r}0,4008 \\
\text { (N.S.) }\end{array}$} \\
\hline & Insatisfatória & 8 & 25 & 12 & 37,5 & 20 & 62,5 & & \\
\hline & Inexistente & 3 & 9,375 & 5 & 15,625 & 8 & 25 & & \\
\hline & Total parcial & 14 & 43,75 & 18 & 56,25 & 32 & 100 & & \\
\hline \multirow{4}{*}{$\begin{array}{c}\text { Oclusão da } \\
\underline{\text { antiga }}\end{array}$} & Satisfatória & 7 & 21,875 & 5 & 15,625 & 12 & 37,5 & \multirow{4}{*}{1,6931} & \multirow{4}{*}{$\begin{array}{r}0,4289 \\
\text { (N.S.) }\end{array}$} \\
\hline & Insatisfatória & 4 & 12,5 & 8 & 25 & 12 & 37,5 & & \\
\hline & Inexistente & 3 & 9,375 & 5 & 15,625 & 8 & 25 & & \\
\hline & Total parcial & 14 & 43,75 & 18 & 56,25 & 32 & 100 & & \\
\hline \multirow{4}{*}{$\begin{array}{c}\text { Retenção e } \\
\text { estabilidade da } \\
\text { PTC antiga }\end{array}$} & Satisfatória & 3 & 9,375 & 2 & 6,25 & 5 & 15,625 & \multirow{4}{*}{0,6844} & \multirow{4}{*}{$\begin{array}{l}0,7102 \\
\text { (N.S.) }\end{array}$} \\
\hline & Insatisfatória & 8 & 25 & 11 & 34,375 & 19 & 59,375 & & \\
\hline & Inexistente & 3 & 9,375 & 5 & 15,625 & 8 & 25 & & \\
\hline & Total parcial & 14 & 43,75 & 18 & 56,25 & 32 & 100 & & \\
\hline
\end{tabular}

Tabela 5.10 - Distribuição de freqüências de pacientes quanto aos resultados obtidos após o relacionamento dos dados referentes à habilidade mastigatória com a inserção de novos alimentos na dieta, dimensão vertical, oclusão, retenção e estabilidade, com PTC nova

\begin{tabular}{|c|c|c|c|c|c|c|c|c|c|}
\hline \multirow{2}{*}{\multicolumn{2}{|c|}{$\begin{array}{c}\text { Relação da habilidade } \\
\text { mastigatória ( PTC nova) } \\
\text { com: }\end{array}$}} & \multicolumn{2}{|c|}{$\begin{array}{c}\text { Conseguem } \\
\text { mastigar tudo }\end{array}$} & \multicolumn{2}{|c|}{$\begin{array}{l}\text { Não conseguem } \\
\text { mastigar tudo }\end{array}$} & \multicolumn{2}{|c|}{ Total geral } & \multirow{2}{*}{$\begin{array}{c}\text { Qui- } \\
\text { quadrado }\end{array}$} & \multirow[t]{2}{*}{$\mathbf{p}$} \\
\hline & & $\overline{\mathbf{N}}$ & $\%$ & $\overline{\mathbf{N}}$ & $\%$ & $\overline{\mathbf{N}}$ & $\%$ & & \\
\hline $\begin{array}{c}\text { Inserção de } \\
\text { novos } \\
\text { alimentos na } \\
\text { dieta com a } \underline{P T C} \\
\text { nova } \\
\end{array}$ & $\begin{array}{c}\text { Inseriram } \\
\text { Não inseriram } \\
\text { Total parcial }\end{array}$ & $\begin{array}{c}20 \\
6 \\
26\end{array}$ & $\begin{array}{c}62,5 \\
18,75 \\
81,25\end{array}$ & $\begin{array}{l}2 \\
4 \\
6\end{array}$ & $\begin{array}{r}6,25 \\
12,5 \\
18,75\end{array}$ & $\begin{array}{l}22 \\
10 \\
32\end{array}$ & $\begin{array}{c}68,75 \\
31,25 \\
100\end{array}$ & 4,3114 & $\underset{*}{0,0379}$ \\
\hline $\begin{array}{c}\text { Dimensão } \\
\text { Vertical da } \underline{P T C} \\
\underline{\text { nova }}\end{array}$ & $\begin{array}{c}\text { Satisfatória } \\
\text { Insatisfatória } \\
\text { Total parcial }\end{array}$ & $\begin{array}{c}25 \\
1 \\
26\end{array}$ & $\begin{array}{l}78,125 \\
3,125 \\
81,25\end{array}$ & $\begin{array}{l}6 \\
0 \\
6\end{array}$ & $\begin{array}{c}18,75 \\
0 \\
18,75\end{array}$ & $\begin{array}{c}31 \\
1 \\
32\end{array}$ & $\begin{array}{c}96,875 \\
3,125 \\
100\end{array}$ & 0,2382 & $\begin{array}{l}0,6255 \\
\text { (N.S.) }\end{array}$ \\
\hline $\begin{array}{c}\text { Oclusão da } \underline{P T C} \\
\text { nova }\end{array}$ & $\begin{array}{l}\text { Satisfatória } \\
\text { Insatisfatória } \\
\text { Total parcial }\end{array}$ & $\begin{array}{c}25 \\
1 \\
26\end{array}$ & $\begin{array}{l}78,125 \\
3,125 \\
81,25\end{array}$ & $\begin{array}{l}4 \\
2 \\
6\end{array}$ & $\begin{array}{r}12,5 \\
6,25 \\
18,75\end{array}$ & $\begin{array}{c}29 \\
3 \\
32\end{array}$ & $\begin{array}{c}90,625 \\
9,375 \\
100\end{array}$ & 4,9891 & $\underset{*}{0,0255}$ \\
\hline $\begin{array}{c}\text { Retenção e } \\
\text { estabilidade da } \\
\text { PTC nova }\end{array}$ & $\begin{array}{c}\text { Satisfatória } \\
\text { Insatisfatória } \\
\text { Total parcial }\end{array}$ & $\begin{array}{c}25 \\
1 \\
26\end{array}$ & $\begin{array}{l}78,125 \\
3,125 \\
81,25\end{array}$ & $\begin{array}{l}6 \\
0 \\
6\end{array}$ & $\begin{array}{c}18,75 \\
0 \\
18,75\end{array}$ & $\begin{array}{c}31 \\
1 \\
32\end{array}$ & $\begin{array}{c}96,875 \\
3,125 \\
100\end{array}$ & 0,2382 & $\begin{array}{l}0,6255 \\
\text { (N.S.) }\end{array}$ \\
\hline
\end{tabular}

${ }^{*}$ ) significante quando $p<0,05 \quad$ Não significante quando $p>0,05 \quad N=$ número de indivíduos 
De acordo com os valores demonstrados na Tabela 5.9, que relaciona habilidade mastigatória com a PTC antiga com: tipo de prótese usada antes da reabilitação protética, dimensão vertical, oclusão, retenção e estabilidade não foram encontradas diferenças significativas. No entanto, com relação à comparação dos mesmos dados, exceto tipo de prótese usada, com a habilidade mastigatória com a PTC nova (Tabela 5.10), observou-se uma significância positiva nos dados estatísticos com relação à inserção de novos alimentos e oclusão.Portanto, é possível observar que quando os pacientes apresentam uma oclusão funcionalmente satisfatória, conseguem mastigar tudo o que pretendem, podendo inserir novos alimentos na sua dieta.

$\mathrm{Na}$ Tabela 5.11 e 5.12 estão demonstradas respectivamente as freqüências de pacientes, quanto aos resultados obtidos após o relacionamento dos dados referentes ao hábito intestinal e o: tipo de prótese usada antes da reabilitação protética, habilidade mastigatória, consistência da dieta, ingestão de líquidos, dimensão vertical, oclusão, retenção e estabilidade em ambas as PTCs. A Tabela 5.12 procurou relacionar ainda o hábito intestinal e a inserção de novos alimentos com a nova condição protética. 
Tabela 5.11 - Distribuição de freqüências de pacientes quanto aos resultados obtidos após o relacionamento dos dados referentes ao hábito intestinal com o tipo de prótese usada antes da reabilitação protética, habilidade mastigatória, consistência da dieta, ingestão de líquidos, dimensão vertical, oclusão, retenção e estabilidade, com a PTC antiga

\begin{tabular}{|c|c|c|c|c|c|c|c|c|c|c|c|}
\hline \multirow{2}{*}{\multicolumn{2}{|c|}{$\begin{array}{c}\text { Relação do hábito } \\
\text { intestinal (PTC antiga) } \\
\text { com: }\end{array}$}} & \multirow{2}{*}{\multicolumn{2}{|c|}{$\begin{array}{l}\text { Evacuações } \\
\text { diárias e em } \\
\text { dias } \\
\text { alternados }\end{array}$}} & \multirow{2}{*}{\multicolumn{2}{|c|}{$\begin{array}{l}\text { Evacuações } \\
\text { a cada } 2 \\
\text { dias }\end{array}$}} & \multirow{2}{*}{\multicolumn{2}{|c|}{$\begin{array}{l}\text { Evacuações } \\
\text { após } 3 \text { dias } \\
\text { ou mais }\end{array}$}} & \multirow{2}{*}{\multicolumn{2}{|c|}{ Total geral }} & \multirow[t]{2}{*}{$\begin{array}{c}\text { Qui- } \\
\text { quadrado }\end{array}$} & \multirow[t]{2}{*}{$\mathbf{p}$} \\
\hline & & & & & & & & & & & \\
\hline \multirow{5}{*}{$\begin{array}{c}\text { Tipo de } \\
\text { prótese } \\
\text { usada } \\
\text { antes da } \\
\text { instalação } \\
\text { da } \underline{P T C} \\
\underline{\text { nova }} \\
\end{array}$} & PTC himavilar & 17 & 53125 & 3 & 9375 & 1 & 3125 & 21 & 65625 & \multirow{5}{*}{2,4586} & \\
\hline & $\begin{array}{l}\text { PTC } \\
\text { PTC }\end{array}$ & 17 & & 3 & $y, 3 / 5$ & 1 & & 21 & $65,0<5$ & & \multirow{4}{*}{$\begin{array}{r}0,6521 \\
\text { (N.S.) }\end{array}$} \\
\hline & unimaxilar & 7 & 21,875 & 0 & 0 & 1 & 3,125 & 8 & 25 & & \\
\hline & $\begin{array}{l}\text { Não usavam } \\
\text { prótese }\end{array}$ & 3 & 9,375 & 0 & 0 & 0 & 0 & 3 & 9,375 & & \\
\hline & Total parcial & 27 & 84,375 & 3 & 9,375 & 2 & 6,25 & 32 & 100 & & \\
\hline \multirow{3}{*}{$\begin{array}{c}\text { Habilidade } \\
\text { mastigató- } \\
\text { ria com a } \\
\text { PTC antiga } \\
\end{array}$} & $\begin{array}{l}\text { Conseguem } \\
\text { mastigar tudo }\end{array}$ & 13 & 40,625 & 1 & 3,125 & 0 & 0 & 14 & 43,75 & \multirow{3}{*}{1,9001} & \multirow{3}{*}{$\begin{array}{r}0,3867 \\
\text { (N.S.) }\end{array}$} \\
\hline & $\begin{array}{c}\text { Não } \\
\text { conseguem } \\
\text { mastigar tudo }\end{array}$ & 14 & 43,75 & 2 & 6,25 & 2 & 6,25 & 18 & 56,25 & & \\
\hline & Total parcial & 27 & 84,375 & 3 & 9,375 & 2 & 6,25 & 32 & 100 & & \\
\hline \multirow{4}{*}{$\begin{array}{l}\text { Consistên- } \\
\text { cia da dieta } \\
\text { com a } P T C \\
\text { antiga }\end{array}$} & Geral & 12 & 37,5 & 2 & 6,25 & 0 & 0 & 14 & 43,75 & \multirow{4}{*}{4,0000} & \multirow{4}{*}{$\begin{array}{r}0,4060 \\
\text { (N.S.) }\end{array}$} \\
\hline & Branda & 12 & 37,5 & 1 & 3,125 & 1 & 3,125 & 14 & 43,75 & & \\
\hline & $\begin{array}{l}\text { Pastosa/ } \\
\text { líquida }\end{array}$ & 3 & 9,375 & 0 & 0 & 1 & 3,125 & 4 & 12,5 & & \\
\hline & Total parcial & 27 & 84,375 & 3 & 9,375 & 2 & 6,25 & 32 & 100 & & \\
\hline \multirow{4}{*}{$\begin{array}{c}\text { Ingestão } \\
\text { de líquidos } \\
\text { com a } \underline{P T C} \\
\underline{\text { antiga }}\end{array}$} & $\begin{array}{c}3 \text { copos ou } \\
\text { menos }\end{array}$ & 4 & 12,5 & 1 & 3,125 & 2 & 6,25 & 7 & 21,875 & \multirow{4}{*}{8,4432} & \multirow{4}{*}{$\begin{array}{r}0,0766 \\
\text { ( N.S.) }\end{array}$} \\
\hline & 4 a 6 copos & 16 & 50 & 1 & 3,125 & 0 & 0 & 17 & 53,125 & & \\
\hline & $\begin{array}{l}7 \text { copos ou } \\
\text { mais }\end{array}$ & 7 & 21,875 & 1 & 3,125 & 0 & 0 & 8 & 25 & & \\
\hline & Total parcial & 27 & 84,375 & 3 & 9,375 & 2 & 6,25 & 32 & 100 & & \\
\hline \multirow{4}{*}{$\begin{array}{l}\text { Dimensão } \\
\text { Vertical da } \\
\text { PTC antiga } \\
\end{array}$} & Satisfatória & 4 & 12,5 & 0 & 0 & 0 & 0 & 4 & 12,5 & \multirow{4}{*}{3,5556} & \multirow{4}{*}{$\begin{array}{r}0,4695 \\
\text { (N.S.) }\end{array}$} \\
\hline & Insatisfatória & 15 & 46,875 & 3 & 9,375 & 2 & 6,25 & 20 & 62,5 & & \\
\hline & Inexistente & 8 & 25 & 0 & 0 & 0 & 0 & 8 & 25 & & \\
\hline & Total parcial & 27 & 84,375 & 3 & 9,375 & 2 & 6,25 & 32 & 100 & & \\
\hline \multirow{4}{*}{$\begin{array}{l}\text { Oclusão da } \\
\text { PTC antiga }\end{array}$} & Satisfatória & 10 & 31,25 & 1 & 3,125 & 1 & 3,125 & 12 & 37,5 & \multirow{4}{*}{2,4691} & \multirow{4}{*}{$\begin{array}{r}0,6502 \\
\text { (N.S.) }\end{array}$} \\
\hline & Insatisfatória & 9 & 28,125 & 2 & 6,25 & 1 & 3,125 & 12 & 37,5 & & \\
\hline & Inexistente & 8 & 25 & 0 & 0 & 0 & 0 & 8 & 25 & & \\
\hline & Total parcial & 27 & 84,375 & 3 & 9,375 & 2 & 6,25 & 32 & 100 & & \\
\hline \multirow{4}{*}{$\begin{array}{c}\text { Retenção e } \\
\text { estabilidad } \\
\text { e da } P T C \\
\text { antiga }\end{array}$} & Satisfatória & 3 & 9,375 & 1 & 3,125 & 1 & 3,125 & 5 & 15,625 & \multirow{4}{*}{4,9988} & \multirow{4}{*}{$\begin{array}{r}0,2874 \\
\text { (N.S.) }\end{array}$} \\
\hline & Insatisfatória & 17 & 53,125 & 2 & 6,25 & 0 & 0 & 19 & 59,375 & & \\
\hline & Inexistente & 7 & 21,875 & 0 & 0 & 1 & 3,125 & 8 & 25 & & \\
\hline & Total parcial & 27 & 84,375 & 3 & 9,375 & 2 & 6,25 & 32 & 100 & & \\
\hline
\end{tabular}


Tabela 5.12 - Distribuição de freqüências de pacientes quanto aos resultados obtidos após o relacionamento dos dados referentes ao hábito intestinal com a habilidade mastigatória, consistência da dieta, inserção de novos alimentos, ingestão de líquidos, dimensão vertical, oclusão, retenção e estabilidade, com a PTC nova

\begin{tabular}{|c|c|c|c|c|c|c|c|c|c|c|c|}
\hline \multirow{2}{*}{\multicolumn{2}{|c|}{$\begin{array}{c}\text { Relação do hábito } \\
\text { intestinal (PTC nova) com: }\end{array}$}} & \multicolumn{2}{|c|}{$\begin{array}{c}\text { Evacuações } \\
\text { diárias e em } \\
\text { dias } \\
\text { alternados }\end{array}$} & \multicolumn{2}{|c|}{$\begin{array}{c}\text { Evacuações } \\
\text { a cada } 2 \\
\text { dias }\end{array}$} & \multicolumn{2}{|c|}{$\begin{array}{l}\text { Evacuações } \\
\text { após } 3 \text { dias } \\
\text { ou mais }\end{array}$} & \multicolumn{2}{|c|}{ Total geral } & \multirow[t]{2}{*}{$\begin{array}{l}\text { Qui- } \\
\text { quadrado }\end{array}$} & \multirow[t]{2}{*}{$\mathbf{p}$} \\
\hline & & $\mathbf{N}$ & $\%$ & $\mathbf{N}$ & $\%$ & $\mathbf{N}$ & $\%$ & $\mathbf{N}$ & $\%$ & & \\
\hline $\begin{array}{c}\text { Habilidade } \\
\text { mastigatória } \\
\text { com a } P T C \\
\underline{\text { nova }}\end{array}$ & $\begin{array}{c}\text { Conseguem } \\
\text { mastigar tudo } \\
\text { Não } \\
\text { conseguem } \\
\text { mastigar tudo } \\
\text { Total parcial }\end{array}$ & $\begin{array}{l}21 \\
5 \\
26\end{array}$ & $\begin{array}{l}15,625 \\
81,25\end{array}$ & 2 & $\begin{array}{c}0 \\
6,25\end{array}$ & 1 & $\begin{array}{r}3,125 \\
12,5\end{array}$ & $\begin{array}{c}6 \\
32\end{array}$ & $\begin{array}{r}18,75 \\
100\end{array}$ & 0,5680 & $\begin{array}{l}0,7527 \\
\text { (N.S.) }\end{array}$ \\
\hline $\begin{array}{c}\text { Consistên- } \\
\text { cia da dieta } \\
\text { com a } P T C \\
\underline{\text { nova }}\end{array}$ & $\begin{array}{c}\text { Geral } \\
\text { Branda } \\
\text { Pastosa/ } \\
\text { líquida } \\
\text { Total parcial }\end{array}$ & $\begin{array}{c}21 \\
4 \\
1 \\
26\end{array}$ & $\begin{array}{c}65,625 \\
12,5 \\
3,125 \\
81,25\end{array}$ & $\begin{array}{l}2 \\
0 \\
0 \\
2\end{array}$ & $\begin{array}{c}6,25 \\
0 \\
0 \\
6,25\end{array}$ & $\begin{array}{l}3 \\
1\end{array}$ & $\begin{array}{c}9,375 \\
3,125 \\
0 \\
12,5\end{array}$ & $\begin{array}{c}26 \\
5 \\
1 \\
32\end{array}$ & $\begin{array}{c}81,25 \\
15,625 \\
3,125 \\
100\end{array}$ & 0,8757 & $\begin{array}{l}0,9280 \\
\text { (N.S.) }\end{array}$ \\
\hline $\begin{array}{l}\text { Inserção de } \\
\text { novos } \\
\text { alimentos na } \\
\text { dieta }\end{array}$ & $\begin{array}{c}\text { Inseriram } \\
\text { Não inseriram } \\
\text { Total parcial }\end{array}$ & $\begin{array}{c}7 \\
19 \\
26\end{array}$ & $\begin{array}{l}21,88 \\
59,38 \\
81,25\end{array}$ & $\begin{array}{l}1 \\
1 \\
2\end{array}$ & $\begin{array}{l}3,12 \\
3,12 \\
6,25\end{array}$ & $\begin{array}{l}3 \\
1 \\
4\end{array}$ & $\begin{array}{l}9,38 \\
3,12 \\
12,5\end{array}$ & $\begin{array}{l}11 \\
21 \\
32\end{array}$ & $\begin{array}{c}34,38 \\
65,62 \\
100\end{array}$ & 3,7829 & $\begin{array}{c}0,1509 \\
\text { (N.S.) }\end{array}$ \\
\hline $\begin{array}{c}\text { Ingestão de } \\
\text { líquidos } \\
\text { com a } P T C \\
\underline{\text { nova }}\end{array}$ & $\begin{array}{c}3 \text { copos ou } \\
\text { menos } \\
4 \text { a } 6 \text { copos } \\
7 \text { copos ou } \\
\text { mais } \\
\text { Total parcial }\end{array}$ & $\begin{array}{c}9 \\
13 \\
4 \\
26\end{array}$ & $\begin{array}{c}28,125 \\
40,625 \\
12,5 \\
81,25\end{array}$ & $\begin{array}{l}0 \\
2 \\
0 \\
2\end{array}$ & $\begin{array}{c}0 \\
6,25 \\
0 \\
6,25\end{array}$ & 1 & $\begin{array}{c}3,125 \\
6,25 \\
3,125 \\
12,5\end{array}$ & $\begin{array}{c}10 \\
17 \\
5 \\
32\end{array}$ & $\begin{array}{c}31,25 \\
53,125 \\
15,625 \\
100\end{array}$ & 2,1900 & $\begin{array}{l}0,7009 \\
\text { (N.S.) }\end{array}$ \\
\hline $\begin{array}{c}\text { Dimensão } \\
\text { Vertical da } \\
\text { PTC nova }\end{array}$ & $\begin{array}{c}\text { Satisfatória } \\
\text { Insatisfatória } \\
\text { Total parcial }\end{array}$ & $\begin{array}{c}25 \\
1 \\
26\end{array}$ & $\begin{array}{c}78,125 \\
3,125 \\
81,25\end{array}$ & $\begin{array}{l}2 \\
0 \\
2\end{array}$ & $\begin{array}{c}6,25 \\
0 \\
6,25\end{array}$ & $\begin{array}{l}4 \\
0 \\
4\end{array}$ & $\begin{array}{c}12,5 \\
0 \\
12,5\end{array}$ & $\begin{array}{c}31 \\
1 \\
32\end{array}$ & $\begin{array}{c}96,875 \\
3,125 \\
100\end{array}$ & 0,2382 & $\begin{array}{r}0,8877 \\
\text { (N.S.) }\end{array}$ \\
\hline $\begin{array}{l}\text { Oclusão da } \\
\text { PTC nova }\end{array}$ & $\begin{array}{l}\text { Satisfatória } \\
\text { Insatis fatória } \\
\text { Total parcial }\end{array}$ & $\begin{array}{c}23 \\
3 \\
26\end{array}$ & $\begin{array}{c}71,875 \\
9,375 \\
81,25\end{array}$ & $\begin{array}{l}2 \\
0 \\
2\end{array}$ & $\begin{array}{c}6,25 \\
0 \\
6,25\end{array}$ & 4 & $\begin{array}{c}12,5 \\
0 \\
12,5\end{array}$ & $\begin{array}{c}29 \\
3 \\
32\end{array}$ & $\begin{array}{c}90,625 \\
9,375 \\
100\end{array}$ & 0,7639 & $\begin{array}{l}0,6825 \\
\text { (N.S.) }\end{array}$ \\
\hline $\begin{array}{l}\text { Retenção e } \\
\text { estabilidade } \\
\text { da } \underline{P T C \text { nova }}\end{array}$ & $\begin{array}{l}\text { Satisfatória } \\
\text { Insatisfatória } \\
\text { Total parcial }\end{array}$ & $\begin{array}{c}26 \\
0\end{array}$ & $\begin{array}{c}81,25 \\
0 \\
81,25\end{array}$ & $\begin{array}{l}1 \\
1\end{array}$ & $\begin{array}{l}3,125 \\
3,125\end{array}$ & 0 & $\begin{array}{c}12,5 \\
0\end{array}$ & $\begin{array}{c}31 \\
1\end{array}$ & $\begin{array}{c}96,875 \\
3,125 \\
100\end{array}$ & 15,4839 & $\underset{*}{0,004}$ \\
\hline
\end{tabular}

$\left(^{*}\right)$ significante quando $p<0,05$

Não significante quando $p>0,05$

$N=$ número de indivíduos

Não foi observado significado estatístico em nenhum dos itens da Tabela 5.11, evidenciando, portanto o fato de não haver relação estatisticamente significante entre o hábito intestinal com a PTC antiga e o tipo de prótese usada 
antes da reabilitação protética, habilidade mastigatória, consistência da dieta, ingestão de líquidos, dimensão vertical, oclusão, retenção e estabilidade.

Por outro lado, por meio da na Tabela 5.12 pode-se observar que com a nova PTC aumentou o número de pacientes que apresentavam retenção e estabilidade satisfatórias.Verificou-se uma correlação positiva referente ao aumento do número de pacientes que passaram a evacuar diariamente, ou em dias alternados.

Nas Tabelas 5.13 e 5.14 estão demonstradas respectivamente as freqüências de pacientes, quanto aos resultados obtidos após o relacionando dos dados referentes à consistência das fezes e: tipo de prótese usada antes da reabilitação protética, habilidade mastigatória, consistência da dieta, ingestão de líquidos, dimensão vertical, oclusão, retenção e estabilidade com a PTC antiga; e em alguns itens com a PTC nova. Na Tabela 5.14 foi removido o item referente ao tipo de prótese e acrescida a avaliação da inserção de novos alimentos na dieta. 
Tabela 5.13 - Distribuição de freqüências de pacientes quanto aos resultados obtidos após o relacionamento dos dados referentes a consistência das fezes com o tipo de prótese usada antes da reabilitação protética, habilidade mastigatória, consistência da dieta, ingestão de líquidos, dimensão vertical, oclusão, retenção e estabilidade, com a PTC antiga

\begin{tabular}{|c|c|c|c|c|c|c|c|c|c|}
\hline \multirow{2}{*}{\multicolumn{2}{|c|}{$\begin{array}{l}\text { Relação da c onsistência das } \\
\text { fezes (PTC antiga) com: }\end{array}$}} & \multicolumn{2}{|c|}{$\begin{array}{c}\text { Normal e } \\
\text { pastosa }\end{array}$} & \multicolumn{2}{|c|}{ Ressecada } & \multicolumn{2}{|c|}{ Total geral } & \multirow{2}{*}{$\begin{array}{l}\text { Qui- } \\
\text { quadrado }\end{array}$} & \multirow[t]{2}{*}{$\mathbf{p}$} \\
\hline & & $\mathbf{N}$ & $\%$ & $\mathbf{N}$ & $\%$ & $\mathbf{N}$ & $\%$ & & \\
\hline $\begin{array}{c}\text { Tipo de } \\
\text { prótese } \\
\text { usada antes } \\
\text { da instalação } \\
\text { da PTC nova }\end{array}$ & $\begin{array}{c}\text { PTC bimaxilar } \\
\text { Usavam ou PTC } \\
\text { superior ou inferior } \\
\text { Não usavam prótese } \\
\text { Total parcial }\end{array}$ & $\begin{array}{c}16 \\
6 \\
3 \\
25\end{array}$ & $\begin{array}{c}50 \\
18,75 \\
9,375 \\
78,125\end{array}$ & $\begin{array}{l}5 \\
2\end{array}$ & $\begin{array}{c}15,625 \\
6,25 \\
0 \\
21,875\end{array}$ & $\begin{array}{l}21 \\
8 \\
3 \\
32\end{array}$ & $\begin{array}{c}65,625 \\
25 \\
9,375 \\
100\end{array}$ & 2,6871 & $\begin{array}{c}0,4424 \\
\text { (N.S.) }\end{array}$ \\
\hline $\begin{array}{c}\text { Habilidade } \\
\text { mastigatória } \\
\text { com a } \underline{P T C} \\
\underline{\text { antiga }}\end{array}$ & $\begin{array}{c}\text { Conseguem mastigar } \\
\text { tudo } \\
\text { Não conseguem } \\
\text { mastigar tudo } \\
\text { Total parcial }\end{array}$ & $\begin{array}{l}12 \\
13 \\
25\end{array}$ & $\begin{array}{c}37,5 \\
40,625 \\
78,125\end{array}$ & $\begin{array}{l}5 \\
7\end{array}$ & $\begin{array}{c}6,25 \\
15,625 \\
\mathbf{2 1 , 8 7 5}\end{array}$ & $\begin{array}{l}18 \\
32\end{array}$ & $\begin{array}{r}43,75 \\
56,25 \\
100\end{array}$ & 0,8388 & $\begin{array}{l}0,3597 \\
\text { (N.S.) }\end{array}$ \\
\hline $\begin{array}{l}\text { Consistência } \\
\text { da dieta com } \\
\text { a PTC antiga }\end{array}$ & $\begin{array}{c}\text { Geral } \\
\text { Branda } \\
\text { Pastosa/líquida } \\
\text { Total parcial }\end{array}$ & $\begin{array}{c}12 \\
10 \\
3 \\
25\end{array}$ & $\begin{array}{c}37,5 \\
31,25 \\
9,375 \\
78,125\end{array}$ & $\begin{array}{l}2 \\
4 \\
1 \\
7\end{array}$ & $\begin{array}{c}6,25 \\
12,5 \\
3,125 \\
\mathbf{2 1 , 8 7 5}\end{array}$ & $\begin{array}{c}14 \\
14 \\
4 \\
32\end{array}$ & $\begin{array}{c}43,75 \\
43,45 \\
12,5 \\
100\end{array}$ & 0,8620 & $\begin{array}{l}0,6498 \\
\text { (N.S.) }\end{array}$ \\
\hline $\begin{array}{l}\text { Ingestão de } \\
\text { líquidos com } \\
\text { a PTC antiga }\end{array}$ & $\begin{array}{c}3 \text { copos ou menos } \\
4 \text { a } 6 \text { copos } \\
7 \text { copos ou mais } \\
\text { Total parcial }\end{array}$ & $\begin{array}{c}5 \\
14 \\
6 \\
25\end{array}$ & $\begin{array}{c}15,625 \\
43,75 \\
18,75 \\
78,125\end{array}$ & $\begin{array}{l}2 \\
3 \\
2 \\
7\end{array}$ & $\begin{array}{c}6,25 \\
9,375 \\
6,25 \\
\mathbf{2 1 , 8 7 5}\end{array}$ & $\begin{array}{c}7 \\
17 \\
8 \\
32\end{array}$ & $\begin{array}{c}21,875 \\
53,125 \\
25 \\
100\end{array}$ & 0,4072 & $\begin{array}{l}0,8158 \\
\text { (N.S.) }\end{array}$ \\
\hline $\begin{array}{l}\text { Dimensão } \\
\text { Vertical da } \\
\text { PTC antiga } \\
\end{array}$ & $\begin{array}{c}\text { Satisfatória } \\
\text { Insatisfatória } \\
\text { Inexistente } \\
\text { Total parcial }\end{array}$ & $\begin{array}{c}4 \\
14 \\
7 \\
25\end{array}$ & $\begin{array}{c}12,5 \\
43,75 \\
21,875 \\
78,125\end{array}$ & $\begin{array}{l}0 \\
6 \\
1 \\
7\end{array}$ & $\begin{array}{c}0 \\
18,75 \\
3,125 \\
\mathbf{2 1 , 8 7 5}\end{array}$ & $\begin{array}{c}4 \\
20 \\
8 \\
32\end{array}$ & $\begin{array}{c}12,5 \\
62,5 \\
25 \\
100\end{array}$ & 2,3040 & $\begin{array}{l}0,3160 \\
\text { (N.S.) }\end{array}$ \\
\hline $\begin{array}{l}\text { Oclusão da } \\
\text { PTC antiga }\end{array}$ & $\begin{array}{c}\text { Satisfatória } \\
\text { Insatisfatória } \\
\text { Inexistente } \\
\text { Total parcial }\end{array}$ & $\begin{array}{c}10 \\
8 \\
7 \\
25\end{array}$ & $\begin{array}{c}31,25 \\
25 \\
21,875 \\
78,125\end{array}$ & $\begin{array}{l}1 \\
7\end{array}$ & $\begin{array}{c}6,25 \\
12,5 \\
3,125 \\
\mathbf{2 1 , 8 7 5}\end{array}$ & $\begin{array}{c}12 \\
12 \\
8 \\
32\end{array}$ & $\begin{array}{c}37,5 \\
37,5 \\
25 \\
100\end{array}$ & 1,5238 & $\begin{array}{l}0,4668 \\
\text { (N.S.) }\end{array}$ \\
\hline $\begin{array}{c}\text { Retenção e } \\
\text { estabilidade } \\
\text { da } \underline{P T C} \\
\underline{\text { antiga }}\end{array}$ & $\begin{array}{l}\text { Satisfatória } \\
\text { Insatisfatória } \\
\text { Inexistente } \\
\text { Total parcial }\end{array}$ & $\begin{array}{c}3 \\
16 \\
6 \\
25\end{array}$ & $\begin{array}{c}9,375 \\
50 \\
18,75 \\
78,125\end{array}$ & $\begin{array}{l}2 \\
3 \\
2 \\
7\end{array}$ & $\begin{array}{c}6,25 \\
9,375 \\
6,25 \\
\mathbf{2 1 , 8 7 5}\end{array}$ & $\begin{array}{c}5 \\
19 \\
8 \\
32\end{array}$ & $\begin{array}{c}15,625 \\
59,375 \\
25 \\
100\end{array}$ & 1,4186 & $\begin{array}{l}0,4920 \\
\text { (N.S.) }\end{array}$ \\
\hline
\end{tabular}


Tabela 5.14 - Distribuição de freqüências de pacientes quanto aos resultados obtidos após o relacionamento dos dados referentes a consistência das fezes com a habilidade mastigatória, consistência da dieta, inserção de novos alimentos,ingestão de líquidos, dimensão vertical, oclusão, retenção e estabilidade, com a PTC nova

\begin{tabular}{|c|c|c|c|c|c|c|c|c|c|}
\hline \multirow{2}{*}{\multicolumn{2}{|c|}{$\begin{array}{l}\text { Relação da c onsistência das } \\
\text { fezes (PTC nova) com: }\end{array}$}} & \multicolumn{2}{|c|}{$\begin{array}{l}\text { Normal e } \\
\text { pastosa }\end{array}$} & \multicolumn{2}{|c|}{ Ressecada } & \multicolumn{2}{|c|}{ Total geral } & \multirow[t]{2}{*}{$\begin{array}{l}\text { Qui- } \\
\text { quadrado }\end{array}$} & \multirow[t]{2}{*}{$\mathbf{p}$} \\
\hline & & $\mathbf{N}$ & $\%$ & $\mathbf{N}$ & $\%$ & $\mathbf{N}$ & $\%$ & & \\
\hline $\begin{array}{c}\text { Habilidade } \\
\text { mastigatória } \\
\text { com a } P T C \\
\underline{\text { nova }}\end{array}$ & $\begin{array}{c}\text { Conseguem mastigar } \\
\text { tudo } \\
\text { Não conseguem } \\
\text { mastigar tudo } \\
\text { Total parcial }\end{array}$ & $\begin{array}{l}21 \\
5 \\
26\end{array}$ & $\begin{array}{l}65,625 \\
15,625 \\
81,25\end{array}$ & $\begin{array}{l}1 \\
6\end{array}$ & $\begin{array}{l}15,625 \\
3,125 \\
18,75\end{array}$ & $\begin{array}{l}26 \\
6 \\
32\end{array}$ & $\begin{array}{c}81,25 \\
18,75 \\
100\end{array}$ & 0,0210 & $\begin{array}{r}0,8847 \\
\text { (N.S.) }\end{array}$ \\
\hline $\begin{array}{l}\text { Consistência } \\
\text { da dieta com } \\
\text { a PTC nova }\end{array}$ & $\begin{array}{c}\text { Geral } \\
\text { Branda } \\
\text { Pastosa/líquida } \\
\text { Total parcial }\end{array}$ & $\begin{array}{c}22 \\
3 \\
1 \\
26\end{array}$ & $\begin{array}{c}68,75 \\
9,38 \\
3,12 \\
81,25\end{array}$ & $\begin{array}{l}4 \\
2 \\
0 \\
6\end{array}$ & $\begin{array}{c}12,5 \\
6,25 \\
0 \\
18,75\end{array}$ & $\begin{array}{c}26 \\
5 \\
1 \\
32\end{array}$ & $\begin{array}{c}81,25 \\
15,63 \\
3,12 \\
100\end{array}$ & 1,9061 & $\begin{array}{l}0,3856 \\
\text { (N.S.) }\end{array}$ \\
\hline $\begin{array}{l}\text { Inserção de } \\
\text { novos } \\
\text { alimentos na } \\
\text { dieta }\end{array}$ & $\begin{array}{c}\text { Inseriram } \\
\text { Não inseriram } \\
\text { Total parcial }\end{array}$ & $\begin{array}{l}17 \\
9 \\
26\end{array}$ & $\begin{array}{c}53,125 \\
28,125 \\
81,25\end{array}$ & $\begin{array}{l}5 \\
1 \\
6\end{array}$ & $\begin{array}{l}15,625 \\
3,125 \\
18,75\end{array}$ & $\begin{array}{l}22 \\
10 \\
32\end{array}$ & $\begin{array}{c}68,75 \\
31,25 \\
100\end{array}$ & 0,7310 & $\begin{array}{l}0,3926 \\
\text { (N.S.) }\end{array}$ \\
\hline $\begin{array}{l}\text { Ingestão de } \\
\text { líquidos com } \\
\text { a } \underline{P T C \text { nova }}\end{array}$ & $\begin{array}{c}3 \text { copos ou menos } \\
4 \text { a } 6 \text { copos } \\
7 \text { copos ou mais } \\
\text { Total parcial }\end{array}$ & $\begin{array}{c}9 \\
13 \\
4 \\
26\end{array}$ & $\begin{array}{c}28,125 \\
40,625 \\
12,5 \\
81,25\end{array}$ & $\begin{array}{l}1 \\
4 \\
1 \\
6\end{array}$ & $\begin{array}{c}3,125 \\
12,5 \\
3,125 \\
18,75\end{array}$ & $\begin{array}{c}10 \\
17 \\
5 \\
32\end{array}$ & $\begin{array}{c}31,25 \\
53,125 \\
15,625 \\
\mathbf{1 0 0}\end{array}$ & 0,7626 & $\begin{array}{l}0,6830 \\
\text { (N.S.) }\end{array}$ \\
\hline $\begin{array}{l}\text { Dimensão } \\
\text { Vertical da } \\
\text { PTC nova }\end{array}$ & $\begin{array}{l}\text { Satisfatória } \\
\text { Insatisfatória } \\
\text { Total parcial }\end{array}$ & $\begin{array}{c}25 \\
1 \\
26\end{array}$ & $\begin{array}{c}78,125 \\
3,125 \\
81,25\end{array}$ & $\begin{array}{l}6 \\
0 \\
6\end{array}$ & $\begin{array}{c}18,75 \\
0 \\
18,75\end{array}$ & $\begin{array}{l}31 \\
1 \\
32\end{array}$ & $\begin{array}{c}96,875 \\
3,125 \\
100\end{array}$ & 0,2382 & $\begin{array}{r}0,6255 \\
\text { (N.S.) }\end{array}$ \\
\hline $\begin{array}{l}\text { Oclusão da } \\
\text { PTC nova }\end{array}$ & $\begin{array}{l}\text { Satisfatória } \\
\text { Insatisfatória } \\
\text { Total parcial }\end{array}$ & $\begin{array}{c}23 \\
3 \\
26\end{array}$ & $\begin{array}{l}71,875 \\
9,375 \\
81,25\end{array}$ & $\begin{array}{l}6 \\
0 \\
6\end{array}$ & $\begin{array}{c}18,75 \\
0 \\
18,75\end{array}$ & $\begin{array}{c}29 \\
3 \\
32\end{array}$ & $\begin{array}{c}90,625 \\
9,375 \\
100\end{array}$ & 0,7639 & $\begin{array}{l}0,3821 \\
\text { (N.S.) }\end{array}$ \\
\hline $\begin{array}{l}\text { Retenção e } \\
\text { estabilidade } \\
\text { da } \underline{P T C \text { nova }}\end{array}$ & $\begin{array}{l}\text { Satisfatória } \\
\text { Insatisfatória } \\
\text { Total parcial }\end{array}$ & $\begin{array}{c}25 \\
1 \\
26\end{array}$ & $\begin{array}{c}78,125 \\
3,125 \\
81,25\end{array}$ & $\begin{array}{l}6 \\
0 \\
6\end{array}$ & $\begin{array}{c}18,75 \\
0 \\
18,75\end{array}$ & $\begin{array}{c}31 \\
1 \\
32\end{array}$ & $\begin{array}{c}96,875 \\
3,125 \\
100\end{array}$ & 0,2382 & $\begin{array}{l}0,6255 \\
\text { (N.S.) }\end{array}$ \\
\hline
\end{tabular}

As Tabelas 5.13 e 5.14, analisaram as possíveis relações entre a consistência das fezes e o tipo de prótese usada antes da reabilitação protética, assim como se houve a inserção de novos alimentos. Foram consideradas também habilidade mastigatória, consistência da dieta, ingestão de líquidos, dimensão 
vertical, oclusão, retenção e estabilidade comparando as PTCs antigas e as novas. Não houve correlação significante entre os dados.

c) Comparação dos alimentos ingeridos antes e após a reabilitação protética

Na Tabela 5.15 estão demonstradas respectivamente as freqüências de respostas referentes à comparação da ingestão de alguns alimentos como: pão francês e pão macio, bolacha seca e bolacha no leite, fruta dura e macia, saladas cruas e cozidas, legumes crus e cozidos, leguminosas, oleaginosas, carne frita e macia, ovos, doces e sopas antes e após a reabilitação protética.

Tabela 5.15 - Distribuição de freqüências de pacientes quanto as respostas referentes à comparação da ingestão de alguns alimentos como : pão francês e pão macio, bolacha seca e bolacha no leite, fruta dura e macia, saladas cruas e cozidas, legumes crus e cozidos, leguminosas, oleaginosas, carne frita e macia, ovos, doces e sopas antes e após a reabilitação protética

\begin{tabular}{|c|c|c|c|c|c|c|c|c|}
\hline \multicolumn{2}{|c|}{ Alimentos } & $\begin{array}{l}\text { Antes da } \\
\text { reabilitacão }\end{array}$ & $\begin{array}{l}\text { Depois da } \\
\text { reabilitacão }\end{array}$ & $\begin{array}{c}\text { Concordância } \\
\text { observada }\end{array}$ & $\begin{array}{l}\text { Concordância } \\
\text { esperada }\end{array}$ & Kappa & $\underset{\text { (Kappa) }}{Z}$ & (p-valor) \\
\hline $\begin{array}{c}\text { Pão } \\
\text { francês }\end{array}$ & $\begin{array}{l}\text { Comiam } \\
\text { Não } \\
\text { comiam }\end{array}$ & $\begin{array}{l}13 \\
19\end{array}$ & $\begin{array}{l}24 \\
8\end{array}$ & 0,3281 & 0,50 & $-0,3438$ & 2,7842 & $\underset{*}{0,0027}$ \\
\hline Pão macio & $\begin{array}{l}\text { Comiam } \\
\text { Não } \\
\text { comiam }\end{array}$ & $\begin{array}{l}21 \\
11\end{array}$ & $\begin{array}{l}21 \\
11\end{array}$ & 0,50 & 0,50 & 0,0 & 0,0 & 0,50 (ns) \\
\hline $\begin{array}{l}\text { Bolacha } \\
\text { seca }\end{array}$ & $\begin{array}{c}\text { Comiam } \\
\text { Não } \\
\text { comiam }\end{array}$ & $\begin{array}{l}15 \\
17\end{array}$ & $\begin{array}{l}16 \\
16\end{array}$ & 0,4844 & 0,50 & $-0,0313$ & 0,2501 & $\begin{array}{c}0,4012 \\
\text { (ns) }\end{array}$ \\
\hline $\begin{array}{l}\text { Bolacha } \\
\text { no leite }\end{array}$ & $\begin{array}{c}\text { Comiam } \\
\text { Não } \\
\text { comiam }\end{array}$ & $\begin{array}{c}1 \\
31\end{array}$ & $\begin{array}{c}1 \\
31\end{array}$ & 0,50 & 0,50 & 0,0 & 0,0 & 0,50 (ns) \\
\hline $\begin{array}{l}\text { Frutas } \\
\text { duras }\end{array}$ & $\begin{array}{c}\text { Comiam } \\
\text { Não } \\
\text { comiam }\end{array}$ & $\begin{array}{c}7 \\
25\end{array}$ & $\begin{array}{l}13 \\
19\end{array}$ & 0,4063 & 0,50 & $-0,1875$ & 1,6181 & $\begin{array}{c}0,0528 \\
\text { (ns) }\end{array}$ \\
\hline
\end{tabular}

Continua... 
Continuação...

\begin{tabular}{|c|c|c|c|c|c|c|c|c|}
\hline $\begin{array}{c}\text { Frutas } \\
\text { macias }\end{array}$ & $\begin{array}{c}\text { Comiam } \\
\text { Não } \\
\text { comiam }\end{array}$ & $\begin{array}{c}28 \\
4\end{array}$ & $\begin{array}{c}28 \\
4\end{array}$ & 0,50 & 0,50 & 0,0 & 0,0 & 0,50 (ns) \\
\hline $\begin{array}{l}\text { Folhas } \\
\text { cruas }\end{array}$ & $\begin{array}{c}\text { Comiam } \\
\text { Não } \\
\text { comiam }\end{array}$ & $\begin{array}{c}30 \\
2\end{array}$ & $\begin{array}{c}30 \\
2\end{array}$ & 0,50 & 0,50 & 0,0 & 0,0 & 0,50 (ns) \\
\hline $\begin{array}{l}\text { Folhas } \\
\text { cozidas }\end{array}$ & $\begin{array}{l}\text { Comiam } \\
\text { Não } \\
\text { comiam }\end{array}$ & $\begin{array}{c}9 \\
14\end{array}$ & $\begin{array}{l}23 \\
18\end{array}$ & 0,4219 & 0,50 & $-0,1563$ & 1,3026 & $\begin{array}{c}0,0964 \\
\text { (ns) }\end{array}$ \\
\hline $\begin{array}{l}\text { Legumes } \\
\text { crus }\end{array}$ & $\begin{array}{c}\text { Comiam } \\
\text { Não } \\
\text { comiam }\end{array}$ & $\begin{array}{c}5 \\
12\end{array}$ & $\begin{array}{l}27 \\
20\end{array}$ & 0,3906 & 0,50 & $-0,2188$ & 1,9811 & $\underset{*}{0,0238}$ \\
\hline $\begin{array}{l}\text { Legumes } \\
\text { cozidos }\end{array}$ & $\begin{array}{c}\text { Comiam } \\
\text { Não } \\
\text { comiam }\end{array}$ & $\begin{array}{c}27 \\
5\end{array}$ & $\begin{array}{c}27 \\
5\end{array}$ & 0,50 & 0,50 & 0,0 & 0,0 & 0,50 (ns) \\
\hline $\begin{array}{c}\text { Legumi } \\
\text { nosas }\end{array}$ & $\begin{array}{c}\text { Comiam } \\
\text { Não } \\
\text { comiam }\end{array}$ & $\begin{array}{c}30 \\
2\end{array}$ & $\begin{array}{c}30 \\
2\end{array}$ & 0,50 & 0,50 & 0,0 & 0,0 & 0,50 (ns) \\
\hline $\begin{array}{l}\text { Oleagi- } \\
\text { nosas }\end{array}$ & $\begin{array}{c}\text { Comiam } \\
\text { Não } \\
\text { comiam }\end{array}$ & $\begin{array}{c}0 \\
32\end{array}$ & $\begin{array}{l}13 \\
19\end{array}$ & 0,2669 & 0,50 & $-0,4063$ & 4,0390 & $\underset{*}{0.0000}$ \\
\hline $\begin{array}{c}\text { Carnes } \\
\text { Fritas }\end{array}$ & $\begin{array}{l}\text { Comiam } \\
\text { Não } \\
\text { comiam }\end{array}$ & $\begin{array}{c}8 \\
24\end{array}$ & $\begin{array}{c}23 \\
9\end{array}$ & 0,2656 & 0,50 & $-0,4688$ & 3,7518 & $\underset{*}{0,0001}$ \\
\hline $\begin{array}{l}\text { Carnes } \\
\text { macias }\end{array}$ & $\begin{array}{c}\text { Comiam } \\
\text { Não } \\
\text { comiam }\end{array}$ & $\begin{array}{c}30 \\
2\end{array}$ & $\begin{array}{c}30 \\
2\end{array}$ & 0,50 & 0,50 & 0,0 & 0,0 & 0,50 (ns) \\
\hline Ovos & $\begin{array}{c}\text { Comiam } \\
\text { Não } \\
\text { comiam }\end{array}$ & $\begin{array}{l}13 \\
19\end{array}$ & $\begin{array}{l}13 \\
19\end{array}$ & 0,50 & 0,50 & 0,0 & 0,0 & 0,50 (ns) \\
\hline Doces & $\begin{array}{c}\text { Comiam } \\
\text { Não } \\
\text { comiam }\end{array}$ & $\begin{array}{l}10 \\
22\end{array}$ & $\begin{array}{l}10 \\
22\end{array}$ & 0,50 & 0,50 & 0,0 & 0,0 & 0,50 (ns) \\
\hline Sopas & $\begin{array}{l}\text { Comiam } \\
\text { Não } \\
\text { comiam }\end{array}$ & $\begin{array}{l}15 \\
17\end{array}$ & $\begin{array}{l}15 \\
17\end{array}$ & 0,50 & 0,50 & 0,0 & 0,0 & 0,50 (ns) \\
\hline
\end{tabular}

De acordo com os valores demonstrados na Tabela 5.15 que buscava a comparação da ingestão de determinados grupos de alimentos antes e após a reabilitação protética, somente foram encontradas variações estatisticamente significantes com relação ao aumento do número de pacientes que passaram a ingerir mais pães do tipo francês, legumes crus, oleaginosas e carnes fritas. 


\section{DISCUSSÃO}

A análise dos resultados obtidos com o desenvolvimento desse trabalho vai de encontro aos achados de Marucci (1992) e Frank e Soares (2004), que observaram a predominância da raça branca sobre a não branca, assim como do sexo feminino sobre o masculino (Tabela 5.1). Apesar de ter sido verificado um decréscimo da taxa de edentulismo (HÁ 30 MI[...], 2004; JONES et al., 2003; PAPAS et al., 1998; SANDSTRÖM; LINDQUIST, 1987) pudemos verificar, por meio da Tabela 5.2, que um amplo segmento populacional permanece desdentado.

A grande maioria dos pacientes analisados apresentou algum tipo de tratamento protético reabilitador (JEMT, 1981; MANLY; VINTON, 1951; PAPAS; PALMER; ROUNDS, 1989; WAYLER; CHAUNCEY, 1983), enquanto uma minoria não usava prótese (Tabela 5.2).

Foi possível verificar ainda que não era suficiente o paciente ser usuário de um aparelho protético reabilitador, se este não apresentasse condições de compensar a redução da eficiência mastigatória conseqüente da perda dental (BERG, 1992; BUDTZ-JORGENSEN, 1999; GARRET; KAPUR; PEREZ, 1996; OBREZ; GRUSSING, 1999).

Antes da reabilitação protética, os pacientes possuíam aparelhos considerados insatisfatórios clinicamente, tanto com relação ao estado de conservação (Tabela 5.2), como à dimensão vertical, à oclusão, à retenção e à estabilidade (Tabela 5.3b). Ao relatarem a presença de problemas durante a mastigação, imaginamos que tal fato poderia influenciar a consistência da dieta ingerida (Tabelas 5.3a). Após a instalação das novas próteses confeccionadas no 
rigor da técnica (TAMAKI, 1988), esse quadro foi alterado de forma positiva (Tabelas 5.3a e 5.3b).

Outra importante evidência que foi observada nesse estudo e que pode estar diretamente relacionada com os achados de autores como Hoad-Reddick (1989) e Lang (1994) é o tempo de uso das próteses. Para esses autores, bem como para o estudo em questão, o tempo de uso dos aparelhos protéticos pode influenciar a funcionalidade das próteses que atuariam de forma negativa sobre a mastigação, repercutindo sobre a consistência dos alimentos ingeridos. A maioria dos indivíduos analisados no início desse trabalho usava próteses por um período superior a 7 anos (Tabelas 5.2) apresentando problemas funcionais (Tabelas 5.3b) e limitações com relação à habilidade mastigatória e alterações na consistência da dieta ingerida (Tabelas 5.3a).

Assim, após a troca das próteses, houve uma alteração estatisticamente significante nesses dois itens, ou seja, os indivíduos estudados que antes não mastigavam tudo o que pretendiam $(43,75 \%)$, passaram a comer alimentos de consistência mais firme - geral (81,25\%) (Tabela 5.3a). Antes da instalação das próteses novas, parte dos pacientes (12,5\%) comiam alimentos de consistência pastosa/líquida e outra parte (43,5\%) alimentos de consistência branda, o que vai de encontro às observações de Ettinger e Beck (1984), Soini et al. (2003) e Frank e Soares (2004). Convém ressaltar os trabalhos de Frank e Soares (2004), Joshipura, Wille e Douglas (1996), Hutton, Feine e Morais (2002) e Reavley e Holt (1999), e que comentam que as dietas de consistência mais amolecida muitas vezes são ricas em gorduras saturadas, colesterol e calorias podendo elevar o risco de doenças cardiovasculares, infartos do miocárdio e hipertensão. No entanto, tal 
confirmação implicaria numa avaliação nutricional mais específica e completa, que lançaria mão de testes bioquímicos, o que não foi possível realizar nesse trabalho.

Pode-se observar que, no início deste estudo, a soma dos pacientes, que se alimentavam com uma dieta de consistência mais branda, com os que se alimentavam com uma dieta de mais pastosa para líq uida, superava aqueles que se alimentavam com alimentos de consistência mais firme (Tabela 5.3a). Os achados do trabalho em questão corroboram tanto com autores como McMillan e Wong (2004) e Oliveira (2001), que acreditavam na relação direta entre a falta de integridade bucal e a ingestão inadequada de alimentos, como com os trabalhos desenvolvidos por Geisseler e Bates (1984), Joshipura, Wille e Douglas (1996), Roisinblit (1995), Sheiham et al. (1999), Sheiham et al. (2001), Willett (1994), que verificaram a adaptação da dieta a alimentos mais macios e fáceis de serem mastigados, sendo que em alguns casos a opção era por ingerir grandes pedaços de alimentos.

Convém mencionar que os pacientes que apresentavam dificuldades para engolir (Tabela 5.3a), não apresentavam nenhum problema sistêmico que refletisse nesse ato ou qualquer distúrbio de deglutição o que poderia influenciar negativamente na nossa análise. Na presença de tal interferência, ficaria difícil discernir a causa da alteração da dieta, tornando assim os problemas de deglutição fatores de exclusão no trabalho.

A análise da inserção de novos alimentos, após a instalação das novas próteses, por um número significante de pacientes $(62,5 \%)$ que conseguiam mastigar tudo o que pretendiam comer (Tabela 5.10) confirmam os trabalhos de autores como Apopollonio et al. (1997), Ettinger e Beck (1984), Frank e Soares (2004), Galanos et al. (1994), Greksa, Parraga e Clark (1995), Krall, Hayes e Garcia 
(1998), Marshall et al. (2002), Nordstrom (1990), Papas et al. (1998), Soini et al. (2003). Para esses pesquisadores, a melhora da habilidade e da eficiência mastigatória através da confecção de PTCs funcionalmente adequadas possibilitam a alteração da alimentação diária com a inserção de novos alimentos na dieta.

A melhora na relação de oclusão dos aparelhos protéticos influencia de maneira positiva a habilidade mastigatória possibilitando também a inserção de diferentes alimentos na dieta (Tabela 5.10), indo a favor aos achados de Galanos et al. (1994) e Marshall et al. (2002). Enquanto a relação de oclusão se apresentou estatisticamente significante, o mesmo não se verificou com relação à dimensão vertical e a retenção e estabilidade das PTCs (Tabela 5.10).

É importante mencionar que nesse estudo não foi encontrada diferença estatisticamente significante com relação à inserção de novos alimentos na dieta após a instalação de novas próteses tanto por homens como pelas mulheres analisadas (Tabela 5.4)

Procuramos comparar ainda a ingestão de alguns alimentos antes e após a instalação das PTCs novas, tais como: pão francês e pão macio, bolacha seca e bolacha no leite, fruta dura e macia, saladas cruas e cozidas, legumes crus e cozidos, leguminosas, oleaginosas, carne frita e macia, ovos, doces e sopas, que foram escolhidos com base na proximidade da maior prevalência da composição vitamínica e de sais minerais e na observação de critérios que influenciassem a mastigação como: dureza, umidade (secos ou macios) e presença de fibras. Variações estatisticamente significantes somente foram encontradas com relação ao aumento do número de pacientes que passaram a ingerir mais pães do tipo francês, legumes crus, oleaginosas e carnes fritas (Tabela 5.15). Mesmo não tendo alterações comprovadas estatisticamente, o número de pacientes que passaram a 
comer bolachas secas, frutas duras e folhas cozidas também aumentou após a instalação da PTC nova (Tabela 5.15). Ficou comprovado mais uma vez o fato de que com a instalação das próteses funcionalmente satisfatórias, os indivíduos passaram a procurar alimentos considerados de consistência mais firme e, em alguns casos, com maior quantidade de fibras, que exigem uma melhor habilidade mastigatória.

Mas, tanto nesse trabalho como no de Sandström e Lindquist (1987), não se avaliou a adequação nutricional da dieta de cada indivíduo, nem a alteração dos nutrientes após a instalação das novas próteses; não fo mos capazes de afirmar também se novos alimentos passaram ou não a fazer parte da dieta desses pacientes.Para que essas afirmações pudessem ser comprovadas, necessitaríamos do desenvolvimento de outras metodologias e do prolongamento do estudo em questão.

Além disso, procuramos comparar a consistência da dieta e a habilidade mastigatória a outros itens. No caso da consistência da dieta, esta foi analisada com relação ao tipo de prótese usada antes da reabilitação protética (Tabela 5.7), levando em consideração a habilidade mastigatória tanto com a PTC antiga como a nova (Tabelas 5.7 e 5.8) e a inserção de novos alimentos (Tabela 5.8) após a instalação das novas próteses. O que pudemos verificar foi a ausência de diferenças estatisticamente significantes, quando todos esses itens foram relacionados. Mesmo sem apresentar diferenças comprovadas estatisticamente, é importante observar que houve um aumento de $28,125 \%$ para $65,625 \%$, no número de indivíduos que não apresentavam problemas de habilidade mastigatória e, por conseguinte possuíam uma dieta de consistência geral (Tabelas 5.7 e 5.8). 
A habilidade mastigatória foi comparada não só com relação à inserção de novos alimentos e a alguns caracteres funcionais como: dimensão vertical, oclusão, retenção e estabilidade, como já foi mencionado anteriormente, mas também com o tipo de prótese usada antes da reabilitação protética (Tabela 5.9). Não foi comprovada nenhuma diferença estatisticamente significante.

Desta forma, o trabalho em questão foi ao encontro aos achados descritos por alguns autores como Apopollonio et al. (1997), Greksa, Parraga e Clark (1995), Krall, Hayes e Garcia (1998), Marshall et al. (2002), Nordstrom (1990), Papas, Palmer e Rounds (1989), Papas et al. (1998), Soini et al. (2003), dentre outros. Foi possível observar a relação positiva entre a qualidade funcional dos aparelhos protéticos, a habilidade mastigatória e a consistência da dieta. Pesquisadores como Perez, Kapur e Garrett (1985) defendem a premissa da melhora da atividade mastigatória estar relacionada somente com a melhora das atividades neuromusculares orais; já autores como Budtz-Jorgensen (1994), Davis e Watson (2000), Ettinger (1998), Gunne (1985), MacEntee e Walton (1998), Norlen, Johansson e Birkhed (1996), Sandström e Lindquist (1987), Sebring (1995) e Shinkai et al. (2002) acreditam que para concretizar mudanças no hábito alimentar, independente da melhora na habilidade mastigatória, seja necessária a interferência de outros fatores como, por exemplo, uma abordagem multidisciplinar, que muito provavelmente requer uma orientação profissional direta e individual.

Já é consenso a importância da alimentação adequada para a manutenção da saúde geral e bucal do indivíduo (BAXTER, 1984; BUDTZJORGENSEN, 1999; FANTASIA, 1997; FIORE, 1999; FRANK; SOARES, 2004; GEERING; KUNDERT; KELSEY, 1993; LUECKENOTTE, 2002; MARSHALL et al., 2002; ROISINBLIT, 1995; THOMAS, 1998). Procuramos realizar outras 
comparações, não comuns na literatura nacional e internacional, com o objetivo de verificarmos se essas possíveis alterações provocadas por essa troca dos aparelhos protéticos exerciam também influências tanto no Índice de Massa Corporal (IMC) dos indivíduos estudados, como na consistência das fezes e até mesmo na freqüência de evacuações.

O que pudemos verificar foi a ausência de diferenças estatisticamente significantes entre os dados coletados do IMC, tanto no período em que o paciente era portador das PTCs antigas, quanto nos dois períodos que sucederam a instalação das PTCs novas (Tabela 5.3a). Essa falta de significado comprovado estatisticamente também pode ser observado quando correlacionamos - IMC com o tipo de prótese usada antes da reabilitação protética, habilidade mastigatória e consistência da dieta com a PTC antiga e com a PTC nova respectivamente (Tabelas 5.5 e 5.6). Talvez uma observação durante um prazo maior permita alterar esse resultado, pois um período de 6 meses pode ser insuficiente para que possamos observar uma alteração significativa nesse índice.

A comprovação estatística de que com a troca das PTCs há uma melhora funcional das próteses dos pacientes analisados e até mesmo a inserção de novos alimentos na dieta, com possível aumento no aporte de fibras, fez com que também nos preocupássemos em analisar a associação dessas melhorias com a freqüência de evacuações e a consistência das fezes (Tabelas 5.3c), relação essa já mencionada por autores como Ettinger (1998), Frank e Soares (2004), Krause e Mahan, 1991 e Reavley e Holt (1999). Nosso trabalho não pode confirmar essa associação devido à falta de significado estatístico nos dados coletados. O mesmo ocorreu quando esses mesmo dois itens foram relacionados a outros fatores pertinentes a esse estudo como: tipo de prótese usada antes da reabilitação 
protética, a habilidade mastigatória, consistência da dieta, ingestão de líquidos, dimensão vertical e oclusão, tanto das PTCs antigas como das novas (Tabelas $5.11,5.12,5.13$ e 5.14$)$.

De todas essas correlações realizadas, o único item que mostrou significado estatístico foi a relação entre o hábito intestinal e a melhoria na retenção e estabilidade dos aparelhos protéticos (Tabela 5.12), ou seja, houve um aumento do número de pacientes que apresentavam o aparelho protético avaliado como satisfatório no quesito retenção e estabilidade e que possuíam a freqüência de evacuações classificadas como diária ou em dias alternados, mostrando assim uma suposta melhoria no hábito intestinal após a troca das peças protéticas.

Se observarmos os valores numéricos das Tabelas 5.11,5. 12,5. 13 e 5.14, notaremos que os pacientes obtiveram ganhos após a troca dos aparelhos protéticos e que, apesar desses não poderem ter sido comprovados estatisticamente, foram de grande importância para o trabalho em questão. Algumas das alterações numéricas positivas observadas nas Tabelas 5.11 e 5.12 foram: antes da reabilitação protética, 40,62\% dos pacientes que apresentavam o hábito intestinal classificado como diário, ou em dias alternados, mastigavam tudo o que pretendiam comer; após a troca dos aparelhos protéticos por PTCs funcionalmente adequadas esse número foi alterado para $65,62 \%$. Uma alteração numérica também foi observada com relação à consistência da dieta: antes da troca dos aparelhos protéticos, $37,5 \%$ dos pacientes que apresentavam o hábito intestinal classificado como diário, ou em dias alternados, e possuíam a consistência da dieta classificada como geral, após a troca dos aparelhos protéticos por PTCs funcionalmente adequadas passaram para $65,62 \%$. 
Comparando ainda habilidade mastigatória e consistência da dieta com dados das Tabelas 5.13 e 5.14, ou seja, correlacionando com a consistência das fezes, o que pudemos notar foram alterações numéricas em que antes da reabilitação protética, $37,5 \%$ dos pacientes que apresentavam a consistência das fezes considerada normal/pastosa mastigavam tudo o que pretendiam comer e possuíam a consistência da dieta considerada como geral; após a troca dos aparelhos protéticos por PTCs funcionalmente adequadas, esse número foi elevado para $65,62 \%$ dos pacientes apresentando a consistência das fezes considerada normal/pastosa e mastigando tudo o que pretendiam comer e $68,75 \%$ dos pacientes apresentando a consistência das fezes considerada normal/pastosa e possuindo a consistência da dieta classificada como geral, comprovando, portando, numericamente essa alteração, mesmo que estatisticamente essa diferença não esteja evidente.

Além disso, pudemos observar na literatura através de autores como Masseler (1979) e Rugg-Gunn e Nunn (1999) outros fatores como, por exemplo, a contribuição da água na nutrição e a influência que esta poderia exercer sobre a função mastigatória do indivíduo. Nossa avaliação foi meramente descritiva e teve intuito apenas informativo. Assim sendo pudemos notar que os indivíduos permaneceram ingerindo praticamente a mesma quantidade de água antes e após a reabilitação protética (Tabela 5.3a). A falta de comprovação estatística também esteve presente quando buscamos outras associações da ingestão de água como, por exemplo, com o hábito intestinal e com a consistência das fezes (Tabelas 5.11,5. 12,5. 13 e 5.14$)$.

O que muitas vezes ocorre, segundo Nevalainen et al. (1997) é que os pacientes idosos, portadores de próteses totais administram subjetivamente bem 
os seus aparelhos protéticos antigos e freqüentemente tornam-se relutantes ao trocá-los por novos, muito embora esses não estejam funcionalmente adequados para o uso, mostrando mais uma vez a importância do cirurgião-dentista em informar os seus pacientes sobre a necessidade da troca de seus aparelhos protéticos assim como o período adequado para fazê-lo (LANG, 1994; NEVALAINEN et al., 1997).

Uma última consideração diz respeito à dificuldade de consolidar mudanças de hábitos alimentares em indivíduos idosos, uma vez estabelecido um modelo alimentar ao longo dos muitos anos vividos, torna-se difícil à elaboração de mudanças. Faz-se necessário estabelecer um diálogo entre paciente e profissional, sendo fundamental o suporte multiprofissional na busca de uma melhor qualidade de vida. 


\section{CONCLUSÕES}

A análise e discussão dos resultados obtidos no presente trabalho permitiram-nos concluir que após a instalação de uma nova PTC, confeccionada no rigor da técnica temos:

\subsection{Com relação ao exame clínico protético}

- Uma melhora funcional do aparelho protético;

- Uma alteração positiva na habilidade mastigatória dos pacientes.

\subsection{Com relação aos hábitos alimentares}

- Uma pequena variação do IMC dos pacientes, mais sem significado estatístico;

- Uma alteração na consistência da dieta;

- Nenhuma mudança significativa na ingestão hídrica;

- Nenhuma mudança significativa no hábito intestinal dos pacientes;

- Um aumento da capacidade do indivíduo inserir novos alimentos na dieta.

\subsection{Quando relacionamos alguns dos itens analisados antes e após a} reabilitação protética

- Uma relação direta na melhora da habilidade mastigatória após a instalação de PTCs funcionalmente satisfatórias, com a inserção de novos alimentos na dieta; 
- Uma influência positiva no hábito intestinal do paciente, quando a peça protética apresenta a retenção e estabilidade considerada satisfatória.

Além disso, pode-se concluir com esse trabalho que:

- as trocas das PTCs devem ser realizadas após a avaliação das condições do aparelho protético e da conscientização do paciente da importância desse ato e seus possíveis reflexos negativos na nutrição;

- há a necessidade da integração multiprofissional para proporcionar a saúde geral do paciente. 


\section{REFERÊNCIAS ${ }^{1}$}

Adams CD. Gerodontologic aspects of diet and nutrition. J Prosthet Dent $1961 ; 11: 345-8$.

Anderson EL. Eating patterns before and after dentures. J Am Diet Assoc $1971 ; 58: 421-6$.

Appollonio I, Caralellese C, Frattola A, Trabucchi M. Influence of dental status on dietary intake and survival in community: dwelling elderly subjects. Age Ageing 1997;22:445-55.

Ayres M, Ayres JRM, Ayres DL, Santos AS. Aplicações estatísticas nas áreas das ciências biomédicas. Mamirauá: MCT/CNPq: 2003.

Baxter JC. The nutritional intake of geriatric patients with varied dentitions. J Prosthet Dent 1984;51(2):164-8.

Berg E. Acceptance of full dentures. Int Dent J 1992;43:299-307.

Bergendal B. The relative importance of tooth loss and denture wearing in Swedish adults. Community Dent Health 1989;6:103-11.

Berry WTC. Mastication, food and nutrition. Dent Pract 1972;22:249-53.

Budtz-Jorgensen E. Oral problems and nutritional. Age Nutr 1994;5:43-8.

Budtz-Jorgensen E. Prosthodontics for elderly: diagnosis and treatment. Illinois: Quintessence; 1999.

Camargo ABM, Yazaki L M. Diferenças intra-regionais na Grande São Paulo. Os idosos na Grande São Paulo. São Paulo: Fundação SEADE; 1990. (Coleção Realidade Paulista).

\footnotetext{
${ }^{1}$ De acordo com Estilo Vancouver. Abreviatura de periódicos segundo base de dados MEDLINE.
} 
Campos MTFS, Monteiro JBR, Ornelas APRC. Fatores que afetam o consumo alimentar e a nutrição do idoso. Rev Nutr 2000;13(3):25-40.

Carlsson GE. Masticatory efficiency: the effect of age, the loss of teeth and prosthetic rehabilitation. Int Dent J 1984;34(2):93-7.

Cervato AM. Intervenção nutricional educativa: promovendo a saúde de adultos e idosos em Universidades Abertas à Terceira Idade. (Contribuição para o estudo) [Tese de Doutorado]. São Paulo: Faculdade de Saúde Pública da USP; 1999.

Coelho L. Proporção de idosos no mundo dispara. Folha de São Paulo, São Paulo, 2005, fev. 19; Caderno Mundo, p.A17.

Collucci C. Projetos criam arquitetura para idosos. Folha de São Paulo, São Paulo, 2004, ago. 9; Caderno Cotidiano, p. C6.

Davis DM, Watson RM. Significance of tooth loss in the elderly patient. In: Zarb G, Lekholm U, Albrektsson T, Tenenbaum H. Aging, osteoporosis, and dental implants 2000. $1^{\mathrm{a}}$ ed. Chicago: Quintessence books; 2000. cap.11, p.135-46.

Ettinger RL. Changing dietary patterns with changing dentition: how do people cope? Spec Care Dent 1998;18(1):33-9.

Ettinger RL, Beck JD. Geriatric dental curriculum and the needs of the elderly. Spec Care Dent 1984;4:207-13.

Estatuto do idoso. São Paulo: Escala; 2003.

Fantasia JE. Diagnosis and treatment of common oral lesions found in the elderly. Dent Clin North Am 1997;41 (4):877-90.

Ferrari MAC. O envelhecer no Brasil. O mundo da saúde 1999;23(4):197-203.

Fiore EG. Consumo alimentar de portadores de próteses dentárias total e parcial removível. (Contribuição para o estudo) [Dissertação de Mestrado]. São Paulo: Faculdade de Ciências Farmacêuticas,Faculdade de Economia,Administração e Contabilidade/Faculdade de Saúde Pública da Universidade de São Paulo; 1999. 
Fiske J, Davis DM, Frances C, Gelbier S. The emotional effects of tooth loss in edentulous people. Br Dent J 1998;184:90-3.

Frank AA, Soares EA. Nutrição no envelhecer. São Paulo: Atheneu; 2004.

Galanos AN, Pieper CF,Cornoni-Hountley JC, Bales CW, Fillenbaum GG. Nutrition and function: is there a relationship between body mass index and the functional capabilities of community-dwelling elderly? J Am Geriatr Soc 1994;42;368-73.

Garret NR, Kapur KK, Perez P. Effects of improvements of poorly fitting dentares and new dentares on patient satisfection. J Prosthet Dent 1996;769(6):403-13.

Geering $\mathrm{AH}$, Kundert M, Kelsey $\mathrm{CC}$. Complete dentures and overdenture prosthetics. $2^{\mathrm{a}}$ ed. Germany: Thieme Verlag; 1993.

Geisseler CA, Bates JF. The nutritional effects of tooth loss. Am J Clin Nutr 1994;39:478-89.

Gois A. País terá em 2050 indicador do Japão atual. Folha de São Paulo, São Paulo, 2004, ago. 31, Caderno Cotidiano, p.C1.

Greksa LP, Parraga IM, Clark CA. The dietary adequacy of edentulous older adults. J Prosthet Dent 1995;73:142-5.

Gunne HJ. Masticatory efficiency and dental state: A comparison between two methods. Acta Odontol Scand 1985;43:139-46.

Há 30 mi sem dente no país. Folha de São Paulo, São Paulo, 2004, mar 18; Caderno Cotidiano, p. C8.

Hartsook F. Food selection, dieterary adequacy and related dental problems of patients with dental prosthesis. J Prosthet Dent 1974;32:32-40.

Heath MR. The effect of maximum biting force and bone loss on masticatory function and dietery selection of the elderly. Int Dent J 1982;32:345-56.

Hoad-Reddick G. Oral pathology and prosthesis- are they related? Investigations in an elderly population. J Oral Re habil 1989;16:75. 
Horn VJ, Hodge WC, Treuer JP. Dental condition and weight loss in institutionalized demented patients. Spec Care Dent 1994;14(1-3):108-11.

Horwath CC. Nutrition goals for older adults: a review. Gerodontol 1991;31:811-21.

Hutton $\mathrm{B}$, Feine $\mathrm{J}$, Morais $\mathrm{J}$. Is there as association between edentulism and nutritional state? J Calif Dent Assoc 2002;68(3):182-7.

Isosaki M, Cardoso E. Manual de dietoterapia e avaliação nutricional. Serviço de Nutrição e Dietética do Instituto do Coração- HCFMUSP. São Paulo: Atheneu; 2004.

Jemt T. Chewing patterns in dentate and complete denture wears, recorded by light emitting diodes. Swed Dent J 1981:5199-205.

Jones JA, Orner MB, Spiro A, Kressin NR. Tooth loss and dentures: patients perspectives. Int Dent J 2003;53:327-34.

Joshipura KJ, Wille TTWC, Douglas CW. The impact of edentulousness on food and nutrient intake. J Am Dent Assoc 1996;127:459-67.

Kapur KK, Soman SD. Masticatory performance and e fficiency in denture wearers. J Prosthet Dent 1964;14:687-94.

Krall E, Hayes C. Garcia R. How dentition status and mastigatory function affect nutrient intake. J Am Dent Assoc 1998;129:1261-9.

Krause MV, Mahan LK. Alimentos, nutrição e dietoterapia. $7^{\text {ạ }}$ ed. São Paulo: Liv. Roca; 1991.

Lang BR. A review of traditional therapies in complete dentures. J Prosthet Dent $1994 ; 72(5): 538-42$.

Laurin D, Brodeur J, Leduc N. Nutritional deficiencies and gastro-intestinal disorders in the edentulous elderly: a literature review. J Canad Dent Assoc 1992;58(9-12):7389.

Lowental V, Tau S. Effects questionnaire for predicting denture success or failure. J Prosthet Dent 1980;44(2):133-6. 
Lucas PW, Luke DA, Voon FCT, Chew CL, OWR. Food breakdown patterns produced by human subjects possessing artificial and natural teeth. J Oral Rehabil 1986;13:205-14.

Lueckenotte A. Avaliação em gerontologia: avaliação nutricional. $3^{a}$ ed. Rio de Janeiro: Reichmann \& Affonso; 2002.

MacEntee MI, Walton JM. The economics of complete dentures and implant-related services: a framework for analysis and preliminary outcomes. J Prosthet Dent 1998; 79;24-30.

McMillan AS, Wong MC. Emotional effects of tooth loss in communith-dwelling elderly people in Hong Kong. Int J Prosthodont 2004;17(2):172-6.

Manly RS, Vinton PA. Survey of chewing ability of denture wears. J Dent Res 1951; 30:314-321.

Marshall TA, Warren JJ, Hand JS, Xie X-J, Stumbo PJ. Oral health, nutrient intake and dietary quality in very old. J Am Dent Assoc 2002;133;1369-79.

Marucci MF. Aspectos nutricionais e hábitos alimentares de idosos, matriculados em ambulatório geriátrico (Contribuição para o estudo) [Tese de Doutorado]. São Paulo: Faculdade de Saúde Pública da USP; 1992.

Masseler M. Geriatric nutrition II: Dehydration in the elderly. J Prosthet Dent 1979;42:489-91.

Middleton MH, Nazarenko G, Nivison-Smith I, Smerdely P. Prevalence of malnutrition and 12-month incidence of mortality in two Sydney teaching hospitals. Int Med J $2001 ; 31: 455-61$.

Nagle RJ, Sears VH. Relaciones mandibulares. In: Prótesis dental. Barcelona: Toray, 1965. cap. 11, p. 269-313.

Nevalainen MJ, Rantanen T, Narhi T, Ainamo A. Complete dentures in the prosthetic rehabilitation of elderly persons: five different criteria to evaluate the need for replacement. J Oral Rehabil 1997;24(4):251-8. 
Nordstrom G. The impact of socio-medical factors and oral status on dietary intake in the eighth decade of life. Aging 1990;2:371-85.

Norlen P, Johansson I, Birkhed D. Impact of medical and life-style factors on number of teeth in 68 year old men in southern Sweden. Acta Odontol Scand 1996;54:66-74.

Nowjack-Raymer RE, Sheiham A. Association of edentulism and diet and nutrition in US adults. J Dent Res 2003;82(2):123-6.

Nos Números do IBGE, a violência em alta. Jornal da Tarde, São Paulo, 2004, abr 14, p10A.

Obrez A, Grussing PG. Opinions and feelings on eating with complete dentures: a qualitative inquiry. Spec Care Dent 1999;19(5):225-9.

Oliveira TRC. Avaliação nutricional e protética de pacientes senescentes totalmente desdentados (Contribuição para o estudo) [Tese de Doutorado]. São Paulo:

Faculdade de Odontologia da USP; 2001.

Oliveira MAP. Estudo da validade dos métodos fonéticos para determinação da dimensão vertical em próteses (Contribuição para o estudo) [Tese de Doutorado]. São Paulo: Faculdade de Odontologia da USP; 1994.

Österberg T, Steen B. Relationship between dental state and dietary intake in 70year-old man males and females in Goteborg,Sweden: a population study. J Oral Rehabil 1982;9:509-21.

Österberg T, Tsuga K, Rothenberg E, Carlsson G E, Steen B. Masticatory ability in 80 -year-old subjects and its relation to intake of energy, nutrients and food items. Gerodontol 2002;19(2):95-101.

Papas AS, Palmer CA, Rounds MC. Longitudinal relationships between nutrition and oral health. Ann NY Acad Sci 1989;561:124-42.

Papas AS, Palmer CA, Rounds MC, Russell RM. The effects of denture status on nutrition. Spec Care Dent 1998;18:17-25.

Pedersen $\mathrm{H}$, Löe H. Textbook of geriatric dentistry. $2^{\mathrm{a}}$ ed. Copenhagen: Munksgaard textbook; 1996. 
Perez P, Kapur KK, Garrett NR. Studies of biological parameters for denture design. Part III.Effects of oclusal adjustment and base retention and fit on masseter muscle activity and masticatory performance. J Prosthet Dent 1985;53(1-3):69-73.

Perls TT. The oldest old. Scientific American 2004;14(3):6-11.

Pinheiro P. Longevidade desafia previdência no $3^{\circ}$ milênio. O Estado de São Paulo, São Paulo, 2003, mar.24, p.A5.

Reavley N, Holt S. The new encyclopedia of vitamins,minerals, supplements, and herbs: How they are best used to promote health and well-being. New York: M. Evans Publ; 1999.

Roisinblit R. La desnutrición en la tercera edad y su repercusión en las enfermedades de la boca. Rev Asoc Odontol Argent 1995;83(2):143-53.

Rugg-Gunn AJ, Nunn JH. Nutition, diet, and oral health, New York: Oxford University Press; 1999.

Sandström B, Lindquist $L W$. The effect of different prosthetic restorations on the dietary selection in edentulous patients. Acta Odontol Scand 1987;45(6):423-8.

Saúde bucal na terceira idade. RGO 1993;41(2):97-102.

Sebring N G, Guckes A D, Li SH, McCarthy G R. Nutritional adequacy of reported intake of edentulous subjects treated with new conve ntional or implant-supported mandibular dentures. J Prosthet Dent 1995;7494):358-63.

Sheiham A, Steele J G, Mercenes W, Lowe C, Finch S, Walls AWG. The impact of oral health on stated ability to eat certain foods: finding from the National Diet and Nutrition Survey of older people in Great Britain. Gerontol South Harbor 1999;16(1):11-20.

Sheiham A, Steele J G, Mercenes W, Lowe C, Finch S, Bates CJ, et al. The relationship among dental status, nutrient intake, and nutritional status in older people. Chicago: J Dent Res $2001 ; 80(2): 408-13$. 
Shi CS, Ouyang, Gui TW. Comparison of food particle distribution masticated by subjects wearing complete dentures and with natural teeth. J Oral Rehabil 1990;17:611-5.

Shimazaki Y, Sho I, Saito T, Yamashita Y, Koga T, Miyazaki H, et al. Influence of dentition status on physical disability, mental impairment, and mortality in institutionalized elderly people. J Dent Res 2001;80(1):340-5.

Shinkai RSA, Hatch JP, Rugh JD, Sakail S, Mobley CC, Saunders MJ. Dietary intake in edentulous subjects with good and poor quality complete dentures. J Prosthet Dent 2002;87(5):490-8.

Silverman MM. Determination of vertical dimension by phonetics. J Prosthet Dent 1956;6(4):465-71.

Soini H, Routasalo P, Lauri S, Ainamo A. Oral and nutritional status in frail elderly. Spec Care Dent 2003;23(6):209-15.

Tamaki T. Dentaduras completas.4ํㅡㄹ. edão Paulo: Sarvier; 1988.

Thomas PR. Diretrizes para o planejamento dietético. In: Mahan LK, Escott-Stump S. Krause: alimentos, nutrição e dietoterapia. 9ª ed. São Paulo: Roca;1998.

Tosello A, Foti B, Sédarat C, Brodeur M, Ferrigno JM, Tavitian P, et al. Oral functional characteristics and gastrointestinal pathology: an epidemiological approach. J. Oral Rehabil 2001;28:668-72.

Trivalle C. Gérontologie preventive. Éléments de prevention du vieillissement pathologique. Paris: Masson; 2002.

Turano LM. Relacionamento paciente-profissional, fator de sucesso e insucesso em prótese total. Rev. Paul Odontol 2000;22(3):41-4 .

Yurkstas AA, Emerson WH. Dietary selections of persons with natural e artificial teeth. J Prosthet Dent 1964;14:695-7.

Wayler $\mathrm{AH}, \mathrm{Chauncey} \mathrm{HH}$. Impact of complete dentures and impaired natural dentition on masticatory performance and food choice in healthy aging men. $J$ Prosthet Dent 1983;49:427-33. 
Willett WC. Diet and health: what should we eat? Science 1994;264(5158):532-7.

Zuliani G, Romagnoni F, Volpato S. Nutritional parameters, body composition, and progression of disability in older disabled residents living in nursing homes. $J$ Gerodontol A Biol Sci Med Sci 2001;56(4):212-6. 
$\mathrm{Eu}$, portador do $R G$ ou CPF $\mathrm{n}^{\circ}$ residente bairro consinto em participar, na qualidade de paciente da clínica da Faculdade de Odontologia da Universidade de São Paulo (FOUSP), de uma pesquisa que, segundo esclarecimentos por mim recebidos pela mestranda VANESSA NEVES GOMES, visa contribuir para o estudo da correlação entre o hábito alimentar e a qualidade das Próteses Totais Convencionais. Declaro, ainda, que estou ciente de que esta pesquisa aponta para a melhoria do estado de saúde bucal e geral dos usuários de prótese e que, para que ela possa ser desenvolvida, o questionário será aplicado pela pesquisadora para avaliação dos hábitos alimentares, antes e depois da instalação das Próteses Totais Convencionais (PTC). Esse questionário foi desenvolvido com a colaboração da nutricionista MARCIA FIDELIX, CRN $=7090$. Também será realizado um exame tátil e visual, sem desconforto, com possibilidades de ser fotografado. Além disso, serão garantidos a minha privacidade e o meu atendimento, mesmo que eu resolva deixar de participar da pesquisa.

Paciente 


\title{
UNIVERSIDADE DE SÃO PAULO \\ FACULDADE DE ODONTOLOGIA
}

\author{
PARECER $\mathbf{n}^{\circ}$ 231/02
}

Protocolo 247/02

Com base em parecer de relator, o Comitê de Ética em Pesquisa, APROVOU o protocolo de pesquisa "Avaliação do hábito alimentar de pacientes senescentes totalmente desdentados antes e após a reabilitaçāo protética, estimulando a alteração de alguns nutrientes na dieta", de responsabilidade da pesquisadora Vanessa Neves Gomes, sob orientaçăo da Professora Doutora Maria Luiza Moreira Arantes Frigério.

Tendo em vista a legislaçāo vigente, devem ser encaminhados a este Comitê relatórios referentes ao andamento da pesquisa em 20 de maio de 2003 e em 20 de novembro de 2003. Ao término da pesquisa, cópia do trabalho deve ser encaminhada a este CEP.

São Paulo, 20 de novembro de 2002

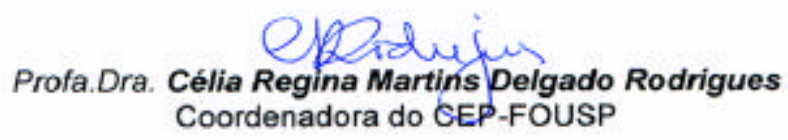

Av. Prof. Lineu Prestes, 2227 - Cidade Universitária "Armando de Salles Oliveira" CEP 05508-900 Sao Paulo - SP - Diretoria Telefax: (011) 3091-0062/3091-7817/3091-7860 - Compras (011) 3091-7895 Impresse $\approx \leq 00$ 
ANEXO C - Ficha clínica - Prótese Total Convencional (PTC)

\section{DADOS PESSOAIS}

Data $=$

Nome $=$

Endereço $=$

Telefone =

Estado civil $=$

Raça = ( ) branca ( ) não branca

\section{FICHA CLÍNICA}

1. Peso $=$

2. Altura $=$

3. Índice de Massa Corporal $(\mathrm{IMC})=$ $\mathrm{Kg} / \mathrm{m}^{2}$

4. Classificação do $\mathrm{IMC}=$

5. Hábito intestinal: () Diário

() Dias alternados () A cada 2 dias () >3dias

( ) Normal

( ) Pastoso

( ) Ressecado

6. Tem problema para engolir alimentos ?

( ) Sim

() Não

Qual?

7. Consistência da Dieta : ()Geral ( )Branda

( ) Pastosa ( )Líquida

8. Ingestão hídrica: ( ) < ou = 3 copos

( ) 4-6 copos

( ) 7-9 copos

( ) $>$ ou $=10$ copos

\section{AVALIAÇÃO PROTÉTICA}

1) Tempo que é desdentado total :

( ) 1 a 9 anos ( ) 10 ou mais

2) Tempo de uso da última Prótese Total ( PT):

Maxila : ( ) 1 a 6 anos ( ) 7 anos ou mais :

Mandíbula: ( ) 1 a 6 anos ( ) 7 anos ou mais:

3) Estado de conservação da PT:

Maxila: ( ) Satisfatório ( ) Insatisfatório

Mandíbula : ( ) Satisfatório ( ) Insatisfatório

4) Dimensão Vertical

( ) Satisfatório ( ) Insatisfatório ( ) Inexistente

5) Oclusão

( ) Satisfatório ( ) Insatisfatório ( ) Inexistente

6) Satisfação com a prótese

a) Retenção e estabilidade dinâmica:

Mandíbula : ( ) Satisfatório ( ) Insatisfatório ( ) Inexistente

7) Habilidade mastigatória

A) Consegue mastigar tudo o que pretende comer? ( ) Sim ( ) Não 
ANEXO D - Anamnese Alimentar

\begin{tabular}{|c|c|c|c|c|c|}
\hline \multicolumn{3}{|l|}{ Nome $=$} & & \multicolumn{2}{|c|}{ / Data= } \\
\hline \multirow{2}{*}{ Refeição } & \multirow{2}{*}{\multicolumn{2}{|c|}{ Alimentos }} & \multicolumn{3}{|c|}{ Frequência } \\
\hline & & & Diário & Semanal (1-6) & Mensal \\
\hline \multirow{16}{*}{ Café da manhã } & \multicolumn{2}{|c|}{ Achocolatado } & & & \\
\hline & \multicolumn{2}{|c|}{ Chá } & & & \\
\hline & \multicolumn{2}{|l|}{ Café } & & & \\
\hline & \multicolumn{2}{|l|}{ Leite } & & & \\
\hline & \multicolumn{2}{|l|}{ Yogurt } & & & \\
\hline & \multirow{2}{*}{ Pão } & francês & & & \\
\hline & & macio & & & \\
\hline & \multirow{2}{*}{ Bolacha } & seca & & & \\
\hline & & no leite & & & \\
\hline & \multicolumn{2}{|c|}{ Margarina /manteiga } & & & \\
\hline & \multirow{2}{*}{ Fruta } & dura & & & \\
\hline & & macia & & & \\
\hline & \multicolumn{2}{|l|}{ Geléia } & & & \\
\hline & \multicolumn{2}{|c|}{ Requeijão } & & & \\
\hline & \multicolumn{2}{|l|}{ Frios } & & & \\
\hline & \multicolumn{2}{|l|}{ Outros } & & & \\
\hline \multirow{11}{*}{$\frac{\text { Lanche da }}{\underline{\text { manhã }}}$} & & & & & \\
\hline & Achocola & & & & \\
\hline & Chá & & & & \\
\hline & Café & & & & \\
\hline & Leite & & & & \\
\hline & Pão & francês & & & \\
\hline & do & macio & & & \\
\hline & Bolacha & seca & & & \\
\hline & Sulacia & no leite & & & \\
\hline & Fruta & dura & & & \\
\hline & & macia & & & \\
\hline & & & & & \\
\hline & Verduras & folhas cruas & & & \\
\hline & & folhas cozidas & & & \\
\hline & I equmes & crus & & & \\
\hline & Legumes & cozidos & & & \\
\hline & Tomate & & & & \\
\hline & Peixe & cozido & & & \\
\hline & T EIXE & frito & & & \\
\hline & Carne de & Frita & & & \\
\hline & porco & cozida & & & \\
\hline & & frita & & & \\
\hline Almoco & Carne & macia & & & \\
\hline & & moída & & & \\
\hline & Frango & com pele & & & \\
\hline & & sem pele & & & \\
\hline & Fígado/m & dos & & & \\
\hline & Salsicha/l & guiça & & & \\
\hline & Arroz & & & & \\
\hline & Feijão & & & & \\
\hline & Legumino & & & & \\
\hline & Oleaginos & & & & \\
\hline & Ervilha & & & & \\
\hline & Grão-de-l & & & & \\
\hline
\end{tabular}




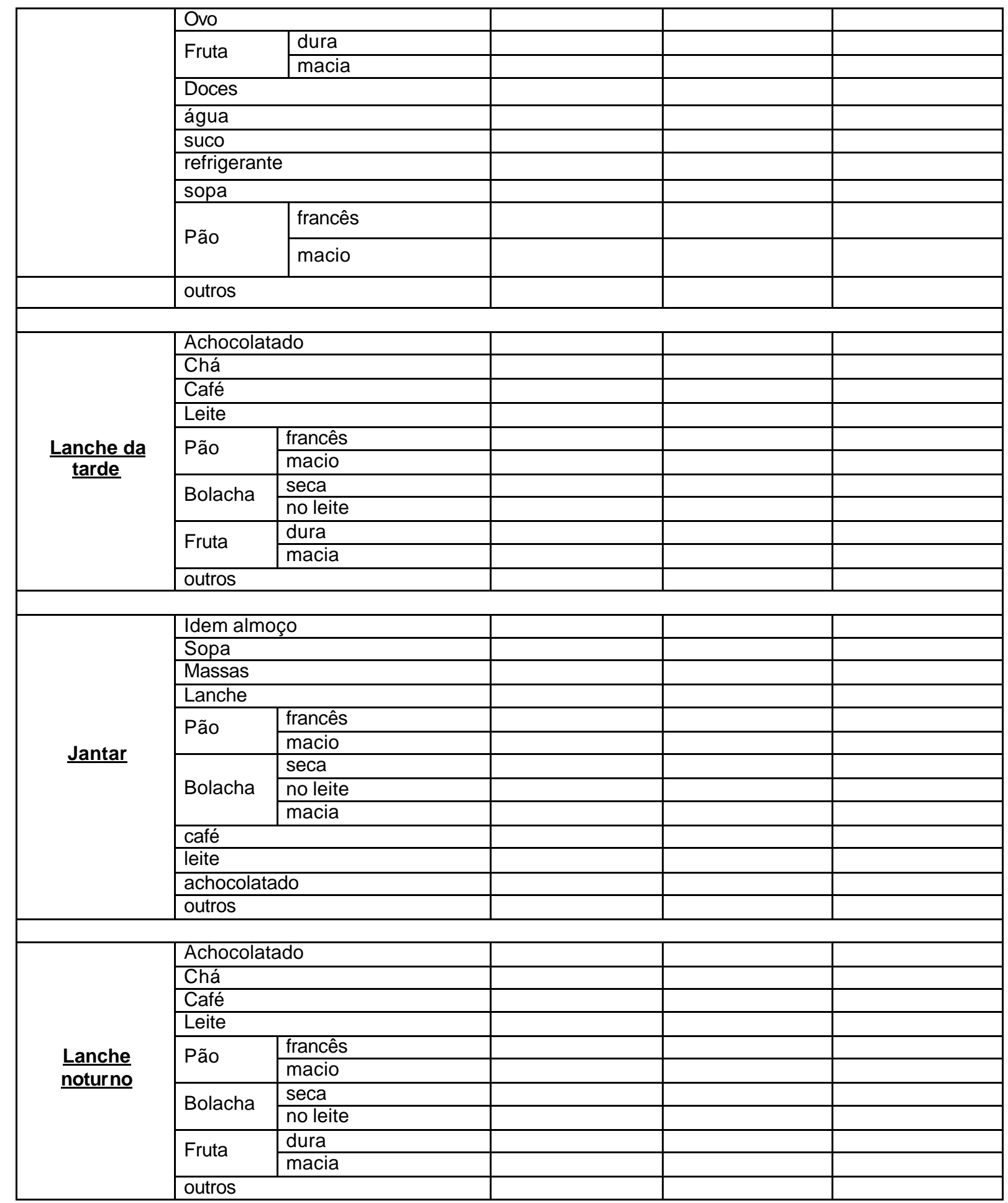


ANEXO E - Ficha clínica - Prótese Total Convencional (PTC) - Após a reabilitação protética

\section{DADOS PESSOAIS}

Data do exame $=$

Nome $=$

\section{FICHA CLÍNICA}

1. Peso $=$

2. Altura $=$

3. Índice de Massa Corporal $(\mathrm{IMC})=$ $\mathrm{Kg} / \mathrm{m}^{2}$

4. Classificação do IMC =

5. Hábito intestinal: () Diário ( ) Normal

() Dias alternados () Pastoso

() A cada 2 dias

( ) >3dias ( )Ressecado

6. Tem problema para engolir alimentos ?

() Sim

( ) Não

Qual?

7. Consistência da Dieta: () Geral

() Branda

( ) Pastosa

( ) Líquida

8. Ingestão hídrica : ( ) < ou $=3$ copos

( ) 4-6 copos

( ) 7-9 copos

( ) $>$ ou $=10$ copos

9. Após a instalação das próteses novas, você incluiu algum alimento diferente na sua dieta?
( ) Não Por que?
( ) Sim Quais?

10. Possuía antes da reabilitação protética: ( ) Nenhuma prótese

( ) Dentes naturais

( ) PPR

( ) Prótese total

(s/inf)

( ) Outro

\section{AVALIAÇÃO PROTÉTICA}

1) Estado de conservação da PT:

Maxila: ( ) Satisfatório ( ) nsatisfatório

Mandíbula : ( ) Satisfatório ( ) Insatisfatório

2)Dimensão Vertical

( ) Satisfatório ( ) Insatisfatório

3)Oclusão

( ) Satisfatório ( ) Insatisfatório

4)Satisfação com a prótese

a) Retenção e estabilidade dinâmica:

Mandíbula : ( ) Satisfatório ( ) Insatisfatório

5) Habilidade mastigatória
A) Consegue mastigar tudo o que pretende comer?
( ) $\operatorname{Sim}$
( ) Não 